Prelinimary version of a chapter in preparation for Psychology of Trust: New

Research D. Gefen (ed.) New York: Nova Science Publishers.(2013)

\title{
Recalibrational Emotions and the Regulation of Trust-Based Behaviors
}

\author{
Eric Schniter \\ The Economic Science Institute (Chapman University, Orange, California) \\ Timothy Shields \\ The Economic Science Institute (Chapman University, Orange, California)
}

\begin{abstract}
Though individuals differ in the degree to which they are predisposed to trust or act trustworthy, we theorize that trust-based behaviors are universally determined by the calibration of conflicting short- and long-sighted behavior regulation programs, and that these programs are calibrated by emotions experienced personally and interpersonally. In this chapter we review both the mainstream and evolutionary theories of emotions that philosophers, psychologists, and behavioral economists have based their work on and which can inform our understanding of trust-based behavior regulation. The standard paradigm for understanding emotions is based on mapping their positive and negative affect valence. While Valence Models often expect that the experience of positive and negative affect is interdependent (leading to the popular use of bipolar affect scales), a multivariate "recalibrational" model based on positive, negative, interpersonal, intrapersonal, short-sighted and long-sighted dimensions predicts and recognizes more complex mixed-valence emotional states. We summarize experimental evidence that supports a model of emotionallycalibrated trust regulation and discuss implications for the use of various emotion measures. Finally, in light of these discussions we suggest future directions for the investigation of emotions and trust psychology.
\end{abstract}

Keywords: emotion, affect valence, recalibrational theory, trust game, experiment

*Corresponding author: Email: eschniter@gmail.com

We thank Joaquin Gómez-Miñambres and David Gefen for their helpful reviews of earlier drafts. 


\section{OUTLINE}

I. Emotions and Rationality: A Brief History of Thought

II. Systematic Approaches to Thinking about Emotions

A. Emotion taxonomies

B. Positive and negative emotions

1. Hedonism, utility, and affect valence

2. Mixed emotional states and surprise as an emotion.

C. Recalibrational emotions

1. Short- and long-sighted behavior regulation programs

2. Inter- and intrapersonal recalibrations in pursuit of short- and long-sighted program goals

D. Etiological classification of twenty basic recalibrational emotions

1. (1-20) Basic recalibrational emotions: functional features proposed

2. Taxonomic organization of twenty basic recalibrational emotions

III. Recalibrational Emotions and Demonstrable Behavior in the Trust Game

A. Exogenously imposed minimum return rules in the Trust game

B. Previously reported effects of minimum return rules on trustbased behaviors

C. Predictions: Patterned experience of recalibrational emotions following trust-based interaction, and the effects of minimum return rules on experienced emotions

1. The patterned experience of emotions $[P 1, P 2]$

2. Effects of minimum return rules on emotions $[P 3, P 4]$

D. Trust-game behaviors and emotional reports: descriptive statistics and cross-tabulations

E. Confirmatory factor analysis

F. "Minimum return rule" effects on emotions

IV. General Discussion

A. Discussion of results

B. Insights and applications of trust and emotion research

C. Important directions for further research 


\section{EMotions AND RATionality: A BRIEF History OF THOUght}

Emotions are transient feelings that orchestrate physiological and cognitive systems for the purpose of predisposing those who feel them to act more or less in a certain way (Gómez-Miñambres and Schniter, 2013). Emotions play important roles in recalibrating our propensity to trust and act trustworthy (reciprocate upon being trusted), a topic that has been of interest to philosophers, psychologists, and economists. However, when their function and practical design is not well understood, emotions may appear as flawed cognitive and behavioral traits that interfere with rationality (Rand, 1964; Scherer, 1984; Elster, 1995; Parrott, 1995). For more than 2000 years, western philosophers (and more recently psychologists) ${ }^{1}$ have suggested that emotions affect judgment, either working with or conflicting with reason. Damasio (2005) has dubbed the more common and traditional belief, that rationality and emotion are separate and opposing forces, "Descarte's Error". We refer readers to Haidt (2001), ${ }^{2}$ King (2010), ${ }^{3}$ and Callahan (1988) ${ }^{4}$ who have reviewed in greater detail this history of philosophical thought about emotions and rationality.

The philosopher Jeremy Bentham (1748-1832) founded utility theory, where happiness is understood as the predominance of "pleasure" over "pain". During the 19th century, economists of the "marginal revolution" (e.g., William Stanley Jevons, Carl Menger, Marie-Esprit-Léon Walras, Alfred Marshall) started to consider the concept of utility to be directly quantifiable. By using the "quantity of feeling" concept, it was possible to understand a rational human action as the one that maximized utility specifically defined by happiness maximization and the reduction of suffering. In 1944, John von Neumann and Oskar Morgenstern presented a normative account of rational decision making with their axiomatic utility function: an ordinal and stable representation of preference relations. Under this (neoclassical) notion of rationality the individual is an automaton with stable preferences that should pursue the best alternatives by integrating all relevant information and then comparing the costs and benefits of all outcomes, ultimately choosing the option with highest utility.

\footnotetext{
${ }^{1}$ Hellenistic Greeks (e.g., Plato, Aristotle, Seneca), Medieval Christians (e.g., St. Augustine, Thomas Aquinas, William of Ockham), $17^{\text {th }}$ century's continental rationalists (e.g., Gottfried Leibniz, Rene Descartes), $18^{\text {th }}$ century Scottish philosophers (e.g. David Hume, Adam Smith), $19^{\text {th }}$ century psychoanalysts (e.g. Sigmund Freud), $19^{\text {th }}$ and $20^{\text {th }}$ century psychologists (e.g., William James, Walter Cannon), and $20^{\text {th }}$ century contemporary moral philosophers (e.g. James Rachels, H. Tristram Engelhardt, Jr.) have all argued that emotions affect judgment.

${ }^{2}$ Haidt (2001, p.815) wrote, "Plato's Timaeus (4th century B.C./1949) presents a charming myth in which the gods first created human heads, with their divine cargo of reason, and then found themselves forced to create seething, passionate bodies to help the heads move around in the world. The drama of human moral life was the struggle of the heads to control the bodies by channeling the bodies' passions toward virtuous ends. The stoic philosophers took an even dimmer view of the emotions, seeing them as conceptual errors that bound one to the material world and therefore to a life of misery (R. C. Solomon, 1993). Medieval Christian philosophers similarly denigrated the emotions because of their link to desire and hence to $\sin$. The $17^{\text {th }}$ century's continental rationalists (e.g., Leibniz, Descartes) worshiped reason as much as Plato had, hoping to model all of philosophy on the deductive method developed by Euclid."

${ }^{3}$ King (2010, p.169) described Augustine (in City of God) adopting "Stoic terminology, often calling the emotions 'disturbances' or 'upheavals' (perturbationes) when not using the neutral 'affections' (affectiones) or the Peripatetic 'passions' (passiones), and agrees with the Stoics that emotions are often contrary to reason and upset the mind..."

${ }^{4}$ Callahan (1988, p.9) quoted Joel Feinberg's (March 26, 1982) Presidential Address to the American Philosophical Association in Sacramento, California, "arguments are one thing, sentiments another, and nothing fogs the mind so thoroughly as emotion."
} 
Emotional experiences triggered by past outcomes and capable of calibrating future choices, are absent from this notion of utility.

If decision makers were actually like Laplacian demons, ${ }^{5}$ with perfect information for forecasting others' behavior and always capable of making the best choices (by accurately evaluating all possible cost-benefit tradeoffs), there would be little value to the pre-decision persuasions or ex-post feedbacks that emotions can provide. Yet, it is rarely the case that we have enough information, mental resources, or time to evaluate all outcomes when presented with a decision task (Simon, 1987; Todd, 2001; Slovic et al., 2002). In fact, many decision tasks are made in the absence of complete relevant information.

Under the proposed recalibrational theory of emotions, emotions affect the decision maker's judgment at a particular point in time. Introducing emotions in a utility function does not break with the original concept of utility (i.e., the decision maker tries to maximize "pleasure" and minimize "pain"). However, in contrast with the axiomatic representation of rationality, a utility function that incorporates emotions would be neither ordinal (the magnitude of utility differences between different options could be relevant) nor stable (emotions created today could affect our decisions tomorrow).

We propose that emotions serve to recalibrate behavior regulation programs ${ }^{6}$ and are triggered when uncertain decision outcomes are finally realized. The ex-post feedback (and affective forecasts) that emotions provide, and their ability to recalibrate both self and others to improve conditions, contributes to an experience-based learning and recalibration process that is useful when taking advantage of opportunities in uncertain environments. Without the ability to update our behavior regulation programs based on this feedback, we might repeatedly set ourselves up for failure where a more socially appropriate or economically viable strategy could be substituted.

Despite the appeal of functional explanations, emotions may appear as flaws of human nature that interfere with rationality (Sherer, 1984; Elster, 1995), especially when descriptions divorce them from their applications. However, if properly contextualized, we can see more clear evidence for the specially designed recalibrational functions of specific emotions. When known dilemmas are re-encountered and the effects of past emotional experiences (previously triggered by those dilemmas) are integrated into a decision calculus (e.g., Ketelaar \& Au, 2003; Schniter, Sheremeta \& Shields, 2013), contextualized learning occurs. As such, emotions which arise after trust-based interaction outcomes are not flaws, but instead helpful tools that recalibrate self and others, better informing future decision processes and ultimately contributing to the cultivation of wisdom and self-control (Heckhausen \& Schulz, 1995; Haselton \& Ketelaar, 2006; Gómez-Miñambres \& Schniter,

\footnotetext{
5 "Laplace's demon" is how later literature referred to (and elaborated the hypothetical extension of omniscience upon) the first argument for causal or scientific determinism by Pierre-Simon Laplace in 1814. For example, Chase, Hertwig, \& Gigerenzer (1998, p. 207) explained that Laplacian demons are all-knowing agents with minds like super-calculators "with unlimited time, knowledge, and computational power".

6 "Programs", from computational science, refers to neural circuits in the brain and body which process input information and accordingly cause outputs either in the form of regulatory variables and feedback (reused as input by programs) or behavior.
} 
2013). We caution, as did Simon (1985), ${ }^{7}$ against the tendency towards decontextualizing psychological and behavioral propensities (e.g. emotions) and thus thinking of them as inherently "irrational".

In this chapter, we take an adaptationist perspective based on the assumption that the mind is best understood not as a general purpose computer, but as containing a multitude of evolved mechanisms designed through a process of natural selection to each solve particular subsets of recurrent problems faced by our ancestors. Different adaptive problems have required different and unique solutions (Barrett, 2005) and emotions appear to be coordinated systems of responses that have been selected for over evolutionary history because they increased individual and perhaps even group fitness by solving specific problems (Plutchik, 1980; Frank, 1988; Nesse, 1990; Panskepp, 1996; Cosmides \& Tooby, 2000) such as maximizing opportunism and cultivating cooperative trust-based relationships. After reviewing various approaches to the classification of emotions based on their similarities, we introduce the recalibrational theory of emotions with specific attention to how emotions are involved in the regulation of trust-based behaviors.

\section{Systematic APProaches to Thinking About EMotions}

\section{A. Emotion taxonomies}

Taxonomy (from the Ancient Greek: taxis, 'order', or 'arrangement' and nomos, 'science') is the science of classifying parts of a whole according to units (taxa) in which parts are grouped together based on one or more shared unique characteristics. Explicitly or implicitly, many theorists have taken a taxonomic approach to organizing and understanding emotions in terms of types or components. Some have proposed classes of emotions such as "knowledge emotions" (e.g., interest, confusion, and surprise), "self-conscious emotions" (e.g., pride, shame, and embarrassment), or "energy and effort regulating emotions" (e.g., malaise, nausea, and shock). Others have decomposed emotions into noteworthy components by which they can be meaningfully classified,

"such as facial, vocal, and postural expressions (an expressive component); a subjective feeling state (a subjective component); a set of cognitive appraisals that bring about the emotion (a cognitive component); a tendency to act (a behavioral component); and changes in the brain and body (a physiological component)." (Silvia, 2009, p.49)

\footnotetext{
${ }^{7}$ Simon (1985, p. 297) wrote: "We may deem behavior irrational because, although it serves some particular impulse, it is inconsistent with other goals that we may deem more important. We may deem it irrational because the actor is proceeding on incorrect facts or ignoring whole areas of relevant facts. We may deem it irrational because the actor has not drawn the correct conclusions from the facts. We may deem it irrational because the actor has failed to consider important alternative courses of action. If the action involves the future, as most action does, we may deem it irrational because we don't think the actor uses the best methods for forming expectations or for adapting to uncertainty. All of these forms of irrationality play important roles in the lives of every one of us, but I think it is misleading to call them irrationality. They are better viewed as forms of bounded rationality."
} 
It is over these qualifying aspects of emotions that theorists have busied themselves quibbling about and declaring what constitutes an emotion. Given the lack of consensus over a definition, many basic questions are often repeated about emotions: How intense must a feeling be felt to qualify as an emotion? When lasting too long, are they no longer emotions but moods? Or, must they be consciously felt at all (must there be first-person awareness of them) to be considered emotions?

In a seminal text entitled "What is an emotion?" William James (1884) introduced what is now called the James-Lange theory of emotion ${ }^{8}$ by famously asking the question: do we run from a bear because we are afraid or are we afraid because we run? James was convinced that we experience fear of the bear because we (first) see it and run. In the processes of reacting to what we see (e.g. by running), the experiences of adaptive lifepreserving bodily reactions associated with predator evasion (e.g., increased blood pressure, racing heart, perspiration, heightened awareness, and quick movements) are perceived as a feeling, or set of feelings, to which we assign an emotion label. Similarly, other kinds of responses to adaptive problem situations result in salient physiological experiences. Each unique combination of sensory feedback for a given type of response or reaction, therefore, can be assigned an identifying label - which the English language has plenty of (e.g., Averill's (1975) Semantic Atlas of Emotional Concepts lists 558 words for emotions), despite being unable to completely label all emotions that humans experience. ${ }^{9}$ James argued that it is these identifying labels of unique physiological experiences that we call emotions. Arguments that emotions are effective because they are felt have been more recently proposed by Damasio's (1994) "somatic marker hypothesis", which argues that emotions are (initially) sensed corporally more than mentally ${ }^{10}$ and by Zeelenberg et al. (2008) who suggested that the effectiveness of emotions comes from the fact that they are "felt" hedonically.

A general criticism made of the James-Lange theory of emotion (e.g. by Damasio, 2004, p.10) has argued that visceral changes alone "are insufficiently differentiated to provide

\footnotetext{
${ }^{8}$ James is one of the two namesakes of the James-Lange theory of emotion, which he formulated independently of Carl Lange in the 1880s (see also Lang's original formulation in the 1885 work On Emotions: A PsychoPhysiological Study). The James-Lange theory of emotion is an intuitively appealing idea because intuitions about emotions are generally rooted in the thoughts or feelings that people are consciously aware of. Nevertheless, insights from psychology and cognitive science have provided reason to caution against exclusive reliance on intuitive appeal as a justification for formulating cognitive models. An oft-quoted principle of evolutionary psychology thus states: "Consciousness is just the tip of the iceberg; most of what goes on in your mind is hidden from you. As a result, your conscious experience can mislead you into thinking that our circuitry is simpler that it really is." (Cosmides \& Tooby, 1997)

${ }^{9}$ The Japanese have the word "amae" for the satisfaction that is felt when one is humbled before their benefactors and those more dominant or senior to them, and another word "oime" for feeling indebted, neither of which English speakers have (Markus \& Kitayama, 1991). For further discussion of universal versus culturally-specific emotions see Wierzbicka (1986).

${ }^{10}$ Damasio (2004) suggests that somatic markers act as pre-decision "gut feeling" forecasts of hypothetical outcomes (and, in turn, emotional feelings are triggered by recognition/thought of these). In doing so, somatic markers (which Hume called "passions") provide decision makers a limited and manageable set of alternatives to consider (as opposed to the full spectrum of possibilities - which due to its enormity presents a frame problem (see de Sousa, 1994)), when engaging their reason (i.e., by making logic-based cost-benefit analyses). Ketelaar and Todd (2001) also describe emotion as a simple mechanism that might "help us surmount the frame problem". Note also that Hume's earlier words on the matter seemed to say much the same about passions preceding and informing reason: "Reason is, and ought only be the slave of passions, and can never pretend to any other office than to serve and obey them" (1740/1978, book II, part III, section III, p. 415).
} 
a specific basis for the different emotions...they are unusually confined to measures of heart rhythm, respiration, skin conductance and temperature, and blood pressure". Along with the experience of physiological changes (reactions), what has come to be known as the Schachter-Singer theory (1962) states that, in addition to corporeal biofeedback, we also need cognitive input (Barrett (2006) specifically suggested context, prior experience, and social cues) about what is being reacted to in order to properly interpret, and thus label our emotional experiences. ${ }^{11}$ An alternative definition of emotions as "situation detecting algorithms" which trigger physiological and cognitive states (whether or not deliberative), lends itself, as suggested by Tooby and Cosmides (2008), to consider the inclusion of nonconscious states such as coma ${ }^{12}$ that would be precluded by standard definitions of emotion that require a conscious experience.

Focusing more on how the organism is prepared to deal with problems (via purposeful actions) or to communicate its state to other organisms (via muscular movements), Darwin (1872/1965) classified emotions according to the basic postures, physiological aspects, and facial expressions associated with them. Darwin argued that many of the emotions he studied (e.g. despair, anger, disgust, guilt, pride, shame) must be universal to humans and, because of homologues found in non-human mammals, must share evolutionarily deep phylogenetic roots. A century later, cross-cultural studies of emotional expressions and their identification (e.g., see Ekman \& Friesen, 1971; Ekman et al., 1972; Izard, 1977) ${ }^{13}$ neuropsychological studies (Lawrence \& Calder, 2004), ${ }^{14}$ and phylogenetic studies of emotion homologues (e.g., see Griffiths, 1997; Panskepp, 1998) have provided empirical support for Darwin's early insights that emotions are adaptations.

Following Darwin's lead, we take an etiological approach, considering emotions' ultimate adaptive functions (that is, what they are designed to do). Regarding their more proximate functions (that is, how they do what they do), we defer to the detailed

\footnotetext{
${ }^{11}$ Cannon (1927) argued that the same visceral responses such as increased heart rate, sweating, widening of the pupils, and the discharge of adrenaline can be associated with either the experience of fear or anger. However, the same visceral responses are also connected to conditions such as fever, feeling cold, and having difficulty breathing. In a famous study, Schachter and Singer (1962) injected college students with epinephrine (although all participants were told that they were given a new drug called "Suproxin" to test their eyesight). The study showed that depending on small contextual changes, equal doses of the drug could variably result (due either to manipulations or absence of manipulations) in experienced states of euphoria, anger, or amusement. Therefore, as suggested earlier by Cannon and others, physical responses (alone) are insufficient for identifying specific emotions.

${ }^{12}$ Tooby and Cosmides (2008, p.129-130) wrote that, "when situation-detecting algorithms detect the presence of a very grave internal injury, or the potential for one as indicated by a major blow, these may trigger a mode of operation of the psychological architecture that is designed to prevent any discretionary movement: coma. The function of coma, in a world before hospitals, was to prevent further injury from being done, minimize blood loss and internal hemorrhaging, and allow the mobilization of the body's resources toward repair of immediate threats to life. Note that a coma is not a physically mandated state of paralysis; it is a computational state - technically, 'a state of unconsciousness from which the patient cannot be roused' (Miller, 1976, p. 46), or 'unarousable unresponsiveness' (Berkow, 1992, p. 1398)."

${ }^{13}$ In various studies Paul Ekman, Wallace Friesen, Phoebe Elsworth, Carroll Izard and others found that either posed photographs or videos of facial expressions of basic emotions (anger, disgust, fear, happiness, sadness, and surprise) from Westerners (who have been exposed to media depictions of emotions - a potential confound) and from preliterate non-Westerners (with no previous exposure to mass-media) could be accurately decoded within and between groups (Ekman \& Friesen, 1971; Ekman et al., 1972, Izard, 1977; Ekman, 1992).

14 Examining evidence from cognitive deficits on task performance, Lawrence and Calder (2004) found neuropsychological evidence for three dissociable emotion systems: fear, disgust, and anger. Their evidence suggests that these emotion systems are isolable, specialized, and internally cohesive.
} 
psychophysiological studies which clearly show that neural, hormonal, circulatory, and muscular mechanisms are intricately involved in dissociable sets of emotional reactions. Levenson (1994, p.123) suggested that,

\begin{abstract}
"Psychologically, emotions alter attention, shift certain behaviors upward in response hierarchies, and activate relevant associative networks in memory. Physiologically, emotions rapidly organize the responses of disparate biological systems including facial expression, somatic muscular tonus, voice tone, autonomic nervous system activity, and endocrine activity to produce a bodily milieu that is optimal for effective response."
\end{abstract}

Similarly, Cosmides and Tooby (2000, p. 93) suggested that an emotion can orchestrate competing programs (an ultimate function) via its proximate "effects on physiology, behavioral inclinations, cognitive appraisals, or feeling states, because it involves evolved instructions for all of them together, as well as other mechanisms distributed throughout the human mental and physical architecture."

In the next section we review the notion of affect valence and propose that the emotions we consider facilitate behavioral regulation because they provide either positive or negative affective feedback (experienced as pleasant and unpleasant feelings) that is used in updating the calibration of one's conflicting internal regulatory variables (Tooby \& Cosmides, 1990, 2008). As Lerner and Keltner (2000, p.475) have explained, "Valence-based approaches face one obvious shortcoming, however. They fail to specify whether different emotions of the same valence differentially influence judgments and choices." After identifying some of the shortcomings of modeling emotions in terms of valence alone, we discuss the distinction between intrapersonal emotions that may affect reinforcement, maintenance, or change of one's own behavior, and interpersonal emotions that may ultimately affect reinforcement, maintenance, or change of another's behavior.

\title{
B. Positive and negative emotions
}

1. Hedonism, utility, and affect valence. An epistemology of emotions understood according to a single positive-negative dimension of affective experience traces its roots back to the ancient philosophy of hedonism formalized a little over 2000 years ago. More recently, during the past 100 years, hedonist philosophy has been integrated into mainstream academia.

Hedonism, which traces back to Sumerian civilization, ${ }^{15}$ Ancient Egypt, ${ }^{16}$ Ancient India, ${ }^{17}$ and Ancient Greece (Democritus, ${ }^{18}$ Aristippus $^{19}$ and later Epicurus ${ }^{20}$ ), is a school of

\footnotetext{
15 In the original Old Babylonian version of the Epic of Gilgamesh, written briefly after the invention of writing, Siduri gave the following advice: "Fill your belly. Day and night make merry. Let days be full of joy. Dance and make music day and night", which may represent the first recorded advocacy of a hedonistic philosophy." (Sandars, 1972)

${ }^{16}$ Hedonistic scenes of musicians providing entertainment for guests at feasts have been found in ancient Egyptian tombs. A common interpretation for the revelry depicted has been that these pleasures were indulged and indulgence was encouraged in this world, because the afterlife provided no such pleasures.

${ }^{17}$ The Cārvākas school of thought $\left(600 \mathrm{BC}-14^{\text {th }}\right.$ century $\left.\mathrm{AD}\right)$ maintained a naturalistic worldview, arguing against the idea of an afterlife as described by Hindu scriptures and priests. The Cārvākas argued that nothing is wrong with sensual indulgence, and given no afterlife, pleasure should be the aim of living.

${ }^{18}$ Democritus (370 BC) seems to be the earliest philosopher on record to have categorically embraced a hedonistic philosophy; he called the supreme goal of life "contentment" or "cheerfulness", claiming that "joy and sorrow are the distinguishing mark of things beneficial and harmful" (DK 68 B 188 - Taylor, 2005, p125).
} 
thought arguing that pleasure is the only intrinsic good. More recently, the academic "fields" of aesthetic psychology, ${ }^{21}$ psychobiology, and psychology of emotion have developed their understanding of emotions according to a positive-negative affect valence, while economists and cognitive psychologists have developed their understanding of choice preference and rational behavior (and the influence of emotions on choice) by identifying utility ${ }^{22}$ as a cardinal measure of pleasure derived from a desirable outcome. However, the question of why some people find some outcomes aversive while others find them attractive, is a puzzle that has classically been avoided: De gustibus non est disputandum. ${ }^{23}$ Never the less, it has been widely noted that the valenced affective nature of how we each experience things, in turn affects how we are each inclined to further experience things or avoid experiencing things. ${ }^{24}$ Or, in the parlance of economists, our emotions assign subjective "utilities" to the options available to us based on the pleasure they give us and the pleasures they give others. ${ }^{25}$ As a result of this history of thought, the standard model used in the social sciences to understand emotions is based on the fundamentals of affect valence. While we also base our model of emotions on positive and negative dimensions, we argue that a deeper understanding of patterned emotional response can be achieved by considering additional intrapersonal,

\footnotetext{
${ }^{19}$ The Cyrenaics (named after Cyrene, the birthplace of founder Aristippus) were an ultra-hedonist Socratic school of philosophy founded in the 4th century BCE. The Cyrenaics taught that the only intrinsic good is pleasure, which meant not just the absence of pain, but positively enjoyable sensations.

${ }^{20}$ Epicurus (307 BC) taught a form of hedonism which is now referred to as Epicureanism. Epicureanism declares pleasure to be linked to achieving an intrinsic good, and that pleasure and pain are the measures of what is good and evil. Epicurus also recognized the importance of living modestly, not over-indulging in pleasurable things, and practicing moderation to achieve tranquility.

${ }^{21}$ Silvia (2009, pp.48-49) summarized some notable achievements in the domain of aesthetic and emotion psychology: "Henry Rutgers Marshall's (1894) classic_Pain, Pleasure, and Aesthetics-accurately captures his unidimensional model of aesthetics. By the time of Kate Gordon's (1909) Esthetics - perhaps the first textbook in psychological aesthetics - the positive-negative dimension of affective experience was well established. Much later, Berlyne $(1960,1971)$ developed a sophisticated behavioral theory based on reward and aversion systems. The success of Berlyne's approach ensured a long life for research on positive and negative aesthetic feelings. As Berlyne (1971) and his group were conducting their landmark experiments, the psychology of emotion was emerging as an interdisciplinary field (Izard, 1971)."

${ }^{22}$ In economics, utility is understood to be ordinal and cardinal. It has been proposed that utility is experienced and even measurable as hedonic utility - in terms of units of positive and negative affect (i.e., emotional experience that is pleasurable or aversive). This notion was introduced into classical economics by Bentham (1948) and has been revisited in modern behavioral economics (Kahneman et al., 1997). Standard behavioral models in contemporary economics have been based on the notion of "Max-U", that given a choice among alternatives, people will choose the action that maximizes measured utility (though see critical discussion by McCloskey, 2006). Smith and Wilson (2013, p.3) argue that the legacy of "Max-U" is widespread in economics: "Utility preference functions perform heavy duty work in modeling a vast range of human decisions: isolated individuals in psychophysical measurements, individuals choosing among uncertain probabilistic prospects, interactive agents in supply-anddemand auction and asset markets, and individuals interacting through choices in two-person (e.g., trust) games or in small groups (public good and common property games)."

${ }_{23}$ Merriam Webster dictionary defines De gustibus non est disputandum (2013) as a Latin maxim meaning "In matters of taste, there can be no disputes", or literally, "There must not be debate concerning tastes".

${ }^{24}$ Later, in the development of economic thought, game theory matured from a focus on a money-maximizing selfinterested agent's utility function to a focus on an agent's utility function based on an admixture of self-interest and "other-regarding" interest (e.g. Cox et al., 2007). In turn, notions of emotional contributions to utility maximizing functions also matured.

${ }^{25}$ Adam Smith introduced this notion in The Theory of Moral Sentiments, and also went on to specify (1759, p.13) that most humans experienced a "Pleasure of mutual Sympathy" when they experience the "fellow feeling" of sharing the same emotions with others (and feel a pain when they do not share the same emotions).
} 
interpersonal, short-sighted and long-sighted dimensions (which we elaborate on in the sections below).

In contemporary discussions of emotions, affect valence refers to the intrinsic attraction (positive valence) or aversion (negative valence) that one's feelings (emotions) associate with an event, object, or situation (Fridja, 1986, p. 207). Being positive and negative, emotions facilitate behavioral regulation because they provide recalibrational feedback that we and others (e.g. Tooby \& Cosmides, 2008) have argued is used in updating the weighting of one's internal regulatory variables. Pleasant and unpleasant feelings, experienced as consequences of past actions or interactions, serve as either fundamental incentives or disincentives to motivate change from previous behavioral calibrations. To achieve this, pleasant feelings are rewarding and incentivize approach behavior (Watson et al., 1999) or future continuation of the prior behavior or interaction that triggered them (Carver \& Scheier, 1990). Unpleasant feelings are costly and motivate a change (Gray, 1971), whether through down-regulated behavior, avoidance, or aggression.

In accord with affect-as-information (Ketelaar, 2006; Ketelaar \& Au, 2003) and benefit appraisal (Ellsworth \& Smith, 1988a, 1988b) approaches, positive emotions (in so far as their outputs are experienced consciously as affective states) indicate potential fitness benefits, while negative emotions indicate potential fitness costs. These categories of positive and negative emotions have been shown to be cross-culturally (e.g., Lutz, 1982; Osgood et al., 1975; Russell, 1983) interpreted by those experiencing them in desirability terms - valued as "good" or "bad", respectively.

Given the fundamental structure that the valence dimension factors onto emotion (Higgins, 1997), it is unsurprising that psychophysiologists (Driscoll, Tranel, \& Anderson 2009; Lang, Greenwald, Bradley, \& Hamm 1993) neuroscientists (Proverbio, Zani, \& Adorni 2008; Screenivas, Boehm, \& Linden 2012) behavioral economists (Morretti \& di Pellegrino 2010; Brandts, Riedl, \& van Winden 2009; Van den Berg, Dewitte, \& Warlop 2008; Morris 1995) and decision scientists (Hogarth, Portell, Cuxart, \& Kolev 2011; Reid \& GonzalezVallejo 2009; Schlosser, Dunning, \& Fetchenhauer 2013) have used and continue to use bipolar affect scales. Below we argue that these scales are overly simplistic. One of the most popular among the affect scales (and used by all the above mentioned researchers) is the SelfAssessment-Manikin $(\mathrm{SAM})^{26}$ scale (see Figure 1), which can be used to study people's emotional states, for example, following decisions and interactions.

\footnotetext{
${ }^{26}$ SAM scales were introduced and developed by Lang (1980), Lang et al. (1999) as quick, cheap, and easy nonverbal methods of quantifying subjective feeling states (e.g., valence) that are not be subject to age (Backs et al., 2005), verbal (Bradley \& Lang, 1994) or cultural (Morris, 1995) factors. The Valence scale also exists as a portrait version as first used by Suk (2006). Touted in defense of their "validity", ratings along the SAM predict physiological reactions like skin conductance, heart rate, and facial electro-myographic measurement (Bradley, Codispoti, Cuthbert, \& Lang, 2001; Güntekin \& Basar, 2007; for further validation data see Lang, Bradley, \& Cuthbert, 1997) - however, because (as we have already discussed) positive affective states may accompany the same physiological traits as negative affective states (e.g. euphoria and anger) - the correlation of positive and negative affect with physiological effects is unremarkable.
} 

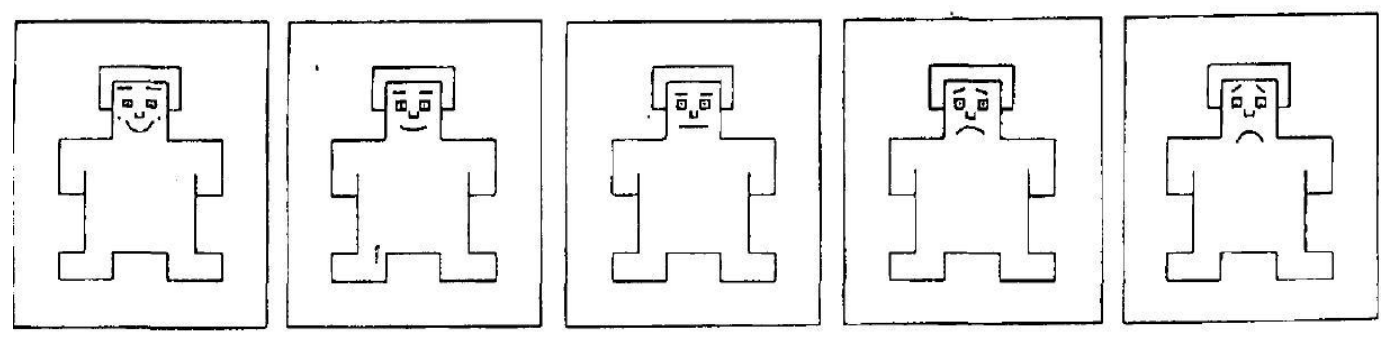

Figure 1. Self-Assessment-Manikin scale. Participants are required to choose one of five (or in another version one of nine) images to represent their emotional state.

2. Mixed emotional states and surprise as an emotion. Previous work (Schniter, Sheremeta, \& Shields, 2013) has identified two limitations to relying exclusively on bipolar affect scales: first, mixed emotional states (with simultaneous experience of both positive and negative affects like triumph, a positive emotion, and guilt, a negative emotion) are common and cannot be well represented by scales based on a simplistic positive-negative affect dimension alone, and second, some emotions (e.g., surprise, discussed below) are not exclusively positive or negative.

Dilemmas involve basic tradeoffs between pursuits of mutually exclusive (yet individually attainable) goals. This definition holds true whether considering self-control dilemmas (e.g. Gómez-Miñambres \& Schniter, 2013), where indulgence and restraint are traded off, or social dilemmas (where opportunism and cooperation are traded off). Because a dilemma presents a decision maker with two (exclusive) available goals, we conjecture that the presence of a dilemma simultaneously activates competing programs. In support of this, neural imaging studies have provided confirmation of dual programs simultaneously activating in subjects exposed to decision dilemmas (McClure et al. 2004; Hare et al. 2009).

After a decision has been made as to how to behave in the face of a dilemma, the decision outcome, whether "successful" or not (from the goal achievement perspective of each of the competing programs), may result in a mix of both positive and negative emotions (Cacciopo et al., 1999). Hume (1978/1740) described how the opposing passions of desire and aversion are exacerbated by dilemmas and can appear as "disorders": "For 'tis observable that an opposition of passions commonly causes a new emotion in the spirits, and produces more disorder, than the concurrence of any two affections of equal force. ... The same effect follows whether the opposition arises from internal motives or external obstacles..." (Hume 1978/1740, book II, part III, section III, p. 415, 421) While the experience of mixed emotions has been evoked with wins and losses in the laboratory (Larsen et al., 2001, 2004), it has been little appreciated in the context of trust psychology. We believe mixed emotions have received little attention, generally, because as Hume suggested, they challenge our intuitions of singular internal interests and the consonance of a non-contradictory self-representation generally attributed to a sane mind. Kurzban (2012, p.56) suggested the alternative to be grappled with when adopting a modular perspective of ourselves,

"if it's true that your brain consists of many, many little modules with various functions, and if only a small number of them are conscious, then there might not be any particular reason to 
consider some of them to be "you" or "really you" or your "self"... And for that matter, there might be no particular reason to consider your intuitions about your choices, or your ability to know your "self" reliably."

History has demonstrated that valence (typically considered to be either exclusively positive or exclusively negative) is the most intuitive criterion used in defining an emotion. As such, the simplest and most basic (Tellegen et al., 1999) taxonomy proposed for emotions has long been based on valence: emotions are either positively valenced or negatively valenced. Surprise, which has been viewed as both positively and negatively valenced, breaks with this formal definition of what constitutes an emotion. For this reason, surprise does not conform to a bipolar valence dimension and has been either excluded from lists of basic emotions (e.g. see Ortony et al., 1988, pp. 32 \&125-127; Ben-Ze'ev, 2000, p. 56), relegated to an exclusively "positive" valenced assignment, ${ }^{27}$ or else included in special categories of emotions like "knowledge emotions" (Silvia, 2009). Other emotions, also concerned with attention and ruminations, ${ }^{28}$ that do not conform well to a undimensional valence criterion have also received similar treatment. Silvia (2009, p. 49) suggested that knowledge emotions, "stem from people's appraisals of what they know, what they expect to happen, and what they think they can learn and understand. [In turn they] ... motivate learning, thinking, and exploring, actions that foster the growth of knowledge." According to this account, "incongruity creates surprise".

We propose that the functional account of surprise being capable of both positive and negative valence, contingent on the nature of the adaptive problem triggering it, makes sense. Casti (1994, p. ix) elaborated:

\begin{abstract}
"When the rules of reality generating events of daily life separate from the rules of thumb expectations, surprise is the outcome. ...Surprise represents the difference between expectations and reality, the gap between our assumptions and expectations about worldly events and the way that those events actually turn out. In essence, surprises are the end result of predictions that fail."
\end{abstract}

In this chapter, we consider how twenty of the emotions frequently surveyed by researchers (e.g. as part of the Positive and Negative Affect Scale (PANAS)), and relevant to the regulation of trust-based behaviors, fit into functionally unique taxa. Because surprise may be either positively or negatively valenced, for example following a trust-based interaction, it is in a unique taxon based on this feature (and does not get included in some of our analyses of positive and negative emotions). The effects of surprise, as such, on competing short-sighted and long-sighted programs (we describe these in greater detail in the next section below) could be either positive (encouraging) or negative (discouraging). For example, an Investor who has invested in another - trusting in expectation of the other acting in a trustworthy manner, only to discover that the Trustee has acted opportunistically (e.g. by not returning the investment, but instead keeping it), will be "surprised" (in this case, negatively so). We believe that this negative surprise will act to calibrate (downregulating the

\footnotetext{
${ }^{27}$ Surprise has been among the "positive" emotions included in some versions of the Positive and Negative Affect Scale (e.g. see the PANAS-X by Watson \& Clark, 1999).

${ }^{28}$ Examples of emotions not conforming to a unidimensional Valence Model include coma, thrill, vigilance, saudade, nostalgia, and confusion.
} 
relative power of) the long-sighted (pro-cooperation) program that was responsible for the (failed) trust-based investment. An Investor who was negatively surprised by a failed trustbased investment should, according to this theory, be less likely to trust in the future.

Alternatively, consider a Trustee in a trust game who has been invested in despite expecting no investment. Despite his previous expectation of non-trust by the Investor, this Trustee is "surprised" (in this case, positively so) to learn that the Investor's long-sighted (pro-cooperation) program was actually relatively powerful (outweighing the competing short-sighted pro-opportunism program), leading to the trust-based transfer. According to our theory, the surprised Trustee's long-sighted program will be upregulated, making him even more likely to cooperate with the other in similar trust-based exchanges. In the next section, before elaborating on the recalibrational functions suggested for the twenty emotions that we have studied following trust based interactions, we develop our theory of recalibrational emotions and the regulation of trust-based behaviors.

\section{Recalibrational emotions}

1. Short- and long-sighted behavior regulation programs. The recalibrational theory of emotions (Schniter et al., 2013) hinges on a cognitive model including short-sighted and long-sighted programs that each respond to fundamental adaptive problems. Internally conflicting programs with emotions as their co-evolved "guidance systems" may have been selected for because they can provide efficient solutions to the dynamic problems of changing environments (Tooby \& Cosmides, 1992; Livnat \& Pippenger, 2006). Human society has presented itself as a recurrent selection pressure with features of constant change: on larger social scales whole social groups may oscillate between periods of propensity towards peaceful cooperation and war (Pinker, 2011) while on smaller social scales an individual's exchange partners might be engaged in Machiavellian manipulations by alternating between tendencies to cooperate and defect (Humphrey, 1976; Byrne \& Whiten, 1988). It is this uncertainty in human social relationships which has presented a fundamental adaptive problem.

Over the course of human evolutionary history, interactions with specific others were likely followed up by further interactions with those same individuals due to their expected location (Krasnow et al., 2013) and social ties. ${ }^{29}$ Due to the likelihood of repeat interactions, the problem of entering into and maintaining iterated asynchronous exchange relationships presented our ancestors with a selection pressure. Those more capable of cooperating in society, presumably outcompeted those less capable of cooperation, due to the risk-buffering benefits which they derived (e.g. see Sugiyama \& Sugiyama 2003; Sugiyama 2004). Thus, it is hypothesized that the highly social and cooperative lifestyle, which characterizes our human ancestry (Sahlins, 1972; Isaac, 1978), led to selection for a long-sighted, pro-social program producing favorable social norms through the use of social emotions and morals.

\footnotetext{
${ }^{29}$ Among hunter-gatherers, who subsist, organize, and socialize much like our human ancestors did for more than 99\% of human history, most interactions are frequent, among people known and related by blood or marriage (e.g. see Hill et al., 2011), and organized into a three-generational family structure (Kaplan et al., 2009). In extant forager populations, the human family continues to be a principal nexus of resource exchange (Kelly, 1983).
} 
Consistent with this hypothesis, research has shown that humans are capable of developing and tracking reputations in iterated reciprocity relationships (Axelrod \& Hamilton, 1981; Cosmides \& Tooby, 1989; Kaplan et al., 2012) and capable of exchanging scarce and valuable resources within small-scale subsistence societies (Kaplan et al., 1985; Hawkes et al., 1991; Gurven, 2004).

According to our theory, long-sighted programs are designed to pursue the promise of risk-buffering benefits, provided over the long-term, by preferring the pursuit of reliable reciprocal exchange relationships and investments over immediate rewards, and by preferring a form of social behavior that conforms to ethical and moral standards and does not offend others and thus facilitates cooperative relationships. In calculating the promise of long-term rewards from exchange relationships or investments, long-sighted programs concern themselves with demonstrable reputations (social investments) of trust and trustworthiness and norm-adherence. These long-term cooperation goals are achieved at the expense of the short-sighted program that was designed to act in an expedient way (e.g. by processing only the minimum critical information for activation) to seize present and certain opportunities (short-term goals) before they are depleted, foregone, or the possibility of seizing them becomes less certain or riskier. As we will argue below, a set of social emotions appears to have also evolved in light of these tradeoffs, designed for specifically regulating the interaction behaviors of self and others when faced with social dilemmas.

Focusing on the adaptive problem of managing trust-based interactions, we define "trust" (after Rousseau et al., 1998) as that which is demonstrated by willfully ceding resources or control to another with the expectation (but no necessary assurance) that the other intends to reciprocate and not be opportunistic. Likewise, "trustworthiness" is that which is demonstrated by not succumbing to available opportunism so as to restitute the resources or control that another has ceded by extending trust. Later in this chapter we present data about the activation of emotions, arguing that their patterned experience is affected by the amount to which trust and trustworthiness can actually be demonstrated, which we claim depends on the amount of opportunism available.

For the purpose of understanding the regulation of trust-based behaviors, we hypothesize that both investors and trustees have two mutually exclusive goals $\{U, V\}$ that are traded off. $U$, the long-term goal of developing a trust-based exchange relationship is achieved when an investor cedes resources, investing them in the Trustee stranger and then recouping investment when the Trustee fulfills the implicit expectation of a trust-based exchange relationship by returning a value equal to or in excess of the investment. Assuming an unrestricted action space and no certain assurances of returns, the larger the amount invested, the greater the Investor's demonstrable trust. We consider demonstrable trustworthiness to be conservatively bounded and achieved when, at minimum, the amount returned under these conditions is greater or equal to the amount sent. $V$, the short-term goal of securing material gains, is achieved by maximizing earnings given the opportunities and decisions made. For a more detailed computational explanation of how successes and failures of short- and long-sighted behavior regulation programs trigger specific emotions see Schniter, Sheremeta, and Shields (2013). 
2. Intra- and interpersonal recalibrations in pursuit of short- and long-sighted program goals. Evolutionary psychologists (Tooby \& Cosmides, 1990, Cosmides \& Tooby, 2000) have argued that emotions are ultimately designed to deal with adaptive problems requiring program orchestration. Such problems arise, for example, when decision dilemmas simultaneous activate competing behavior regulation programs within an individual's mind. We theorize that the emotional system, serving short and long-sighted programs, computationally assesses and manages the internal (intrapersonal) and external (interpersonal) conflicts aroused by social dilemmas, through activating mixes of both positive and negative emotional outputs. These emotional outputs affect homeostatic regulation, reinforcement, and targeted deregulation of behavior regulating programs in self and others.

We conjecture that while most (15/20) emotions studied are capable of serving both short-sighted and long-sighted programs, the remaining 5 (proud, believable, embarrassed, ashamed, guilty) appear designed for facilitating the long-sighted program's goal pursuit. Several theorists including moral philosophers (Hume, 1740; Smith, 1759), moral psychologists (Kohlberg, 1971; Haidt, 2003; Ketelaar, 2006) evolutionary biologists (Darwin, 1872/1965; Trivers, 1971; Nesse, 1990), and economists (Hirschleifer, 1987; Frank, 1988) have also identified among humans a set of emotions designed to reinforce or commit one towards socially appropriate behavior, or recalibrate self and others towards socially desirable behavior. For example, in his first book, The Theory of Moral Sentiments, Adam Smith (1759, Part I, Section I, Chapter II, p. 13) describes "the Pleasure of mutual Sympathy":

But whatever may be the cause of sympathy, or however it may be excited, nothing pleases us more than to observe in other men a fellow-feeling with all the emotions of our own breast; nor are we ever so much shocked as by the appearance of the contrary. Those who are fond of deducing all our sentiments from certain refinements of self-love, think themselves at no loss to account, according to their own principles, both for this pleasure and this pain. As the person who is principally interested in any event is pleased with our sympathy, and hurt by the want of it, so we, too, seem to be pleased when we are able to sympathize with him, and to be hurt when we are unable.

Social emotions appear designed to service the adaptive goals of the long-sighted program: they encourage pursuit and cultivation of reciprocal exchange relationships and concern individuals with their efficient integration into society. Social emotions may encourage cooperation by either directly or indirectly inducing commitments to long-term exchange relationships, despite the "commitment" problem (Frank, 1988) presented by the interests of the short-sighted program (i.e., that immediate rewards are highly attractive and thus incentivize against the pursuit of long-term rewards).

In the next section we elaborate on the functions of some specific social emotions, suggesting that the experience of certain emotions (e.g., feeling believable and proud in the context of social exchange dilemmas) serves to positively reinforce the relative calibration of the long-sighted program with reward by encouraging the recognition and derivation of pleasure from the achievement of its goal. Likewise, when one behaves in a way that would harm one's positive reputation in the adaptive ancestral environment, some form of postdecision regret triggered by the long-sighted program may provide a "feeling" that, at the next decision juncture, serves to motivate a stronger pursuit of the cooperative goals of the longsighted program (e.g. see Zeelenberg, 1999; Zeelenberg et al., 2008). We suggest that feeling guilty, embarrassed, and ashamed in the context of these social exchange interactions is one 
of various ways that emotions serving the long-sighted program coerce a downregulation of the short-sighted program. In the next section we elaborate on recalibrational functions of several of the social emotions that can increase cooperative propensity, while indicating which emotions can also function to promote opportunism.

\section{Etiological classification of twenty basic recalibrational emotions}

A few theoreticians (Lerner \& Keltner, 2000, 2001; Van Kleef et al., 2004) have argued that by moving beyond the more simplistic models of valence (or positive and negative affect) to models of design-specific emotions, we gain even greater explanatory power of how emotions affect behavior. We are sympathetic to the arguments (e.g. Frank, 1988; Griffiths, 1990; Cosmides \& Tooby, 2000; Ketelaar \& Au, 2003; Haselton \& Ketelaar, 2006; Tooby et al., 2008) that specific emotions are designed to solve specific adaptive problems because by identifying designs specifics we can generate nuanced predictions.

In this section we propose etiologies of 20 recalibrational emotions, the emotional states associated with these emotions, and finally a parsimonious functional taxonomy based on their positive, negative, intrapersonal, interpersonal, short-sighted and long-sighted dimensions. We constructed a survey of a large array of (twenty) emotional states, based on the Positive and Negative Affect Scale (PANAS), a self-report measure of positive and negative affect states developed by Watson et al. (1988) that has been demonstrated across large non-clinical samples to be a reliable and valid measure of these states (Crawford \& Henry, 2004). We chose to functionally classify and predict the reported experience of these 20 emotions sometimes used in versions of the PANAS and detailed below because we recognized from prior work that laboratory participants likely experienced these and would be willing to report those experiences (e.g. after engaging in incentivized trust-based interactions).

Variants of the PANAS are among the most widely used surveys of emotional states in the social sciences today. The classification system which we propose allows us to not only identify the positive and negative affect valence of emotions that recalibrate short- and longsighted behavior regulation programs, but also to identify the behavior regulation programs they serve, and whether the programs that they target (for recalibration) are in self or other. In later sections we provide results of confirmatory factor analyses of these two alternatives, and in doing so attempt to persuade the reader that our multidimensional Recalibrational Model is more interpretable and better describes the data than the standard Valence Model. But first, we describe the functional features that we conjecture each of these 20 recalibrational emotions to have.

\section{1. (1-20) Basic recalibrational emotions: functional features proposed.}


(1/20) Appreciation: Appreciation, like "gratitude", 30 is a positive emotion (experienced when one feels appreciative) that is triggered when short- and/or long-sighted program goals were achieved as a consequence of another's non-opportunistic actions, and under conditions where similar non-opportunistic actions (e.g. reciprocation) could not be immediately demonstrable (consistent with Lazarus \& Lazarus, 1994). As an inter-personal ${ }^{31}$ positive emotion, the signal features of gratitude indicate to a receiver that the appreciative signaler has positive regard for the receiver's welfare and acknowledges a present debt while simultaneously indicating a willingness or propensity to engage in cooperative or helpful interaction (Tooby \& Cosmides, 2008). Gratitude effectively signals to a receiver that a cooperative relationship, now with intent to deliver future returns, has been established, representing a successful achievement of the receiver's long-sighted program. In turn, this input causes the receiver's programs to maintain homeostasis (i.e., the intrapersonal function), so as to ensure future cooperative interactions with the appreciative signaler. Experimental evidence supports a similar functional account of gratitude (Algoe et al., 2008; Algoe \& Haidt, 2009; McCullough et al., 2001).

(2/20) Happiness: Happiness is a positive emotion ${ }^{32}$ (experienced when one feels happy) that is triggered when the short- and/or long-sighted program goals were achieved. ${ }^{33}$ As a positive emotion, it maintains the homeostatic calibration of ego's successful program(s) used for making decisions under situations similar to the one which led to the success. Happiness also acts as a signal, giving it interpersonal functionality that encourages calibration to ensure the homeostatic maintenance of the other's program(s) that ensured the outcome which triggered it. When happiness is consequent of an interpersonal interaction and a happy individual signals her happiness to a receiver, it indicates to the receiver a successful achievement of one or both of the signaler's short- and long-sighted programs. In turn, this input causes the receiver's behavior regulation programs to maintain homeostasis, so as to ensure future successful interactions with the signaler.

(3/20) Contentment: Contentment, like happiness, is a positive emotion (experienced when one feels content) that is triggered when the short- and/or long-sighted program goals were achieved. ${ }^{34}$ As a positive emotion that accompanies an increased sense of security, relief, or satiation, it maintains the homeostatic calibration of successful program(s) used for making decisions under situations similar to the one that led to the contentment. Contentment also acts as a signal, giving it interpersonal functionality. When contentment is consequent of

\footnotetext{
${ }^{30}$ For similar perspectives on gratitude see Smith (1759), Trivers (1971), Hirshleifer (1987), Haidt (2003), Cosmides and Tooby (2000), Tooby and Cosmides (1990), Gallup (1998), McCullough et al. (2001), and Algoe et al. (2008).

${ }^{31}$ However, for an intrapersonal account of gratitude, see Simmel (1950) and Gouldner (1960).

${ }^{32}$ According to Shaver et al. (1987) happiness is within a "joy" category along with contentment, cheerfulness, triumph, and overlapping subcategories including excitement, zest, contentment, pride, optimism, enthrallment, and relief.

${ }^{33}$ For similar accounts of happiness specific to adaptive goals see Nesse and Williams (1999), and Cosmides and Tooby (2000); for similar accounts of happiness generalized to generic goals see Izard (1977), Smith and Lazarus (1990), Lazarus (1991), Nesse (1990), de Catanzaro (1999), and Rayo and Becker (2007).

${ }^{34}$ For similar accounts of contentment specific to adaptive goals see Ellsworth and Smith (1988b), Izard (1977), Lazarus (1991), Nesse and Williams (1999), and Cosmides and Tooby (2000).
} 
an interpersonal interaction and a content individual signals her contentment to a receiver, it indicates a successful achievement from perspective of one or both of the signaler's shortand long-sighted programs. In turn, this input causes the receiver's behavior regulation programs to maintain homeostasis, so as to ensure future successful interactions with the signaler.

(4/20) Cheerfulness: Cheerfulness is a positive emotion ${ }^{35}$ (experienced when one feels cheerful) that is triggered when the short- and/or long-sighted program goals were achieved. ${ }^{36}$ As an intrapersonally functional positive emotion, it should maintain homeostatic calibration of successful program(s) used for making decisions under situations similar to the one which led to the cheer. Cheerfulness also acts as a signal (sometimes called "cheer"), giving it interpersonal functionality. ${ }^{37}$ When cheerfulness is consequent of an interpersonal interaction and a cheerful individual signals her cheerfulness to a receiver, the receiver's long-sighted program recognizes cues of successful goal achievement(s) in the signaler. This input sometimes causes the recipient to creating a mirrored cheerfulness, but more importantly it causes the receiver's programs to maintain homeostatic calibration, so as to ensure future successful interactions with the signaler.

(5/20) Triumph: Triumph is a positive emotion (experienced when one feels triumphant $)^{38}$ that is triggered when the short- and/or long-sighted program goals were achieved ${ }^{39}$ (or when success is recognized) ${ }^{40}$ despite the "effort" (a time-cumulative emotion produced by the non-dominant program consequent of its forgone utilities) and encumbrance experience in pursuing those achieved goals. As an intra-personal positive emotion, ${ }^{41}$ it should maintain homeostatic calibration of ego's successful program(s) used for making decisions under situations similar to the one which led to the triumph, or else (for example if a change of events has made available an opportunity) increase the goal pursuit of the potentially successful program relative to a competing program.

(6/20) Inspiration: Inspiration (synonymous with "hope") ${ }^{42}$ is a positive emotion (experienced when one feels inspired) that is triggered when events have indicated that the short- and/or long-sighted program goals were achieved. As an intra-personal positive emotion, it should maintain the relative calibration of ego's successful program(s) used for making decisions under situations similar to the one which led to the inspiration, or else (for

\footnotetext{
${ }^{35}$ Alternatively, Frijda (2000) argued that cheerfulness is not an emotion but a mood that might not be tied to an antecedent and might endure over a long time.

${ }^{36}$ For a similar account of cheerfulness specific to adaptive goals see Grinde (2002).

${ }^{37}$ For similar perspective of cheerfulness as an interpersonal signal see Metts and Bowers (1994).

${ }^{38}$ Triumph is not to be confused with dominance, the emotion that (when one feels "triumphant over" another) is sometimes experienced positively on the intrapersonal level, but negatively on the interpersonal level (when one signals a confident aggressive positioning over another).

${ }^{39}$ For similar perspective on triumph see Sauter and Scott (2007).

${ }^{40}$ See de Catanzaro (1999, p.228) who wrote that success "is energizing and can encourage effort".

${ }^{41}$ Alternatively, Sauter and Scott (2007) argued that non-verbal vocalizations can signal a triumphant state.

${ }^{42}$ For example, see Lazarus et al. (1980), and Smith and Lazarus (1990) for similar interpretations of hope.
} 
example if a change of events has made available an opportunity) increase the goal pursuit ${ }^{43}$ of the potentially successful program relative to a competing program.

(7/20) Security: Security, similar to "confidence", ${ }^{44}$ self-assurance and certainty, is a positive emotion ${ }^{45}$ (experienced when one feels secure) that is triggered when the shortand/or long-sighted program goals were achieved, bringing the perspective that risks of not achieving the relevant goal are manageable or low. ${ }^{46}$ If a change of events has provoked it, security may be felt when one no longer feels the despair of prior uncertainty (for example as exacerbated by dilemmas). ${ }^{47}$ As an intra-personal positive emotion that accompanies an increased sense of contentment, relief, or satiation, it should maintain ego's homeostatic calibration of the successful program it serves under choice dilemmas similar to the one which led to the success.

(8/20) Pride: Pride is a positive emotion ${ }^{48}$ (experienced when one feels proud) that is triggered when long-sighted program goals were achieved ${ }^{49}$ and when a choice dilemma has put one's social position at stake. ${ }^{50}$ As an intra-personal ${ }^{51}$ positive emotion, it should maintain homeostatic calibration of ego's successful long-sighted program under choice dilemmas similar to the one that led to the success.

(9/20) Believability: Believability, similar to "reliability" or "trustworthiness", 52 "credulousness" and "credibility", 53 is an intrapersonal positive emotion (experienced when

\footnotetext{
${ }^{43}$ For a similar account of inspiration provoking goal pursuit see Thrash and Elliot (2004).

${ }^{44}$ See Folkman and Lazarus (1988) who defined confidence as an upregulator of motivation to continue pursuit of a goal.

${ }^{45}$ See Shaver et al. (1987) who argue that security is within a "loving" category along with feeling loved, warm, and trusting.

${ }^{46}$ For a similar account of the "feeling" of security, distinct from the reality state, see Schneier (2008).

${ }^{47}$ Hume described (1740/1978, book II, part III, section III, p. 421-422) security in the absence of despair from uncertainty exacerbated by dilemmas: "For 'tis observable that an opposition of passions commonly causes a new emotion in the spirits, and produces more disorder, than the concurrence of any two affections of equal force. ... The same effect follows whether the opposition arises from internal motives or external obstacles... Uncertainty has the same influence on opposition. The agitation of the thought; the quick turns it makes from one view to another; the variety of passions, which succeed each other, according to different views: All these produce an agitation in the mind, and transfuse themselves into the predominant passion. There is not in my opinion any other natural cause, why security diminishes the passions, than because it removes that uncertainty, which increases them....For the same reason, despair, tho' contrary to security, has a like in fluence."

${ }^{48}$ For similar accounts see Fessler (2001) who argues pride is a "reward", and Nesse (1990) who argues pride brings "moral satisfaction".

${ }^{49}$ Darwin (1872/1965) used "pride" synonymously with "arrogance". At the time of Darwin and at least a century earlier (e.g. see the original A Dictionary of the English Language by Samuel Johnson, 1755) pride was typically understood as a socially undesirable emotion ("which manifests itself in lofty airs, distance, reserve and often contempt of others") felt after one's short-term self-interested goals were achieved. Several dictionaries still carry this negative connotation for pride, e.g. Wiktionary gave "pride" (2013 - having imported its definitions from the 1913 edition of Webster's Dictionary) the former and following (quoted) definitions: "unreasonable conceit of one's own superiority... insolence or arrogance of demeanor; haughty bearing and conduct; insolent exultation; disdain".

${ }^{50}$ See Gilbert \& Andrews (1998) who argued that pride is triggered when social attention is directed towards one for actions which were appropriate, customary, and not excessive.

${ }^{51}$ Alternatively, an interpersonal account of pride has been argued by Fessler (1999).

${ }^{52}$ For accounts of "reliability" or "trustworthiness" similar to "believability" see Maathuis et al. (2004).

${ }^{53}$ For accounts of "credulousness" and "credibility" similar to "believability" see Keller and Aaker (1998).
} 
one feels believable) that is triggered when one's long-sighted program goals were achieved because another has trusted ego and ego has acted in a trustworthy manner. ${ }^{54}$ After a trustbased interaction, only the Trustee, who may have been trusted or "believed in", has a (interaction antecedent) reason to feel believable or trustworthy. As an intra-personal positive emotion, it should maintain the homeostatic calibration of ego's successful long-sighted program under choice dilemmas similar to the one that led to the success.

(10/20) Surprise: Surprise is an intrapersonal emotion ${ }^{55}$ (experienced when one feels surprised), either positively ${ }^{56}$ or negatively valenced that is triggered when the short- and/or long-sighted program goals failed to be achieved despite expectations to the contrary. Negative surprise, sometimes called "shock" (Ortony et al., 1988), is often accompanied by any of several potential concomitant negative emotions (e.g. disappointment, sadness, anger). Negative surprise recalibrates one to be more likely to expect unfulfilled goals so that their goal systems do not inappropriately expect goals achieved in conditions where one's own actions were to blame or in conditions contingent on others' actions. ${ }^{57}$ It is remarkably difficult to interpret the valence (positive or negative) of others surprise reactions without contextual cues or concomitant valenced emotional signals. On its own, surprise does not appear to be a signal designed for affecting inter-personal recalibration.

(11/20) Disgust: Disgust has deep phylogenetic roots as an emotion, ${ }^{58}$ and was originally evolved to act as a revulsion response towards potential contamination, helping protect an organism from ingesting potentially harmful substances, thereby promoting disease avoidance. ${ }^{59}$ Disgust appears to have more recently been adapted to function as an interpersonal and intrapersonal negative emotion for dealing with "contamination" of socially undesirable elements (experienced when one feels disgusted by, or revulsion towards, others or domains of behavior). When another's actions have caused one to fail to achieve one's own short- and/or long-sighted program goals, and when recalibration of the other's responsible behaviors is not a worthwhile endeavor (e.g. recalibration attempts via anger or verbal communication would lead to more losses than gains), then the negative "disgust" emotion is triggered, making the other a social object of disgust. As a negative emotion, it downregulates the likelihood of interaction with the disgusting person ${ }^{60}$ under choice dilemmas similar to the

\footnotetext{
${ }^{54}$ For similar accounts of believability see Maathuis et al. (2004), Hovland et al. (1953), Sternthal and Craig (1982).

${ }^{55}$ For a similar account of surprise as an emotion see Wierzbicka (1992). Alternatively, Ortony et al. (1988) and Ortony and Turner (1990) argued that because surprise is not "valenced" as only positive or only negative, it is not an emotion.

${ }^{56}$ See Shaver et al. (1987) who argued that "amazement" and "astonishment" are emotions often associated with positive surprise.

${ }^{57}$ See Izard (1991) and Tomkins (1962) who argued that surprise encourages adjustment of expectation.

${ }^{58}$ Comparative, phylogenetic work has shown selective impairment in humans in the recognition and experience of disgust, together with strong evidence of homology in mammals' (rats, mice, monkeys) and also lizards' and electric fish's emotion systems (Lawrence \& Calder, 2004).

${ }^{59}$ For functional accounts of disgust as a human universal for contamination avoidance see Cisler et al. (2009) and David and Olatunji (2011).

${ }^{60}$ For similar arguments about the social avoidance and distancing functions of disgust, see Haselton and Ketelaar (2006), Tybur et al. (2009), and Rozin et al. (1993). For a compatible argument about avoidance of risks, see Fessler et al., (2004). The generic feature of disgust, downregulating the likelihood of interaction with an object of disgust, also generalizes to mate and incest avoidance functions of disgust (e.g. see Westermarck, 1926; Tybur et al., 2009;
} 
one which led to the failure of the program it serves. Disgust also acts as a signal, giving it interpersonal functionality. When a disgusted individual signals her disgust to a receiver, the receiver experiences a negative emotion that likewise downregulates the programs which were instrumental in the interaction's "failure" to achieve the signaler's program(s') goals.

(12/20) Jealousy: Jealousy is an interpersonal and intrapersonal negative emotion (experienced when one feels jealous). When, contrary to expectations, another's actions have caused one to fail to achieve one's own short- and/or long-sighted program goals, yet consequent on those actions the other has achieved their own goals, ${ }^{61}$ then the negative "jealousy" emotion is triggered. ${ }^{62}$ As a negative emotion, it downregulates the competing program that has compromised the success of the program it is serves. Coupled with an outlook that should prohibit the repetition of past mistakes, jealousy encourages the recruitment of, and increase in behaviors like monitoring, vigilance, and aggression. These behaviors can alter the parameters of choice dilemmas to increase the chance of a jealous individual achieving her short- and/or long-sighted program goals. Jealousy also acts as a signal, giving it interpersonal functionality. When a jealous individual signals her jealousy to a receiver, the receiver experiences a negative emotion which likewise downregulates any of his programs which were instrumental in the "failure" to achieve the signaler's program(s') goals.

(13/20) Aggravation: Aggravation, like frustration, is an interpersonal and intrapersonal negative emotion (experienced when one feels aggravated). When obstacles, one's own actions, and/or another's actions prevent one from achieving one's own shortand/or long-sighted program goal(s), then aggravation can inhibit continued attempts under similar conditions. ${ }^{63}$ Aggravation, more than frustration, is triggered by others actions. As an intrapersonal negative emotion, aggravation downregulates the previously unsuccessful program (competing within ego) in the choice dilemma. Aggravation also acts as a signal, giving it interpersonal functionality. When an aggravated individual signals her aggravation to a receiver, the receiver experiences a negative emotion which likewise downregulates targeted programs which might have been instrumental in the signaler's "failure" to achieve his program(s') goals. By downregulating problematic programs in the other, an aggravated individual can alter the parameters of her choice dilemmas, increasing the chance of achieving short- and/or long-sighted program goals.

(14/20) Frustration: Frustration, like aggravation, is an interpersonal and intrapersonal negative emotion (experienced when one feels frustrated). When obstacles, one's own actions, and/or another's actions in pursuit of ego's short- and/or long-sighted

Lieberman, et al., 2003; Fessler \& Navarette, 2003, 2004) as well as toxin avoidance, contamination avoidance, and evacuation functions of disgusts (e.g., see Rozin et al., 1994; Haselton \& Ketelaar, 2006; Tybur et al., 2009; Curtis et al., 2004; Fessler, et al., 2004; Cosmides \& Tooby, 2000; Curtis \& Biran, 2001; and Levenson, 1999).

${ }^{61}$ For similar accounts of jealousy given one's relative misfortune see Clanton and Smith (1987), Parrot and Smith (1993), and de Catanzaro (1999).

${ }^{62}$ While the antecedent of jealousy that we identify roughly maps onto the antecedent conditions that activate sexual jealousy (e.g. see Thornhill \& Palmer, 2000), we consider sexual jealousy a distinctly different emotion.

${ }^{63}$ For a similar account of aggravation see Ortony et al. (1988). 
program goals produced a failure (i.e. those goals could not be achieved), then frustration can inhibit continued attempts under similar conditions. Frustration, more than aggravation, is triggered by obstacles or one's own actions. As an intrapersonal negative emotion, frustration downregulates the previously unsuccessful program competing in the choice dilemma. Frustration can also encourage aggression against others that inhibit goal achievement and/or it can act as a signal, giving it interpersonal functionality. When a frustrated individual signals her frustration, the receiver experiences a negative emotion which likewise downregulates any of his targeted programs which might have been instrumental in the signaler's "failure" to achieve his program(s') goals. By downregulating problematic programs in the other, an aggravated individual can alter the parameters of her choice dilemmas, increasing the chance of achieving short- and/or long-sighted program goals.

(15/20) Anger: Anger has deep phylogenetic roots as an emotion. ${ }^{64}$ Anger is an interpersonal and intrapersonal negative emotion (experienced when one feels angry). When another has caused one an offense or another's actions have caused one to fail to achieve one's own short- and/or long-sighted program goals, and when recalibration of the other's responsible behaviors via inflicted harm or restricted benefits might bring improvements, then the interpersonal negative "anger" emotion is triggered. ${ }^{65}$ As a negative emotion, it leads to the imposition of costs or restriction of benefits on the targeted individual, ultimately downregulating (within the targeted individual) the targeted program's weight relative to other competing programs under choice dilemmas like the one that led to the failure. ${ }^{66}$ The interpersonal function of anger has been recognized since at least the time of Aristotle. ${ }^{67} \mathrm{By}$ inflicting costs or restricting benefits to the other, an angered individual can alter the parameters of her choice dilemmas, increasing the chance of achieving her short- and/or longsighted program goals. Anger also acts as a signal, giving it additional interpersonal functionality. ${ }^{68}$ When an angry individual signals her anger, the receiver experiences a

\footnotetext{
${ }^{64}$ Comparative, phylogenetic work has shown selective impairment in humans in the recognition and experience of anger -together with strong evidence of homology across various mammals' (rats, mice, monkeys) and also lizards' and electric fish's emotion systems (Lawrence \& Calder, 2004)

${ }^{65}$ For similar interpersonal functional accounts of anger, see Nesse (1990), Keltner et al. (1993), Allred et al. (1997), Fehr and Gachter (2002), Cohen et al. (1996), Daly and Wilson (1988), Luckenbill (1977), Toch (1969), Webster and Kirkpatrick (2006), Sell (2006), Sell et al. (2009), Tooby et al. (2008), and Ortony et al. (1988).

${ }^{66}$ Some scholars have proposed that anger may have evolved to address defection in an interaction partner (Fessler \& Haley, 2003; Keltner, et al., 1993). For example, retaliation against defectors, as motivated by anger, may be costly in the short-term but pay off in the long-term if it leads defectors to repent and become cooperative (Fessler \& Haley, 2003). Physiologically and cognitively, anger has been shown to facilitate retaliatory action (Cannon, 1929; Lerner \& Tiedens, 2006), making defectors more likely to cooperate because their costs of future defection are increased. Experimental evidence of altruistic or costly punishment has shown that this deterrence mechanism is plausible (Fehr \& Gächter, 2002).

${ }^{67}$ Aristotle (in Rhetoric, Book II chapter 2) argued that "anger" is an emotion that is both practical and intelligent, essentially involving both goals and cognition. Aristotle reasoned that anger provokes a desire for vengeance because of an unjustified offense or slight.

${ }^{68}$ Fessler (2010) and Frank (1988) proposed that anger had "deterrence" effects on third parties. Anger has also been suggested to be a powerful way of averting defection, because it signals retaliation or opposition, rectifies injustice, and socially corrects wrongdoings (Averill, 1983; De Cremer, Van Kleef, \& Wubben, 2007; Frijda \& Mesquita, 1994). Nesse (1990) wrote: "Anger includes not only threats to abandon the relationship, but also spiteful threats to harm the other person, often at great cost to the self. Anger is not a reasoned negotiating ploy; it is an agitated, irrational, unpredictable state of aggressive arousal. Anger signals that a defection or potential defection has been detected and will not be tolerated. Its most basic function is to protect against exploitation. But by
} 
negative emotion that likewise downregulates any of his programs which were instrumental in the interaction's "failure" at achieving the signaler's program(s') goals. When one's own actions in pursuit of short- and/or long-sighted program goals produced the failure, then one's anger can be self-directed. ${ }^{69}$ Acting as an intra-personal negative emotion, self-anger downregulates the competing program that has compromised the success of the program it serves.

(16/20) Depression: Depression is an interpersonal and intrapersonal negative emotion (experienced when one feels depressed, melancholic, sad, despondent, hopeless, uninterested, anhedonic, and unable to focus on normal activities). Depression is triggered when one's own and/or another's actions or other obstacles produced a failure to achieve one's own short- and/or long-sighted program goals (i.e. those goals could not be achieved). For example when one's functional status becomes reduces (e.g. as a result of disability, bad luck) or when one experiences social conflict, then the negative "depression" emotion is triggered. As a negative emotion, it downregulates the previously failed program's weight relative to other competing programs under choice dilemmas like the one that led to the triggering failure. ${ }^{70}$ An additional feature of depressive symptoms is the focusing and rumination of thoughts pertaining to the failed goal pursuit. ${ }^{71}$ In doing so, depression "punishes", inflicting costs and/or restricting benefits on both self and other. As a depressive episode progresses it may intensify and either lead the victim into self-destruction or motivate her to avoid its destructive and unproductive sentence (e.g. through pursuit of new goals or transition to a new environment). Chances to achieve short- and/or long-sighted program goals may also be improved through indirect signaling effects of depression, giving it interpersonal functionality. When a depressed individual signals her depression to a receiver, the receiver experiences a negative emotion which likewise downregulates any of his programs which may have contributed to triggering the signaler's depression. ${ }^{72}$ Conditional on sympathy, the receiver's long-sighted program may be encouraged to upregulate its calibration relative to competing programs, so as to assist in a rehabilitation of the depressed individual and ensure future successful interactions with the signaler.

(17/20) Sadness: Sadness, also melancholy, depression, or disappointment, ${ }^{73}$ is an interpersonal and intrapersonal negative emotion (experienced when one feels sad). When

increasing the cost to a potential defector, the threat of spiteful retaliation also, paradoxically, helps to preserve relationships."

${ }^{69}$ For similar accounts of a self-angry state, synonymous with "regretful", see Ellsworth and Tong (2006), Zeelenberg and Beattie (1997), Zeelenberg (1999), and Zeelenberg et al., (2008).

${ }^{70}$ For similar accounts made of behavior deregulating effects of depression and like phenomena, see Darwin (1872/1965), Lewis (1934), Nesse and Williams (1999), Nesse (2000), and Hagen (2003).

${ }^{71}$ For similar accounts of cognitive effects of depression (e.g. rumination) see Nesse (1991), Taylor (1989), Gut (1989), and Nesse and Williams (1999).

${ }^{72}$ Consistent with a downregulation of an offender's program that promoted another's depression, competing programs in the offender gain greater relative efficacy, which may in turn lead to behaviors that assist in achieving goals of the depressed persons goals (e.g. depression may function to recruit help, see Smith \& Lazarus, 1990 and Hagen, 2003).

${ }^{73}$ Disappointment has been suggested to be an emotion which can help address the problem of others' defection (Lelieveld et al., 2011; Van Kleef et al., 2006; Van Kleef \& Van Lange, 2008; Wubben, De Cremer, \& Van Dijk, 2009). As an emotional reaction experienced in response to unfulfilled positive expectations (Frijda, 1986; Van Dijk 
one's own and/or another's actions in pursuit of one's short- and/or long-sighted program goals produced a failure (i.e. those goals could not be achieved), then the negative "sadness" emotion is triggered. As a negative intra-personal emotion, it downregulates ego's unsuccessful program's weight relative to other competing programs under choice dilemmas like the one that led to the failure. ${ }^{74}$ Displayed sadness can have mirrored effects on observers and in doing so can lead to paralysis of social interactions with the sad person. In doing so, sadness inflicts costs and/or restricts benefits to both self and other. Chances to achieve shortand/or long-sighted program goals may be indirectly affected by signaling effects of sadness, giving it interpersonal functionality. When a sad individual signals her sadness to a receiver, the receiver experiences a negative emotion that likewise downregulates any of his programs which were instrumental in the interaction's "failure" at achieving the signaler's program(s') goal(s). ${ }^{75}$ Conditional on sympathy, the receiver's long-sighted program may be encouraged to upregulate its relative calibration to competing programs, so as to assist in a rehabilitation of the sad individual and ensure future successful interactions with the signaler.

(18/20) Embarrassment: Embarrassment is an interpersonal and intrapersonal negative emotion (experienced when one feels embarrassed). When one's actions in pursuit of short-sighted program goals produced a failure that affects one's character as a cooperator or as an adherent of social conventions ${ }^{76}$ maintenance of which is pursuant to one's longsighted program goals of developing cooperative relationships, then the negative "embarrassment" emotion is triggered. Acting as an intrapersonal negative emotion, embarrassment recalibrates the value of the long-sighted program goals (e.g. conforming to social conventions) revaluing the tradeoffs between opportunism and trust-based cooperation. In carrying out this recalibrational work, embarrassment motivates behavior conforming to social conventions and/or appeasing the offended. ${ }^{77}$ Embarrassment also acts as a signal, giving it interpersonal functionality. ${ }^{78}$ When an embarrassed individual signals she is

\& Van Harreveld, 2008; Van Dijk, Zeelenberg, \& Van der Pligt, 1999), expressing disappointment to the person that caused this emotion communicates that one had higher expectations of this person. It is this message rather than its action tendency (because disappointment is associated with a tendency to do nothing) that makes disappointment effective in inducing cooperation (Van Dijk \& Van Harreveld, 2008), eliciting concessions (Timmers, Fischer, \& Manstead, 1998; Van Kleef et al., 2006; Van Kleef \& Van Lange, 2008), and motivating corrective and remedial behaviors like making amends and rectifying transgressions (Baumeister, Stillwell, \& Heatherton, 1994; Frijda \& Mesquita, 1994; Lewis, 2008).

${ }^{74}$ For similar accounts of sadness like phenomena see Nesse (1990, 1999), Fredrickson (1998), and Smith and Lazarus (1990).

${ }^{75}$ Consistent with a downregulation of programs that led to another's sadness, competing programs gain relative efficacy, which may in turn lead to behaviors that assist in achieving goals of the sad person (e.g. sadness may function to recruit help, see Smith \& Lazarus, 1990; Hagen, 2003).

${ }^{76}$ For similar accounts, see Edelmann (1987), Keltner (1995), Keltner and Buswell (1996, 1997), Keltner et al. (1997), Miller (1992), Miller and Tangney (1994), Tangney (1992), and Buss (1980).

${ }^{77}$ For similar accounts of appeasement and reconciliations functions of embarrassment, see Goffman (1967), Miller and Leary (1992), Eisenberg et al. (1989), Keltner (1995). Keltner and Buswell (1997), Keltner et al., (1997), Gilbert and Trower (1990), Scheff (1988), Semin and Manstead (1982), Tangney et al. (1996), de Waal (1989), Shields et al., (1990), and de Jong, (1999).

${ }^{78}$ Borg et al. (1988), Izard (1977), Kaufman (1989), Lewis (1971), and Lewis (1990) have all argued that embarrassment is theoretically equivalent or highly similar to shame (with embarrassment being a "mild form" of shame). While we note the similarities, we agree with Tangney et al. (1996) who distinguished the experience of embarrassment with an accompanied sense of social exposure and heightened concern for others' judgments features that, unlike guilt, also make it more difficult to experience privately. 
embarrassed to an offended individual or a social group at large, the receiver(s) of the signal may recognize that pre-emptive recalibration has been taken, voluntarily on the part of the embarrassed signaler. If an embarrassed signaler has already recalibrated herself appropriately, then the recalibrational emotions (e.g. anger or disgust) that the offence would otherwise trigger, and their consequent behavioral outputs (e.g., aggression or revulsion), may be unnecessary.

(19/20) Shame: Shame is an interpersonal and intrapersonal negative emotion (experienced when one feels ashamed). When one's opportunistic actions in pursuit of shortsighted program goals produced a failure that affects one's trusting or trustworthy character, maintenance of which is pursuant to the long-sighted program goals, ${ }^{79}$ then the negative "shame" emotion is triggered. Acting as an intrapersonal negative emotion, shame recalibrates the value of the long-sighted program's goal (e.g. conforming to social conventions), revaluing the tradeoffs between opportunism and trust-based cooperation, ${ }^{80}$ downregulating the short-sighted program which produced the previous opportunistic behaviors. To rebuild their harmed reputations, ashamed offenders tend to increase their propensity to act in a trusting or trustworthy manner and/or appease the offended. ${ }^{81}$ Shame also acts as a signal, giving it interpersonal functionality. ${ }^{82}$ When a shameful individual signals $^{83}$ she is ashamed, the offended party receiving the signal may recognize that preemptive recalibration, in some form of hedonic self-abasement, has been voluntarily taken on the part of the ashamed signaler ${ }^{84}$ and that the interpersonal recalibrational emotions (e.g. anger or disgust) that the offence would otherwise trigger in the victim of the offence, and their consequent behavioral outputs (e.g. aggression or revulsion) may be unnecessary. ${ }^{85}$

\footnotetext{
${ }^{79}$ Fessler $(2001,2007)$ argued that shame is an aversive feeling produced when social actions (e.g. a failure to act responsibly or violation of a norm) produce a perceived lowering of one's relative social status. For other similar accounts, see Buss (1980), Scheff (1988), Edelmann (1987), Keltner (1995), Keltner and Buswell (1996, 1997), Keltner et al. (1997), Miller (1992), Miller and Tangney (1994), and Tangney (1992).

${ }^{80}$ Cosmides and Tooby (2000), and Tooby and Cosmides (1990) offer a "recomputational" account of shame.

${ }^{81}$ For similar accounts of appeasement and reconciliations functions of embarrassment, see Miller and Leary (1992), Eisenberg et al. (1989), Keltner and Buswell (1996, 1997), Keltner et al. (1997), Gilbert and Trower (1990), Scheff (1988), de Waal (1989), Shields et al. (1990), de Hooge et al. (2008), and de Jong (1999). Additionally, Nesse (1990) suggested that guilt enforces obedience to rules of social conduct.

${ }^{82}$ For a similar intrapersonal and interpersonal account of shame see Sznycer et al. (2012).

${ }^{83}$ Darwin (1872/1965, p.325) argued that blushing, which he attributed to "self-attention... [about]...what others think of us...", is a recognized cue that might be at work in the signaling of shame. Fessler (2007) described the role of shame and pride in rank-striving and approval-seeking behavior. Fessler also described behavioral features of shame and pride (e.g. avoiding eye contact and seeking it, respectively) making shame appear much like a form of "self-disgust" or "self-punishment" (Wallington, 1973).

${ }^{84}$ Regret and depression, which may accompany shame after the commission of an offense, contribute to the offender's demeanor and, in their expressions, signal that the offender has undergone recalibration (reforming towards a more socially desirable disposition) since having committed the offense (Buss, 1990; Plutchik, 1980).

${ }^{85}$ Giner-Sorolla et al. (2008) have shown that an offender's self-abasement, as opposed to a mere admission of culpability and regret decreases the insult that those in the "outgroup" attribute to the offense: when offenders felt ashamed and issue apologies, recipients of the apologies felt less offended than when offenders felt guilty (but not ashamed) and issue apologies.
} 
(20/20) Guilt: Guilt is an intrapersonal negative emotion (experienced when one feels guilty). When, in pursuit of short-sighted program goals, one's opportunistic actions ${ }^{86}$ produced a failure that affects one's trusting or trustworthy character (maintenance of which is pursuant to one's long-sighted program goals), ${ }^{87}$ then the negative "guilt" emotion is triggered. Acting as an intra-personal negative emotion, guilt downregulates the short-sighted program that previously produced opportunistic behaviors, thereby producing behaviors which increase long-sighted program goals (e.g., developing exchange relationships, issuing confessions and apologies, and appeasing the offended). ${ }^{88}$ Unlike shame and embarrassment, guilt does not have strong signaling functions. ${ }^{89}$

2. Taxonomic organization of twenty basic recalibrational emotions. Emotions are ultimately designed to deal with the adaptive problem of program orchestration (Tooby \& Cosmides, 1990) that arises by the simultaneous activation of competing behavior regulation programs within an individual's mind. In considering the nature of adaptive decision problems encountered in trust-based interactions, we recognize that the outcomes of these decisions are contingent on not only one's own actions (according to the calibration of our internal programs), but also the actions of others (according to the calibration of their programs). To solve this adaptive problem, triggered emotions have been designed by natural selection to recalibrate targeted programs in one self and others. As such, it is helpful to consider a typology of these adaptive problems in terms of their solutions: positive and negative recalibrations arrived at via intrapersonal and/or interpersonal behavior regulation (e.g. see Bowlby, 1969; Levenson, 1999; Van Kleef et al., 2004; Butt et al., 2005). A parsimonious organization of twenty emotional states based on the proposed recalibrational functions (that we have characterized as positive and negative recalibrations, intrapersonally and interpersonally targeting short-sighted and long-sighted programs) yields five unique sets of emotional states, each sharing unique functional features (see table 1) that we expect to be triggered in concert for common functional purposes.

Of the set of twenty emotional states, nine [appreciative, happy, content, cheerful, triumphant, inspired, secure, proud, believable] are experienced as positive, one [surprise] could be either positive OR negative (forming the unique Set 3), and ten [disgusted, jealous, aggravated, frustrated, angry, depressed, sad, embarrassed, ashamed, guilty] are negative. Seven [triumphant, inspired, secure, proud, believable, surprised, guilty] are exclusively intrapersonal. Fifteen of the twenty emotional states may serve the interests of either short- or long-sighted adaptive goals. The five emotional states (proud, believable, embarrassed,

\footnotetext{
${ }^{86}$ For accounts of guilt being produced consequent on recognizing that one's actions appear "wrong" or immoral to others, see Baumeister et al. (1994, 1995), and Tangney (1991).

${ }^{87}$ For similar accounts of guilt see Baumeister et al. (1995), Ketelaar \& Au (2003), de Hooge et al. (2007), and Frank (1988).

${ }^{88}$ Several have argued that guilt provokes an increase in remedial and cooperative behaviors (e.g. Ketelaar \& Au, 2003; Zeelenberg, 1999; Zeelenberg et al., 2008; Sznycer et al., 2011; Frank, 1988; Wicker et al., 1983; de Hooge et al., 2007; Baumeister et al., 1994, 1995; Ohtsubo \& Watanabe, 2009; Tangney et al., 1996; and McCullough et al., 2001).

${ }^{89}$ However, others have argued that guilt has intrapersonal functions (attributed to targeted effects on others by the guilty person). Wicker et al. (1983) argued that guilt in an offender stops the offended from inflicting costs (on the offender), while Tangney (1991) and Leith and Baumeister (1998) have argued that guilt increases the offender's empathy.
} 
ashamed, guilty) exclusively serving the long-sighted adaptive goal of achieving cooperation by encouraging trusting and trustworthy exchange behavior split into two unique sets, one that is positive (Set 2) and one that is negative (Set 5). The positive emotional states that are intrapersonal and serve both short-sighted and long-sighted adaptive goals [happy, content, cheerful, triumphant, inspired, secure] form the unique Set 1. The negative emotional states that are both intrapersonal and interpersonal, and serve both short-sighted and long-sighted adaptive goals [disgusted, jealous, aggravated, frustrated, angry, depressed, sad] form the unique Set 4.

Table 1: Recalibrational taxonomy of twenty basic emotional states.

\begin{tabular}{|c|c|c|c|c|c|c|c|}
\hline \multirow{2}{*}{ Set } & \multirow{2}{*}{ Emotional State } & \multicolumn{2}{|c|}{ Adaptive Goal } & \multicolumn{4}{|c|}{ Recalibration } \\
\hline & & $\begin{array}{l}\text { Long- } \\
\text { sighted }\end{array}$ & $\begin{array}{l}\text { Short- } \\
\text { sighted }\end{array}$ & Positive & Negative & Intrapersonal & Interpersonal \\
\hline \multirow{7}{*}{1} & Appreciative & $\mathrm{X}$ & $\mathrm{X}$ & $\mathrm{X}$ & & $\mathrm{X}$ & $\mathrm{X}$ \\
\hline & Happy & $\mathrm{X}$ & $\mathrm{X}$ & $\mathrm{X}$ & & $\mathrm{X}$ & $\mathrm{X}$ \\
\hline & Content & $\mathrm{X}$ & $\mathrm{X}$ & $\mathrm{X}$ & & $\mathrm{X}$ & $\mathrm{X}$ \\
\hline & Cheerful & $\mathrm{X}$ & $\mathrm{X}$ & $\mathrm{X}$ & & $\mathrm{X}$ & $\mathrm{X}$ \\
\hline & Triumphant & $\mathrm{X}$ & $\mathrm{X}$ & $\mathrm{X}$ & & $\mathrm{X}$ & \\
\hline & Inspired & $\mathrm{X}$ & $\mathrm{X}$ & $\mathrm{X}$ & & $\mathrm{X}$ & \\
\hline & Secure & $\mathrm{X}$ & $X$ & $X$ & & $\mathrm{X}$ & \\
\hline \multirow{2}{*}{2} & Proud & $\mathrm{X}$ & & $\mathrm{X}$ & & $\mathrm{X}$ & \\
\hline & Believable & $\mathrm{X}$ & & $\mathrm{X}$ & & $\mathrm{X}$ & \\
\hline 3 & Surprised & $\mathrm{X}$ & $\mathrm{X}$ & $\mathrm{X}$ & $\mathrm{X}$ & $\mathrm{X}$ & \\
\hline \multirow{7}{*}{4} & Disgusted & $\mathrm{X}$ & $\mathrm{X}$ & & $\mathrm{X}$ & $\mathrm{X}$ & $\mathrm{X}$ \\
\hline & Jealous & $\mathrm{X}$ & $\mathrm{X}$ & & $\mathrm{X}$ & $X$ & $\mathrm{X}$ \\
\hline & Aggravated & $\mathrm{X}$ & $\mathrm{X}$ & & $\mathrm{X}$ & $\mathrm{X}$ & $\mathrm{X}$ \\
\hline & Frustrated & $\mathrm{X}$ & $\mathrm{X}$ & & $\mathrm{X}$ & $\mathrm{X}$ & $\mathrm{X}$ \\
\hline & Angry & $\mathrm{X}$ & $\mathrm{X}$ & & $\mathrm{X}$ & $\mathrm{X}$ & $\mathrm{X}$ \\
\hline & Depressed & $\mathrm{X}$ & $\mathrm{X}$ & & $\mathrm{X}$ & $\mathrm{X}$ & $\mathrm{X}$ \\
\hline & Sad & $\mathrm{X}$ & $X$ & & $\mathrm{X}$ & $\mathrm{X}$ & $\mathrm{X}$ \\
\hline \multirow{3}{*}{5} & Embarrassed & $\mathrm{X}$ & & & $\mathrm{X}$ & $\mathrm{X}$ & $X$ \\
\hline & Ashamed & $\mathrm{X}$ & & & $\mathrm{X}$ & $\mathrm{X}$ & $\mathrm{X}$ \\
\hline & Guilty & $\mathrm{X}$ & & & $X$ & $\mathrm{X}$ & \\
\hline
\end{tabular}

Note: X's indicate conjectured recalibrational features of emotions. 


\section{RECALIBRATIONAL EMOTIONS AND DEMONSTRABLE BEHAVIOR IN THE TRUST GAME}

\section{A. Exogenously imposed minimum return rules in the Trust game}

Interactions that require trust involve a basic social dilemma where agents have to trade off the immediate safety that comes with opportunism with the potential delayed benefits (both monetary and informational) that arise from trusting and trustworthy behavior. Various researchers have demonstrated that the transfer of resources or power (producing vulnerability) under dilemma situations characterized by conflict of interests (e.g. opportunism vs. cooperation) is essential to the development of trusting relationships. These fundamental principles of trust and trustworthiness have been demonstrated in organizational research (Curseu \& Schruijer, 2010; Yakovleva et al., 2010), in social dilemma research (Balliet et al., 2013; Parks \& Hulbert, 1995; Yamagishi, 2011) and in close relationships research (Murray et al., 2003; Shallcross \& Simpson, 2012).

In the trust game of Berg, Dickhaut and McCabe (1995), trust leads to greater efficiency and creates possible profits for investors. Another incentive that offsets the financial risk of investment is the information gained about the propensity to trust and the trustworthiness of exchange partners in general. ${ }^{90}$ In the classic trust game, Investors demonstrate their trust according to the amount of their endowment that they are willing to put at risk (via trust-based investment) and Trustees demonstrate trustworthiness according to the proportion of income (from investments) that they voluntarily return to Investors.

Recognizing that the Trust game presents participants with choice dilemmas between opportunistic short-term rewards and the long-term rewards associated with cultivated reciprocal exchange relationships, we have previously evaluated participants' emotional reports after trust-based interactions, providing evidence that economic decisions and interactions in a Trust game are reliable predictors of subsequent emotional states (Schniter et al., 2013). In this chapter we expand the scope of our previous inquiry considering whether constraints on demonstrable behavior tamper, magnify, or have non-linear effects on recalibrational emotions. The imposition of minimum return rules in a trust game (such as implemented by Rietz et al., 2013) to reduce downside risk for investors brings welcome "assurance" (Yamagishi, 2011) that, at least when sufficient, may trigger positive emotions. However, in doing so, the imposition of minimum standards of behavior also limits the information generating potential of the trust-game exchange by constraining the amount that can be returned voluntarily. As such, under institutions leaving very little discretionary space for trust-based behavior demonstration, investors and trustees may end up not expecting to achieve and not fulfilling the goals of the long-sighted program. In turn, these participants for

\footnotetext{
${ }^{90}$ While we studied single, anonymous interactions, we believe trust and reciprocity are rooted in a complex set of social interactions, experience, and evolved computational psychology that integrate information and apply our gathered knowledge. Every opportunity to show trust and trustworthiness builds the stock of reputational information that people can potentially capitalize on or computationally apply to contextualized interactions. In the trust game, Investors are making choices that not only affect their immediate payoffs, but also allow them to learn about the reputations of the Trustees that they may find valuable in their own right, in future trust and investment games, or in other potential interactions or applications.
} 
whom long-sighted goals are relatively moot, may experience relatively little in terms of emotions triggered by long-sighted goal outcomes.

To test the effect of demonstrable trust and trustworthiness on reported emotional experiences following trust-based interactions we modified the basic Trust Game in three additional treatments. In these treatments we imposed minimum return rules that limited demonstrable trustworthiness by requiring the Trustee to return to the Investor: either 10\%, $20 \%$ or $30 \%$ of the tripled investment amount received, thereby guaranteeing to the Investor a $10 \%, 20 \%$ or $30 \%$ reduction in his downside risk. By limiting the downside risk to the Investor, the demonstrability of trust via investment becomes proportionally limited. Likewise, by mandating the minimum amount of a received income that a Trustee must return, the demonstrability of trustworthiness via returns on investment becomes proportionally limited as well.

Our trust games proceeded as followed. Each participant was assigned a role, labeled "Person 1" for the Investor and "Person 2" for the Trustee. The participants interacted only once in the trust game described below. Each participant was paid \$7 for participation and any additional payoffs from the trust game after signing a receipt. On average participants earned \$10.98 in addition to their participation payment. Three hundred and six participants interacted in one of the four treatments. In each treatment, the Investor could send any portion of his $\$ 10$ endowment to the Trustee with that investment amount tripled on the way. The Trustee, having received a tripled investment amount, then decided how much to send back contingent upon the minimum return rule. In the baseline $0 \%$ rule treatment, the Trustee could send back none of the amount received. ${ }^{91}$ In $10 \%, 20 \%$ and $30 \%$ rule the Trustee had to send back at least $10 \%, 20 \%$ and $30 \%$ of the tripled investment amount received, respectively. ${ }^{92}$

\section{B. Previously reported effects of minimum return rules on trust-based behaviors}

With Thomas Rietz and Roman Sheremeta, we previously conducted research investigating effects of the imposition of minimum return rules on trust and trustworthiness (see Rietz et al., 2013) and reported results for a data set comprised of 178 participants, a subset of the larger dataset of 306 participants for which we report new results in this chapter. Before reviewing our predictions and new results we would like to draw attention to two important results from our prior study.

Prior Result 1. Exogenously imposed minimum return rule treatments had economic effects on Investors' and Trustees' earnings because of the changes seen in investment and return rates. Investor and Trustee net profit rates fell to their lowest when a $10 \%$ minimum return rule was imposed. Then, as the restrictiveness of the rule increased across treatments,

\footnotetext{
${ }^{91}$ We used neutral language and did not use words such as "rules." Moreover, to avoid any confounding effects, we used the following language in baseline treatment for the trustee: "Person 2 can send back none, more than none, or all of the amount in Person 2's account." In the other three treatments we used: "Person 2 can send back 10\% [20\%, $30 \%]$, more than $10 \%[20 \%, 30 \%]$, or all of the amount in Person 2 's account."

${ }^{92}$ A button was placed on the Trustees' screen that, if selected, would trigger a pop-up window displaying the minimal amount that could be returned.
} 
profits rose, reaching their maxima in the $30 \%$ rule condition where assurance was greatest. Across treatments, median amounts sent and returned also followed a U-shaped pattern, similar to the one reported in Figure 2.

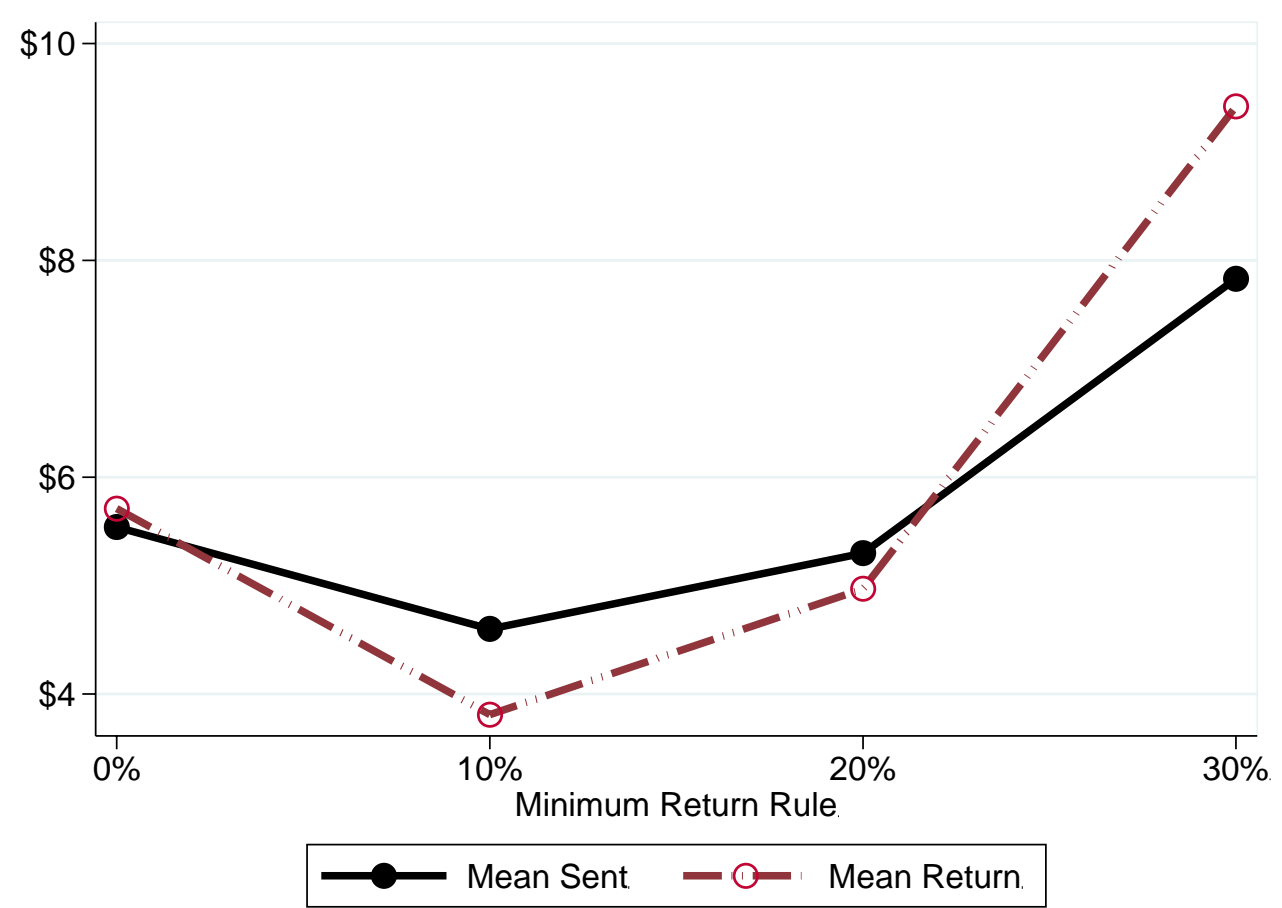

Figure 2. Mean amount sent and returned per treatment (from Rietz et al., 2013)

Prior Result 2. Exogenously imposed minimum return rule treatments had behavioral effects on Investors' demonstrated trust and Trustees' demonstrated trustworthiness. By increasing minimum return rules, we not only created an institutional effect of reducing the limits on downside risk that investors could demonstrate, but also compromised the propensity to voluntarily demonstrate trust- lowering the median investment levels from what they may have been without the rule. Figure 2 shows that, as the rule's restrictiveness increased, Investors' demonstrated trust fell, as measured by the percentage of investment that was at risk. Overall, we also saw that Trustees' demonstrated trustworthiness, as indicated by voluntary discretionary returns, was impacted by imposition of the rules. Upon imposition of the $10 \%$ rule, trustworthiness disappeared for the typical Trustee. Under the 20\% and 30\% rules, discretionary reciprocity improved slightly, however the dominant mode remained equal to the minimum required. Thus, like trust, trustworthiness never returned to the levels observed under the $0 \%$ rule. 


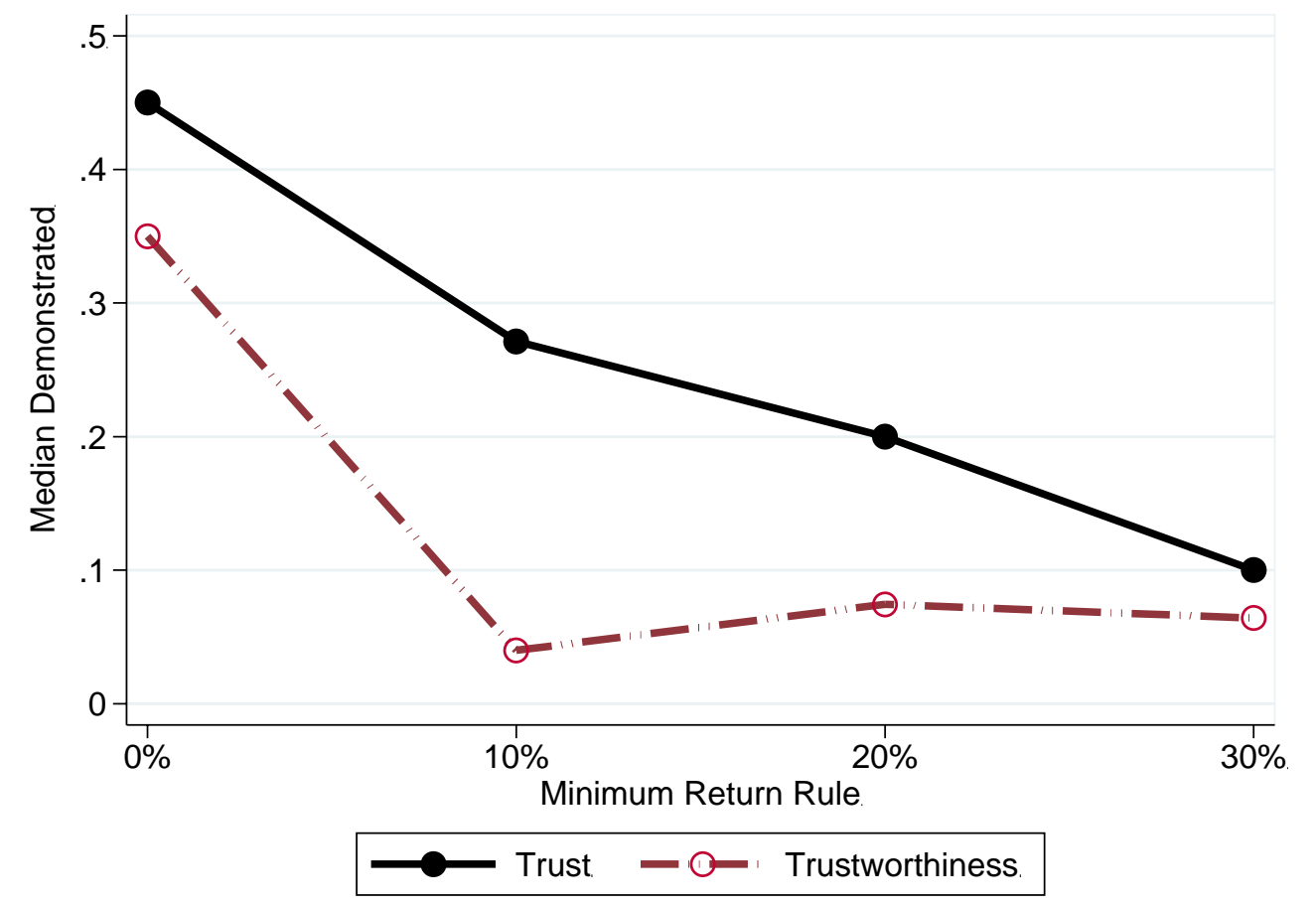

Figure 3. Median demonstrable trust and trust worthiness per treatment (from Rietz et al., 2013)

Other studies have examined the effects of risk-reducing institutions in online marketplaces (Gefen \& Pavlou, 2012) the imposition of threatened sanctions on reciprocity in the trust game (Houser et al. 2008; Li et al, 2009) and performance requirements on work motivation (Falk \& Kosfeld, 2006) also finding similar patterns of effects. For example, analogous to the u-shape of our first prior result seen in Figure 2, Falk and Kosfeld (2006) found that imposition of a small minimum performance requirement initially decreased workers' performance compared to the voluntary performance demonstrated under no requirement, however as performance requirement increased performance also increased.

As we explain below, these results, considered along with our dual program theory of trust-based behavior regulation, lead to several predictions about effects of "assurance" on recalibrational emotions following trust-based interactions.

\section{Predictions: Patterned experience of recalibrational emotions following trust-based interaction, and the effects of minimum return rules on experienced emotions}

1. The patterned experience of emotions. Valence Models assume two factors: one comprised of a standard set of positive emotions that positively correlate with one another [appreciative, happy, content, cheerful, triumphant, inspired, secure, proud, believable, and surprised], and the other comprised of a standard set of negative emotions that positively 
correlate with one another [disgusted, jealous, aggravated, frustrated, angry, depressed, sad, embarrassed, ashamed, and guilty]. The Recalibrational Model specifies more than two functionally unique sets (we suggest five, though other parsing are possible) based on shortsighted, long-sighted, interpersonal, intrapersonal, positive, and negative functions of emotions. Valence Models assume that either negative emotion(s) are activated or positive emotions are activated, whereas the Recalibrational Model allows for the simultaneous activation of positive and negative emotions. Based on the standard Valence theory and the multivariate Recalibrational theory, we tested the following predictions.

Prediction 1. Consistent with the Valence Model, PA and NA sets are strictly interdependent with negative $(=-1)$ correlation between them.

Prediction 2. The four factor solution (not including the factor set containing "surprise") proposed for the Recalibrational Model fits the data of emotional reports after trust based interactions better than the two factor solutions that have been proposed for the Valence Model.

2. Effects of minimum return rules on emotions. We make prediction(s), informed by the Recalibrational model, concerning the effects of minimum return rule impositions on emotions given two important results demonstrated by previous work: (1) that (compared to no minimum return rule) the imposition of minimum return rules that limit Investor's downside risk initially reduce the rate of investment and return and, when sufficiently large, bring the rates of investment and return back up to relatively high levels; and (2) the reduction in risky investment and discretionary returns as imposed by minimum return rules leads to less demonstrated trust and less demonstrated trustworthiness than otherwise observed in the absence of the rules. Each of these results should effect the triggering of positive and negative emotions which we hypothesize to be experienced in response to the achievements or failures of short- and long- sighted programs across treatments.

Previous results show that the money maximizing goals of Investors' and Trustees' short-sighted programs were achieved most often in $0 \%$ and $30 \%$ minimum return rule treatments, but were not achieved (i.e. amounts sent and returned were significantly less) at such high rates in 10\% and 20\% treatments (see Figure 2). Most emotions in our set of 20 are hypothesized to respond to the success and failure of the short-sighted program (i.e. negative emotions should be experienced less intensely and positive emotions experienced more intensely in $0 \%$ and $30 \%$ as opposed to $10 \%$ and $20 \%$ treatments), leading to the following prediction.

Prediction 3. The set of 9 positive emotions (surprise not included) and the set of 10 negative emotions will respond to the economic trend of changing Investor and Trustee profits as affected by investment and return levels previously reported across minimum return rule treatments such that a curvilinear trend across treatments $(0 \%, 10 \%, 20 \%, 30 \%)$ will be seen. This trend should be convex for the set of all positive emotions and concave for the set of all negative emotions. 
We also predict that emotions derived from achievement and failure of long-sighted goals should be most active at the $0 \%$ end of our treatment spectrum where trust and trustworthiness are most demonstrable, but least active at the $30 \%$ end of our treatment spectrum where the demonstrability of trust and trustworthiness is most constrained. That is, as rules are imposed and increase towards $30 \%$, the long-sighted program's goals become increasingly moot - as such, the long-sighted program should not be as active, and as such failures and successes of the long-sighted program should be less relevant (and the triggering of any emotions serving the goals of the long-sighted program should be experienced in less of a patterned way). Specifically, Sets 2 and 5 (the emotion sets exclusively serving the longsighted program goals) should not be experienced in a patterned way as strongly in higher rule conditions as they are in $0 \%$, while Sets 1 and 4 (by virtue of their service to shortsighted goals) should show strong response patterns across $0 \%, 10 \%, 20 \%, 30 \%$ treatments, affected by rules effects on earnings.

Prediction 4. The curvilinear relationship between emotional responses and rule predicted in P2 should have stronger effects for Sets 1 and 4 than for Sets 2 and 5.

Prediction 1 supports the Valence Model over the Recalibrational Model, Prediction 3 is consistent with both the Valence and Recalibrational Models, and Predictions 2 and 4 support the Recalibrational Model over the Valence Model.

\section{Trust-game behaviors and emotional reports: descriptive statistics and cross-tabulations}

According to non-cooperative game theory where individuals should always prefer more money over less, the normative (selfish) behavior expected of participants in a trust game is for second movers (trustees) to keep all of any tripled amounts transferred by investors, and for first movers (investors) to, therefore, not transfer any amount. Contrary to non-cooperative game theory, we observed substantial variability in individual behavior with many participants demonstrating trust with investment and trustworthiness with reciprocation. Figure 4 displays the bubble plot of the amount sent and the amount returned for the 306 participants in our study. Overall, our results are consistent with previous findings of Berg et al. (1995); on average, Investors sent $\$ 5.98(S D=3.64)$ and Trustees returned $\$ 6.13$ $(S D=5.63)$, resulting in profits of $\$ 10.16(S D=3.31)$ and $\$ 11.81(S D=6.99)$, respectively.

Likewise, there was substantial variability in individual reports of emotional experience. The average reported emotional experience (as a result of Trust game interactions) had a mean of 2.19 , near 2 ("a little"). Reports of experience on every emotion ranged from 1 ("very slightly or not at all") to 5 ("extremely"). While the modal experience reported for most (18/20) emotions was 1 ("very slightly or not at all") modes were also seen at 3 for happy and 3 for content. Reports of 1 were more frequent for negative emotions than for the positive emotions $(2,006 / 3,060$ versus $1,005 / 3,060$, respectively), contributing to significantly lower intensity of reported negative emotions $(M=1.69, S D=0.80)$ than positive emotions $(M=2.68, S D=1.02)$ according to Wilcoxon matched-pairs tests $(Z=9.227, p<.001)$. The Kruskal-Wallis equality-of-populations rank test indicated no differences in proportions 
of 1 reported between treatments $\left(\chi^{2}(3)=2.997, p=.39\right)$. Likewise, the Wilcoxon rank-sum test found no significant differences in proportions of 1 reported between any two treatments.

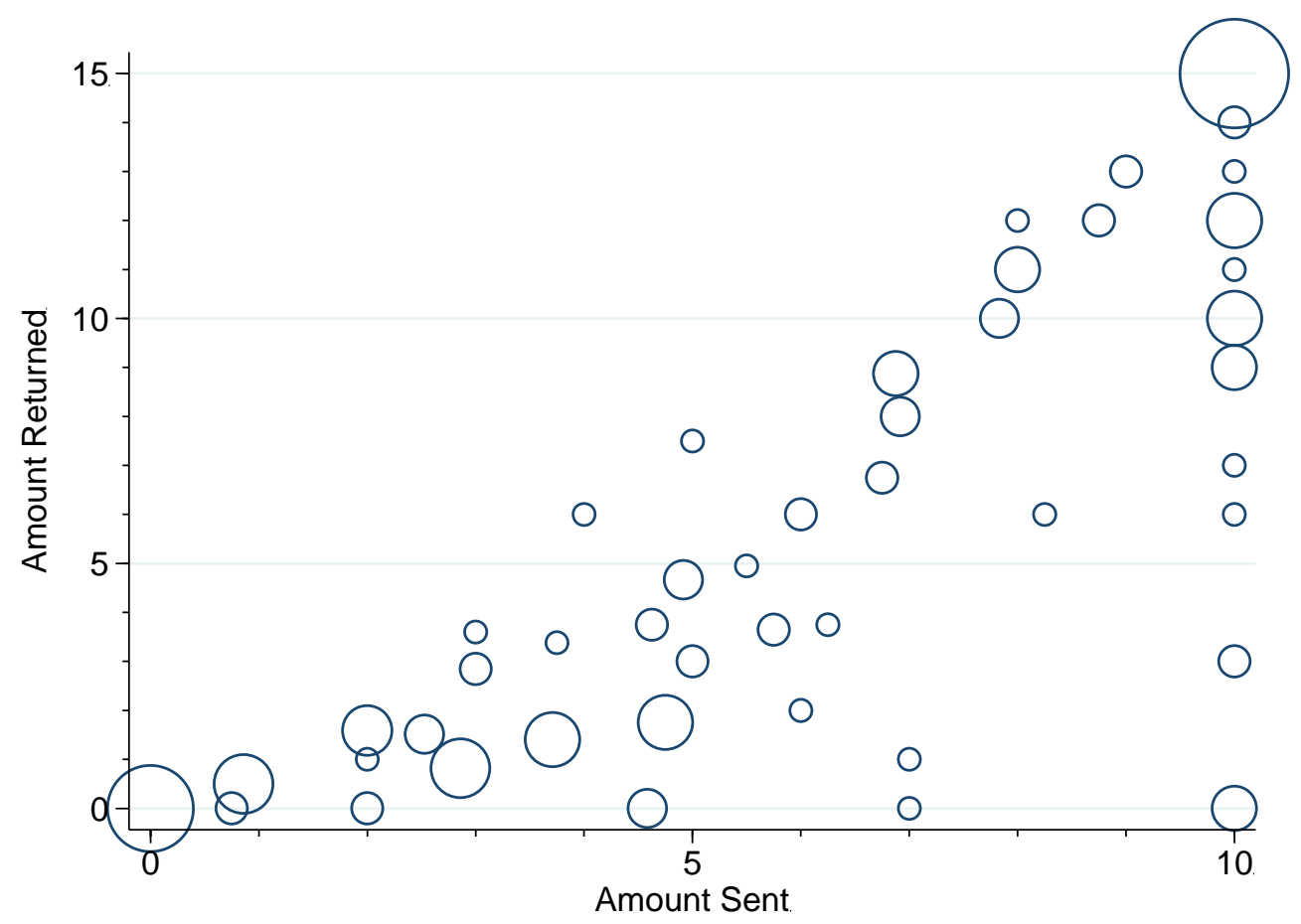

Figure 4: Bubble plot of amounts sent and returned in the Trust game

Note: Observations were plotted with bubbles, where the relative size indicates the number of observations. The smallest bubble plotted represents one observation and the largest bubble plotted represents 12 observations.

Item analysis was conducted on the 20 items hypothesized to assess (10) positive and (10) negative emotional states among our subjects. Some, but not all, positive emotions showed positive correlation with all positive emotions (44 of 45 correlations). Some, but not all, negative emotions showed a positive correlation with other negative emotions (41 of 45 correlations). And some, but not all, negative emotions negatively correlated with the positive emotions (87 of 100 correlations). Guilt and surprise accounted for all positive correlations found between negative and positive emotions. These results indicated that a single factor solution based on valence does not provide sufficient explanatory power to understand how individuals experienced emotions: people did not experience only positive or only negative emotions in an exclusively valenced manner, but instead tended to experience "mixed" positive and negative emotions simultaneously.

According to a purely "bipolar" model of valence, reports of simultaneously experienced strong positive emotion and strong negative emotion are unexpected. However, our results show that a strictly negative or positive activation is the exception and not the norm. Cross tabulation indicated occurrences of simultaneously experienced PA and NA emotions. Each participant reported 10 positive and 10 negative emotional states, yielding 100 pairs of positive and negative emotional state reports (per participant). Among all of 
these pairs of reported emotional states, we observed 130 cases from 25 (8.17\% of) participants who reported PA and NA emotions that were both felt "extremely" $(=5) ; 522$ cases from 74 (22.18\% of) participants who reported PA and NA emotions that were both felt in the range from "quite a bit" to "extremely" $(\geq 4) ; 2,148$ cases from 142 (46.41\% of) participants who reported PA and NA emotions that were both felt in the range from "moderately" to "extremely" ( $\geq 3)$; and 5,675 cases from $220(71.90 \%)$ participants who reported PA and NA emotions that were both felt in the range from "a little" to "extremely" $(\geq 2)$. These cross tabulations are reported in Table 2 where they are also shown by treatment. For every treatment, simultaneously experienced positive and negative emotions were prevalent. Based on descriptive statistics (correlations between positive and negative emotions, and cross tabulations), we failed to find support for Prediction 1 of the Valence Model. Next, we report how we validated this result using inferential statistics.

Table 2. Cross tabulations of simultaneously experienced Positive and Negative emotions by treatment

\begin{tabular}{ccccccccccc} 
& $\begin{array}{c}\text { No }(0 \%) \text { Rule } \\
(N=170)\end{array}$ & \multicolumn{2}{c}{$\begin{array}{c}10 \% \text { Rule } \\
(N=48)\end{array}$} & \multicolumn{2}{c}{$\begin{array}{c}20 \% \text { Rule } \\
(N=40)\end{array}$} & \multicolumn{2}{c}{$\begin{array}{c}30 \% \text { Rule } \\
(N=48)\end{array}$} & \multicolumn{2}{c}{$\begin{array}{c}\text { Combined } \\
(N=306)\end{array}$} \\
Experienced: & (a) $)$ & (b) & (a) $)$ & (b) & (a) & (b) & (a) & (b) & (a) & (b) \\
\hline $\begin{array}{c}\text { "a little" } \\
\text { to }\end{array}$ & & & & & & & & & & \\
"extremely" & 15.6 & 66.5 & 23.4 & 83.3 & 25.7 & 77.5 & 18.1 & 75.0 & 18.5 & 71.9 \\
\hline $\begin{array}{c}\text { "moderately" } \\
\text { to } \\
\text { "extremely" }\end{array}$ & 5.7 & 41.8 & 9.3 & 54.2 & 10.8 & 52.5 & 6.2 & 50.0 & 7.0 & 46.4 \\
\hline $\begin{array}{c}\text { "quite a bit" } \\
\text { to }\end{array}$ & & & & & & & & & & \\
"extremely" & 1.4 & 20.6 & 3.2 & 35.4 & 1.7 & 30.0 & 1.5 & 20.8 & 1.7 & 24.2 \\
\hline "extremely" & 0.3 & 7.6 & 1.0 & 12.5 & 0.0 & 2.5 & 0.5 & 10.4 & 0.4 & 8.2 \\
\hline
\end{tabular}

Note: we report percentages from cross tabulation of (a) the observed frequency of all $N \times 10^{2}$ positive-negative pairs of reports that indicated simultaneously experienced positive and negative emotions, and (2) the observed frequency of $N$ participants who reported simultaneously experienced positive and negative emotions.

In Table 3 we report by treatment the mean and standard deviation of average reported emotion experienced for each of the five Recalibrational Model sets. In all treatments we found the same pattern: participants reported more extremely experienced positive emotions (sets 1 and 2) than negative emotions (sets 4 and 5). Additionally, in the $10 \%$ and $20 \%$ rule treatments compared to the no $(0 \%)$ rule treatment, we found that participants reported extreme experiences of positive emotions relatively less, but extreme experiences of negative emotions relatively more. 
Table 3. Mean (Standard Deviation) of Recalibrational Model emotion sets

\begin{tabular}{lccccc} 
Treatment & Set 1 & Set 2 & Set 3 & Set 4 & Set 5 \\
\hline No $(0 \%)$ rule & 3.31 & 2.64 & 2.82 & 1.66 & 1.51 \\
$N=170$ & $(1.41)$ & $(1.21)$ & $(1.43)$ & $(0.94)$ & $(0.92)$ \\
\hline $10 \%$ rule & 2.57 & 2.16 & 2.88 & 2.08 & 1.74 \\
$N=48$ & $(1.22)$ & $(1.16)$ & $(1.52)$ & $(1.16)$ & $(0.89)$ \\
\hline $20 \%$ rule & 2.8 & 2.54 & 2.73 & 1.93 & 1.72 \\
$N=40$ & $(1.16)$ & $(1.13)$ & $(1.26)$ & $(1.07)$ & $(0.98)$ \\
\hline $30 \%$ rule & 3.46 & 2.91 & 2.68 & 1.59 & 1.45 \\
$N=47$ & $(1.12)$ & $(1.21)$ & $(1.38)$ & $(0.93)$ & $(0.71)$ \\
\hline Total & 3.15 & 2.6 & 2.8 & 1.75 & 1.57 \\
$N=305$ & $(1.34)$ & $(1.21)$ & $(1.41)$ & $(1.00)$ & $(0.89)$ \\
\hline
\end{tabular}

Using exploratory factor analysis, we rejected that a two-factor model fit the data best. The Bayesian information criterion (BIC) ${ }^{93}$ for a two factor model was inferior to models with three, four, five, six, seven, and eight factors. This is true of all data from across treatments, as well as only from the no $(0 \%)$ rule treatment. Next, we used confirmatory factor analysis to evaluate whether the four factor solution (not including the factor set containing "surprise") proposed for the Recalibrational Model fits the data of emotional reports after trust-based interactions better than the two factor solution proposed for the Valence Model.

\section{E. Confirmatory factor analysis}

William James (1890) noted that despite the intuitive impression that there are almost countless emotions and that these emotions blend seamlessly into one another, we might yet be able to distinguish sets of emotions "by their severally appropriate objective stimuli [rather] than by their conscious or subjective tone" (in Plutchik, 1980, p.151). Over the past century, theorists (e.g., Cattell, 1946; Burt, 1950; Guilford \& Zimmerman, 1956; Plutchik, 1980) have explored the analysis of underlying factor sets among the multitude of proposed emotions.

We used confirmatory factor analysis (CFA) to examine the fit of emotional report data in competing models. We began with assessment of a two-factor model based on emotion valence (i.e. positive or negative) and evaluated the fit of twenty emotions into these two factor sets. We allowed correlation between the factors to be estimated rather than forcing the correlation to be zero or negative. ${ }^{94}$ The measures of fit are reported in Table

\footnotetext{
${ }^{93}$ When fitting models, it is possible to increase the likelihood by adding parameters, but doing so may result in overfitting. The BIC resolves this problem by introducing a penalty term for the number of parameters in the model.

${ }^{94}$ We also fit alternative versions of the Valence Model where we forced the correlation to -1 and zero. Allowing the correlation to be estimated resulted in the highest fit, and thus, we compared the highest fit version of Valence Model to our Recalibrational Model.
} 
4Error! Reference source not found.. The fitted measure of correlation between the factors was -.667 [95\% CI: -.736, -.597]. As such we failed to find support for P1 using CFA.

Next, we used CFA to evaluate the fit of twenty emotions into four of the five factors corresponding to the Recalibrational Model's functionally specific sets listed in Table 1Error! Reference source not found. ${ }^{95}$ Again we allowed correlation between the factors to be estimated. All emotions loaded positively and significantly onto the predicted latent factor within the Recalibrational Model at a $1 \%$ level.

According to guidelines set forth by Gefen et al. (2011), all measures of fit (i.e., loglikelihood, root mean squared error of approximation (RMSEA), Akaike information criterion (AIC), Bayesian information criterion (BIC), comparative fit index (CFI), and the standardized root mean squared residual (SRMR)) are better for the Recalibrational Model than the Valence Model. While the 90\% CI of the RMSEA for the Recalibrational Model is below .10 [.083, .098], it exceeds .10 [.114, .129] designating poor fit (Brown \& Cudeck, $1993)$ for the Valence Model. The difference in better fit for the Recalibrational Model is significant $\left(\chi^{2}(5)=158, p<.0001\right)$, providing evidence for $\mathrm{P} 2$ in support of the Recalibrational Model.

Table 4. Confirmatory Factor Analysis results

\begin{tabular}{cccccccc} 
Model & $\begin{array}{c}\text { Log } \\
\text { Likelihood }\end{array}$ & $\begin{array}{c}\text { Degrees } \\
\text { of } \\
\text { Freedom }\end{array}$ & $\begin{array}{c}\text { Root mean } \\
\text { squared error } \\
\text { of } \\
\text { approximation }\end{array}$ & $\begin{array}{c}\text { Akaike } \\
\text { information } \\
\text { criterion }\end{array}$ & $\begin{array}{c}\text { Bayesian } \\
\text { information } \\
\text { criterion }\end{array}$ & $\begin{array}{c}\text { Comparative } \\
\text { fit index }\end{array}$ & $\begin{array}{c}\text { Standardized } \\
\text { root mean } \\
\text { squared } \\
\text { residual }\end{array}$ \\
\hline Valence & $-7,931$ & 58 & 0.12 & 15,978 & 16,194 & 0.83 & 0.09 \\
Recalibration & $-7,773$ & 63 & 0.09 & 15,673 & 15,906 & 0.91 & 0.07 \\
\hline
\end{tabular}

\section{F. "Minimum return rule" effects on emotions}

We found significant quadratic relationships between rules, rules squared, and the positive emotions $\left(F=7.516, p<.001, R^{2}=.047\right)$ and rules, rules squared, and the negative emotions $\left(F=5.480, p=.005, R^{2}=.035\right)$ though relatively little variance is explained. We plotted the two sets of negative and positive emotions across rule treatments in Figure 5. Multivariate regressions were performed using the average of individuals' reported emotions in each set, regressed against the rule and rule squared. The coefficients for rule and rule squared $(\beta=-.704, .025$, respectively) were significant (both $p<.001$ ) for positive emotions and the coefficients for rule and rule squared $(\beta=0.497,-.018$, respectively) were significant (both $p=.001$ ) for negative emotions, providing support for P3, consistent with both Valence and Recalibrational Models.

\footnotetext{
${ }^{95}$ For purposes of fitting data with CFA we exclude one participant who reported "1" on all twenty emotions. We also excluded our set 3 because it was defined by a single emotion variable (surprise). It would be misleading to interpret the results of CFA with this set included because surprise will automatically load significantly on its factor solution, since it is the only variable defining that factor. We also omitted the emotion surprise from the Valence model, so that the comparison of overall fit between the two models is based on the remaining 19 emotions.
} 
After excluding the Recalibrational Model's set 3 with surprise (because it contributes to both positive and negative emotion effects above), we compared effect sizes (adjusted $R^{2}$ ) to evaluate the relative strength of contributions from Set 1, and Set 2 to the above reported treatment effect on Positive emotions. We also compared effect sizes to evaluate the relative strength of contributions from Set 4, and Set 5 to the above reported treatment effect on Negative emotions. While the effect sizes from our quadratic regressions were quite small, we found that the effect size of Set 1 was twice that of Set 2 and the effect size of Set 4 was twice that of Set 5 (see Table 5). These results were consistent with Prediction 4 in support of the Recalibrational Model.

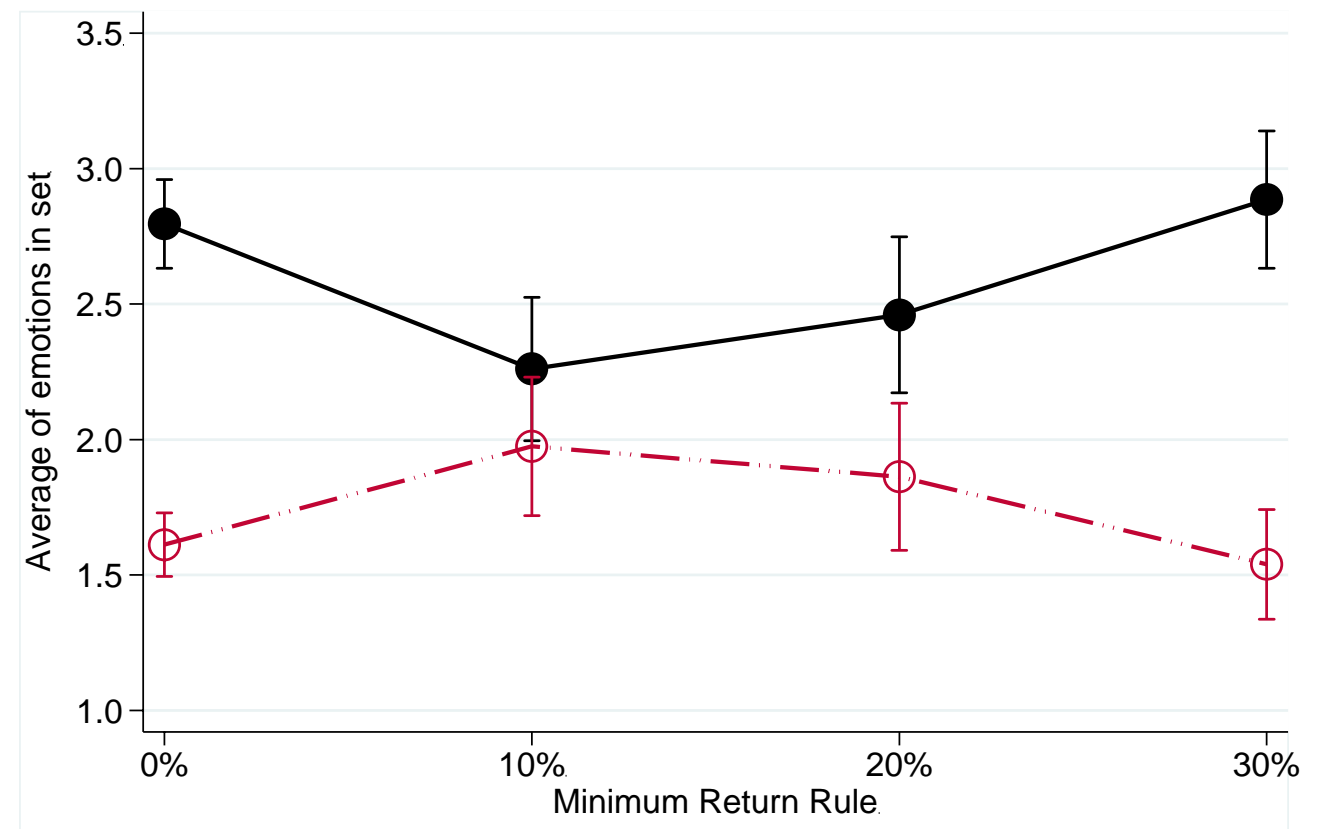

- Positive emotion set $\quad-O-$ Negative emotion set

Figure 5. Mean of positive and negative emotion sets per treatment

Table 5. Results of quadratic regressions for Recalibrational Model emotion sets

Quadratic

\begin{tabular}{cccccc}
$\begin{array}{c}\text { Regression } \\
(\text { on rule, rule }\end{array}$ & Set 1 & Set 2 & Set 3 & Set 4 & Set 5 \\
\hline$P$ value & 0.000 & 0.012 & 0.772 & 0.013 & 0.121 \\
$F$ & & & & & \\
& $F=8.478$ & $F=4.517$ & $F=0.259$ & $F=4.428$ & $F=2.131$ \\
Adjusted $R^{2}$ & 0.053 & 0.029 & 0.002 & 0.029 & 0.014 \\
\hline
\end{tabular}

Note: Multivariate regressions were performed using the average of individuals' reported emotions in each set, regressed against the rule and rule-squared. 


\section{GENERAL DISCUSSION}

\section{A. Discussion of results}

After having reviewed the history of thought on the relationships between emotions' valence, hedonism, and utility we introduced a recalibrational theory of emotions with specific attention to how emotions are involved in the regulation of trust-based behaviors. We proposed specific "recalibrational" features for each of 20 emotions (i.e., assisting in shortsighted goal pursuit, long-sighted goal pursuit, interpersonal recalibration, intrapersonal recalibration, upregulation or homeostatic maintenance or downregulation) commonly used in PANAS scales and with which we surveyed participants concerning their emotional states after (and as a consequence of) anonymously interacting in a Trust game.

We have evaluated the reported experience of 20 emotions, comparing the usefulness and interpretability of either simpler Valence Models (commonly applied to the SAM or PANAS) or the multidimensional model (based on recalibrational theory) that we proposed for understanding emotional experience and trust-based interaction behavior. Both crosstabulation of simultaneously experienced positive and negative emotions and factor analysis demonstrated that the multidimensional Recalibrational Model describes the patterned experience of a large set of emotions following trust based interaction better than the standard Valence Model. Below we discuss these results and their implications for emotion and trust research, consider applications of the insights revealed by this line of research, and finally mention several areas of trust and emotion research in need of further investigation that we feel could offer assistance to the development of both personal and business relationships.

When we used regression to evaluate whether our experimental manipulations (via imposition of minimum return rules) of trust and trustworthiness demonstrability affected the emotional reports we gathered after trust games, we found evidence for a clearly valenced response - with positive and negative sets of the Valence Model responding in a mirrored, almost symmetrically opposite fashion. This valenced response suggests that a model based on the positive and negative clustering of emotional experiences (recognized for millennia by respected scholars and informing the standard models used today) offers intuitive explanatory power for understanding trust-based interactions. Despite the attractive simplicity of considering only two factors with the Valence Model additional factors clearly lie latent.

Further evaluation of Set 1, Set, 2, Set 4, and Set 5 (from the Recalibrational Model) -subsets of the larger clusters of positive and negative emotions considered by the Valence Model-suggested to us that our experimental impositions of minimum return rules did not proportionally effect all sets of the Recalibrational Model the same: some of the sets of our model account for a greater portion of the valenced effect revealed by the simpler Valence Model. Specifically, the effects of demonstrability constraints (imposed by minimum return rules in our experiment) on Sets 2 and 5 of the Recalibrational Model are not as large as those on Sets 1 and 4.

Recalibrational Model Sets 1 and 2, (positive emotions which upregulate or maintain homeostasis of targeted programs) are basically components of the "positive affect set" of the PANAS. Likewise, Recalibrational Model Sets 4 and 5 (negative emotions which downregulate targeted programs) are components of the "negative affect set" of the PANAS. 
Among all the sets affected by the rules treatments, Sets 2 and 5 show comparatively smaller effects. We attribute the smaller effect sizes of Sets 2 and 5 to their unique and distinguishing recalibrational feature: they are made up of social emotions exclusively assisting in longsighted goal pursuit and, thus, concerned more specifically with behaviors demonstrating trust and trustworthiness than with behaviors producing profit. Set 3 (surprise), is an interloper between positive and negative emotion sets (it can serve either function). Incidentally, Set 3 does not show a significant relationship with the minimum return rule imposed (as do the other sets). We suspect that other emotions (reacting to the accuracy of prior beliefs, given a subsequently discovered state of nature) like confusion, bewilderment, amazement, and astonishment would also cluster best with surprise in Set 3 - a "misfit" set that does not cleanly fit the Valence Model. Because each of the sets specified by the Recalibrational Model serves a unique suite of functional features, collapsing these sets into a simple two factor "positive affect" and "negative affect" Valence Model hides these more nuanced recalibrational features and ignores their experience.

As we reviewed above, the standard social science paradigm for studying the patterned experience of emotions tends to survey participants using an instrument (e.g. PANAS, SAM) ultimately understood according to the Valence Model. Some of the larger formulations of the PANAS contain enough variety in terms of the different emotional state items they survey, such that they can be interpreted by the more complex multivariate Recalibrational Model which we have discussed. On the other hand, bipolar affect scale instruments such as the SAM preclude the measure of mixed emotional states (with simultaneous experience of both positively and negatively valenced emotions) or emotional states that are not exclusively positive or negative. We find it especially disconcerting, therefore, that many psychophysiologists, neuroscientists, behavioral economists, and decision scientists have used and continue to use overly simplistic bipolar affect scales. We suggest that researchers either utilize emotional surveys with large arrays of items that can be interpreted by multivariate models of emotion, or else construct their surveys based on the Recalibrational Model of emotions discussed in this chapter. Elsewhere (Schniter et al., 2013), we have suggested based on supporting evidence, that the emotional states appreciative, happy, proud, frustrated, angry, and guilty make up a set with balanced valence that is mostly representative of the functional categories covered by the Recalibrational Model. Emotion sets representative of the Recalibrational Model's functional features (i.e., based on short-sighted, long-sighted, positive, negative, interpersonal and intrapersonal functions) could be used in producing an appropriate survey instrument with sensitivity to the variety of emotional responses triggered after trust-based interactions.

That our CFA results (for both the Recalibrational and Valence models) were not stronger is a feature of this data that we would like to call attention to. As we reported in our descriptive statistics section, analysis of emotion reports revealed a "floor effect" $"$ with many

\footnotetext{
${ }^{96}$ Hessling et al (2004, Sage Encyclopedia of Social Science Research Methods) explain, "A floor effect occurs when a measure possesses a distinct lower limit for potential responses and a large concentration of participants score at or near this limit... Scale attenuation is a methodological problem that occurs whenever variance is restricted in this manner."
} 
values of 1 reported, consistent with either (i) a problem interpreting emotion labels, (ii) difficulty identifying and reporting emotional states, or (iii) inactivation of emotions in the studied context. Indeed, because of the many $1 \mathrm{~s}$ reported for both positive and negative emotional states across our treatments, we conclude that it may not be possible to get much stronger results using data generated from self-reports of emotional states based on Likert scales. Acknowledging this shortcoming, we discuss the promise of future work based on objective coding of facial expressions of emotions below.

\section{B. Insights and applications of trust and emotion research}

The cornerstones of our Recalibrational Model are the competing behavior regulation programs theorized to affect self-control and trust-based behavior propensities in self and others. The recalibrational emotions we have described target and attempt to regulate these short- and long-sighted behavior regulation programs. A better understanding of these fundamental components behind one's own inner conflict under choice dilemmas, and the role of emotions in calibrating the regulation of behavior when faced with dilemmas, can contribute to the cultivation of wisdom and self-control (Heckhausen \& Schulz, 1995; Haselton \& Ketelaar, 2006; Gómez-Miñambres \& Schniter, 2013). However, wisdom and self-control have never been easy for humans to attain. The proposition that our minds contain simultaneously active conflicted programs, and produce contradictory emotional states (such as those bearing mixes of strong simultaneous experience of positive and negative emotions - e.g. pride and guilt) is not agreeably reconciled with most peoples' preferred concept of "self". Rather, it appears to us that many find it preferable to think of themselves as having a singular mind (a singular "self") without inner conflict, and thus prefer thinking that when they experience milieus of emotional states, that these sets of feelings are either clearly positive or negative. The experience of conflicted mixed emotions may not be regarded as a reliable steady state of human experience because it challenges our intuitions of a "self"s" singular internal interests and the consonance of a non-contradictory self-representation generally attributed to a sane mind. Expounding on the existential crisis created by an inherently incomplete awareness of self and selves, Kurzban (2010, p.56) suggests,

\footnotetext{
"if it's true that your brain consists of many, many little modules with various functions, and if only a small number of them are conscious, then there might not be any particular reason to consider some of them to be "you" or "really you" or your "self"... And for that matter, there might be no particular reason to consider your intuitions about your choices, or your ability to know your "self" reliably."
}

As we have reviewed, social dilemmas and behaviors engaged in social dilemmas often invoke social emotions like anger, disgust, guilt, embarrassment, pride, appreciation, and a feeling of being believable. Despite some of these emotions being aversive and considered as "flaws" of human nature, they are hypothesized to encourage individuals towards redressing or abandoning uncooperative relationships, or towards engaging in more cooperation. Evidence of predicted instantiation of these recalibrational emotions' in laboratory-based experimental economic games helps us explain why humans, in these 
conditions, are regularly observed producing trusting, trustworthy, and cooperative behaviors (Johnson et al., 2003).

Furthermore, with a better understanding of the predictable nature of recalibrational emotions triggered in the wake of trust-based interaction, the ability to better predict others' subsequent behavior (based on an understanding of their conflicted minds and the recalibrational function of emotions) could enhance discriminative cooperation. Judgment about others' behavioral propensities, based on their emotional states, is something that comes intuitively and automatically to non-trained lay-people through personable face-to-face interactions. Willis and Todorov (2006) reported that with only one hundred milliseconds of exposure to neutral faces, observers form impressions of facial trustworthiness. Magnetic resonance imaging (fMRI) has shown that this unconscious and automatic judgment process is made in the amygdala (Engell, Haxby, \& Todorov, 2007).

A select minority (Ekman \& O'Sullivan, 1999; O'Sullivan \& Ekman, 2004), or perhaps- most people (Belot, Bhaskar, \& Van De Ven, 2012) may be "naturals" capable of detecting liars. Belot et al. (2012) showed that observers of contestants on a game show playing a Prisoner's Dilemma were able to distinguish truth from lies when the contestants were asked about their intentions by the game show host. Frank, Gilovich and Regan (1993) showed that, after half an hour of social interaction with the other player in a one-shot prisoner's dilemma, participants were able to predict with above-chance accuracy if the other would cooperate or defect.

The ability to "read" other people and gain insight into their behavioral propensities can also be developed further via the Facial Action Coding System (FACS) first developed for training purposes by Ekman and Friesen (1978). This skill of detecting and documenting "action movements" in face muscles, eyes, and posture is now taught in certified courses as an accredited skill. The reading of facial expressions has also been used in conjunction with lie-detection procedures for forensic applications (Kassin \& Fong, 1999).

Research conducted on emotions, cooperation, and relationship maintenance suggests that improvements to cooperative relationships can result with the ability to express emotions (e.g., Xiao \& Houser, 2005), the acquired abilities to both recognize emotional states in self and others, and with an understanding of the functional designs behind these emotional states (to encourage specific behavioral propensities). Perhaps the reason that the ability to detect emotions is most useful is because involuntary facial expressions possess signaling quality affecting relationships (Boone \& Buck, 2003; Brown \& Moore, 2002; Frank, 1998; Krumhuber et al., 2007; Mehu, Little, \& Dunbar, 2007; Oda et al., 2009; Trivers, 1971; Scharlemann, Eckel, Kacelnik, \& Wilson, 2001; Schug et al., 2010). As such, emotions provide reasonably reliable and useful information (Keltner \& Kring, 1998) about one's intentions to forgive, compensate, reciprocate, retaliate against, profit from, leave or exclude other group members in a social dilemma. For example, Chapman et al. (2009) found that the participants in the Ultimatum game who expressed more disgust (in response to proposals) with their leviator labii (the muscle which raises the upper lip to form the classic facial expression of disgust), were more likely to reject those offers. This result suggests that disgust can signal an aversion to unfairness.

When the display of emotional expression is purposefully controlled and emotional states deliberately communicated, verbal contracts can be strengthened. Without the addition 
of reliable signals as guarantees, verbal contract are "cheap" and can easily be used for deception. Words do not reliably reflect underlying behavioral propensities or commitments in the way that emotions do (Boone \& Buck, 2003; Buck, 1985). This is because many facial expressions of negative emotion can be difficult to intentionally falsify (Ekman, 2003; Ekman, Roper, \& Hager, 1980; Porter \& ten Brinke, 2008). Remarkably, and probably because our psychologies that consider emotional expressions unfalsifiable and reliable evolved to do so in a time before computer graphics and virtual communication, people also respond to contrived emotional expressions (e.g., emoticons) as well as induced memories of past emotional states. Stouten and De Cremer (2010) found that sending pictures with happy and angry displays moderated the effect of communicated intentions to cooperate or defect. Ketelaar \& Au (2003) reported that participants who recalled an episode of guilt as opposed to a neutral event cooperated more in an iterated prisoner's dilemma (Ketelaar \& Au, 2003).

\section{Important directions for further research}

The results of research reported in this chapter concern the predictable patterns of self-reported emotional experience following trust based interaction. Here we would like to note the items prioritized on our "wish list" of further research that we hope to see conducted.

First, we would like to see evidence of whether facial expressions of emotion following trust based interactions are predictable as self-reports of experienced emotions. If they cannot be as readily falsified or misreported, facial expressions might provide more objective measures of participants' emotional states than self-reports.

While we have developed a theory of emotions' ultimate functions (i.e., what the mechanisms were selected to do) and derived predictions from our conjectures about those (recalibrational) functions, this study only tested the patterned reporting of how emotions are experienced after interacting with another person anonymously in a particular situation. Future studies can take the Recalibrational Model one step further and test for emotions' ultimate functions. By examining whether the future actions of those individuals who report specific emotions, or show specific facial expressions are affected, we can evaluate what behavioral propensities emotional experiences affect. We would also like to see evidence of whether third party observers are more likely to predict the repeat behaviors of participants in an iterated social dilemma interaction (e.g. the Trust game or Prisoner's Dilemma), given the opportunity to observe the facial expressions produced by those participants upon learning of the outcome of their previous interaction.

Last, we would like to see results from studies investigating whether, with training to detect others' facial expressions of emotions and interpret emotions' functional designs, third parties' ability to predict others' behavioral propensities can be substantially improved. With an understanding of the behavior regulation systems and their emotional orchestrators guiding personal and business relationships, and perhaps with an understanding of the facial expressions signaling people's emotional states, greater wellbeing and economic welfare can be achieved. We hope that our model and suggestions for future work provide a step in the direction of developing better understanding of the human condition. We optimistically look forward to a future where people can better understand the role that emotions play in trustbased behavior. 


\section{REFERENCES}

Algoe, S., Haidt, J., \& Gable, S. (2008). Beyond reciprocity: Gratitude and relationships in everyday life. Emotion, 8, 425-429.

Algoe, S., Haidt, J. (2009). Witnessing excellence in action: The other-praising emotions of elevation, admiration, and gratitude. Journal of Positive Psychology, 4, 105-127.

Allred, K.G., Mallozzi, J.S., Matsui, F., \& Raia, C.P. (1997). The influence of anger and compassion on negotiation performance. Organizational Behavior \& Human Decision Processes, 70, 175-187.

Averill, J.R. (1975). A semantic atlas of emotional concepts. JSAS: Catalog of Selected Documents in Psychology, 5(421), 330.

Averill, J.R. (1983). Studies on anger and aggression. American Psychologist, 38(11), 11451160.

Axelrod, R. \& Hamilton, W.D. (1981). The evolution of cooperation. Science, 27(211), 13901396.

Backs, R.W., da Silva, S.P., \& Han, K. (2005).A comparison of younger and older adults' self-assessment manikin ratings of affective pictures. Experimental Aging Research, 31, 421-440.

Balliet, D., \& Van Lange, P.A. (2013). Trust, conflict, and cooperation: A meta-analysis. Psychological Bulletin. (forthcoming)

Baumeister, R., Stillwell, A., \& Heatherton, T. (1994). Guilt: An interpersonal approach. Psychological Bulletin, 115(2), 243-267.

Baumeister, R.F., Stillwell, A.M., \& Heatherton, T.F. (1995). Personal narratives about guilt: Role in action control and interpersonal relationships. Basic and Applied Social Psychology, 17, 173-198.

Barrett, H.C. (2005). Enzymatic computation and cognitive modularity. Mind and Language, 20, 259-287.

Barrett, L.F. (2006). Solving the emotion paradox: Categorization and the experience of emotion. Personality and Social Psychology Review, 10, 20-46.

Belot, M., Bhaskar, V., \& Van De Ven, J. (2012). Can observers predict trustworthiness? Review of Economics and Statistics, 94(1), 246-259.

Bentham, J. (1948). An Introduction to the Principle of Morals and Legislations (1789), New Jersey: Blackwell.

Ben-Ze'ev, A. (2000). The Subtlety of Emotions. Cambridge: MIT Press.

Berg, J., Dickhaut, J., \& McCabe, K. (1995). Trust, reciprocity and social history. Games and Economic Behavior, 10(1), 122-142.

Boone, R.T. \& Buck, R. (2003). Emotional expressivity and trustworthiness: The role of nonverbal behavior in the evolution of cooperation. Journal of Nonverbal Behavior, 27, 163-182.

Borg, I, Staufenbiel, T., \& Scherer, K.R. (1988). On the symbolic basis of shame. In K.R. Scherer (ed.), Facets of emotion: Recent research (pp.79-98). Hillsdale, NJ: Erlbaum.

Bowlby, J. (1969). Attachment and loss: Volume l. Attachment. New York: Basic Books. 
Bradley, M.M. \& Lang, P. (1994). Measuring emotion: the self-assessment manikin and the semantic differential. Journal of Behavior Therapy and Experimental Psychiatry 25(1), 49-59.

Bradley, M.M., Codispoti, M., Cuthbert, B.N., \& Lang, P.J. (2001). Emotion and motivation I: Defensive and appetitive reactions in picture processing. Emotion, 1(3), 276-298.

Brandts, J., Riedl, A., \& van Winden, F. (2009). Competitive rivalry, social disposition, and subjective well-being: an experiment. Journal of Public Economics, 93(11-12), 11581167.

Browne, M.W., \& Cudeck, R. (1993). Alternative ways of assessing model fit. Reprinted in Testing Structural Equation Models, (K. A. Bollen and J. S. Long, eds.), pp. 136-162. Newbury Park, CA: Sage.

Brown, W.M., \& Moore, C. (2002). Smile asymmetries and reputation as reliable indicators of likelihood to cooperate: An evolutionary analysis. In Advances in Psychology Research, S.P. Shohov (ed.), 11, 59-78.

Buck, R. (1985). The communication of emotion. New York: Guilford Press.

Burt, C. (1950). The factorial study of emotions. In Feelings and emotions, (M.L. Reymert, ed.). New York: McGraw-Hill.

Buss, A.H. (1980). Self-consciousness and Social Anxiety. San Francisco: W.H. Freeman.

Buss, D.M. (1990). Evolutionary social psychology: Prospects and pitfalls. Motivation and Emotion, 14(4), 265-286.

Butt, A.N., Choi, J.N., \& Jaeger, A.M (2005). The effects of self-emotion, counterpart emotion, and counterpart behavior on negotiator behavior: a comparison of individual level and dyad level dynamics. Journal of Organizational Behavior. 26(6), 681-704.

Byrne, R. \& Whiten, A. (eds.) (1988). Machiavellian Intelligence: Social expertise and the evolution of intellect in monkeys, apes, and humans. Oxford University Press.

Cacioppo, J.T., Gardner, W.L., \& Berntson, G.G. (1999). The affect system has parallel and integrative processing components: Form follows function. Journal of Personality and Social Psychology, 76, 839-855.

Callahan, S. (1988). The role of emotion in ethical decision making. Hastings Center Report, 18(3), 9-14.

Cannon, W. (1927). "The James-Lange Theory of Emotions: A Critical Examination and an Alternative Theory". The American Journal of Psychology, 39, 106-124.

Carver, C.S. \& Scheier, M.F. (1990). Origins and functions of positive and negative affect: a control-process view. Psychological Review, 97, 19-35.

Casti, J.L. (1994). Complexification: Explaining a paradoxical world through the science of surprise. New York: Harper Perennial.

Cattell, R.B. (1946). The Description and Measurement of Personality. New York: Harcourt Brace Jovanovich.

Chapman, H.A., Kim, D.A., Susskind, J.M., \& Anderson, A.K. (2009). In bad taste: Evidence for the oral origins of moral disgust. Science, 323 (5918), 1222-1226.

Chase, V.M., Hertwig, R., \& Gigerenzer, G. (1998). Visions of rationality. Trends in Cognitive Sciences, 2(6), 206-214. 
Cisler, J.M.; Olatunji, B.O., Lohr, J.M., \& Williams, N.L. (2009). Attentional bias differences between fear and disgust: Implications for the role of disgust in disgust-related anxiety disorders. Cognition and Emotion, 23(4), 675-687.

Clanton, G. \& Smith, L.G. (1987). Jealousy. Lantham, MD: University Press of America

Cohen, D., Nisbett, R.E., Bowdle, B.F. \& Schwarz, N. (1996). Insult, aggression, and the southern culture of honor: an experimental ethnography. Journal of Personality and Social Psychology, 70(5), 946-960.

Cosmides, L. \& Tooby, J. (1997). Evolutionary psychology: A primer. Retrieved April 9, 2013, from http://www.psych.ucsb.edu/research/cep/primer.html

Cosmides, L. \& Tooby, J. (1989). Evolutionary psychology and the generation of culture, Part II. Case study: A computational theory of social exchange. Ethology and Sociobiology, 10(1-3), 51-97.

Cosmides, L. \& Tooby, J. (2000). Evolutionary psychology and the emotions. In Handbook of Emotions, 2nd Edition. M. Lewis \& J. M. Haviland-Jones (Eds.), pp. 91-115. NY: Guilford.

Cox, J.C., Friedman, D., \& Gjerstad, S. (2007). A tractable model of reciprocity and fairness. Games and Economic Behavior, 59(1), 17-45.

Crawford, J.R. \& Henry, J.D. (2004). The Positive and Negative Affect Schedule (PANAS): construct validity, measurement properties and normative data in a large non-clinical sample. British Journal of Clinical Psychology 43, 243-265.

Curşeu, P.L., \& Schruijer, S.G. (2010). Does conflict shatter trust or does trust obliterate conflict? Revisiting the relationships between team diversity, conflict, and trust. Group Dynamics, 14(1), 66.

Curtis, V., \& Biran, A. (2001). Dirt, disgust, and disease: Is hygiene in our genes? Perspectives in Biology and Medicine, 44, 17-31.

Curtis, V., Aunger, R., \& Rabie, T. (2004). Evidence that disgust evolved to protect from risk of disease. Proceedings of the Royal Society B, 271, S131-S133.

Daly, M. \& Wilson, M. (1988). Homicide. New York: de Gruyter.

Damasio, A. (2004). William James and the modern neurobiology of emotion. In Emotion, Evolution and Rationality. (pp. 3-14). Oxford: Oxford University Press..

Damasio, A. (2005). Descartes' error: Emotion, reason, and the human brain. New York: Penguin Books.

Darwin, C. (1872/1965). Expression of Emotions in Man and Animals. Chicago: University of Chicago Press.

David, B. \& Olatunji, B.O. (2011). The effect of disgust conditioning and disgust sensitivity on appraisals of moral transgressions. Personality \& Individual Differences, 50(7), 11421146.

Dawkins R. (1976). The Selfish Gene. New York: Oxford University Press.

de Catanzaro, D. (1999). Motivation and Emotion: Evolutionary, Physiological, Developmental, and Social Perspectives. Upper Saddle River, NJ: Prentice Hall.

De Cremer, D., van Kleef, G., \& Wubben, M.J. (2007). Do the emotions of others shape justice effects? An interpersonal approach. In Advances in the Psychology of Justice and Affect, D. De Cremer (ed.), pp. 35-57. Charlotte, NC: Information Age. 
"de gustibus non est disputandum" (2013). In Merriam-Webster.com. Retrieved April 9, 2013, from http://www.merriam-webster.com/dictionary/

de Hooge, I.E., Zeelenberg, M., \& Breugelmans, S.M. (2007). Moral sentiments and cooperation: Differential influences of shame and guilt. Cognition \& Emotion, 21(5), 1025-1042.

de Hooge, I.E., Breugelmans, S.M. \& Zeelenberg, M. (2008). Not so ugly after all: when shame acts as a commitment device. Journal of Personality and Social Psychology, 95, 933-943.

de Jong, P.J. (1999). Communicative and remedial effects of social blushing. Journal of Nonverbal Behavior, 23(3),197-217.

de Sousa, R. (1994). Emotion. In A Companion to the Philosophy of Mind, S. Guttenplan (ed.), pp.270-276, Oxford: Blackwell.

de Waal, F.B.M. (1989). Peacemaking Among Primates. Cambridge: Harvard University Press

Driscoll, D., Tranel, D., \& Anderson, S.W. (2009). The effects of voluntary regulation of positive and negative emotion on psychophysiological responsiveness. International Journal of Psychophysiology, 72(1), 61-66.

Edelmann, R.J. (1987): Psychology of Embarrassment. Chichester, UK: John Wiley.

Eisenberg, N., Fabes, R.A., Miller, P.A., Fultz, J., Shell, R., Mathy, R.M., \& Reno, R.R. (1989). Relation of sympathy and personal distress to prosocial behavior: A multimethod study. Journal of Personality and Social Psychology, 57, 55-66.

Ekman, P. (1992). An argument for basic emotions. Cognition and Emotion, 6(3/4), 169-200.

Ekman, P. (2003). Darwin, deception, and facial expression. Annals of the New York Academy of Sciences, 1000, 205-221.

Ekman, P. \& Friesen, W.V. (1971). Constants across cultures in the face and emotion. Journal of Personality and Social Psychology, 17, 124-129.

Ekman, P. \& Friesen, W.V. (1978). Facial Action Coding System: A Technique for the Measurement of Facial Movement. Palo Alto, CA: Consulting Psychologists Press.

Ekman, P., Friesen, W.V., \& Ellsworth, P. (1972). Emotion in the human face: Guidelines for research and an integration of findings. New York: Pergamon Press.

Ekman, P., O’Sullivan, M., \& Frank, M.G. (1999). A few can catch a liar. Psychological Science, 10, 263-266.

Ekman, P., Roper, G., \& Hager, J.C. (1980). Deliberate facial movement. Child Development, 51(3), 886-891.

Ellsworth, P.C. \& Smith, C.A. (1988a). From appraisal to emotion: differences among unpleasant feelings. Motivation and Emotion, 12, 271-302.

Ellsworth, P.C. \& Smith, C.A. (1988b). Shades of joy: patterns of appraisal differentiating pleasant emotions. Cognition and Emotion, 2, 301-331.

Ellsworth, P.C. \& Tong, M.W. (2006). What does it mean to be angry at yourself? Categories, appraisals, and the problem of language. Emotion, 6(4), 572-586.

Elster, J. (1995). Rationality and the emotions. The Economic Journal, 116, 1386-1397.

Engell, A., Haxby, J., Todorov, A. 2007. Implicit Trustworthiness Decisions: Automatic Coding of Face Properties in the Human Amygdala. Journal of Cognitive Neuroscience 19(9), 15081519. 
Falk, A. and Kosfeld, M. The hidden cost of control. American Economic Review, 96(5), 1611-1630.

Fehr, E. \& Gächter, S. (2002). Altruistic punishment in humans. Nature, 415, 137-40.

Fessler, D.M. (1999). Toward an understanding of the universality of second order emotions. In Beyond Nature or Nurture: Biocultural Approaches to the Emotions, A. Hinton (ed.), pp.75-116. New York: Cambridge University Press.

Fessler, D.M. (2001). Emotions and cost-benefit assessment: the role of shame and selfesteem in risk taking. In Bounded Rationality: the Adaptive Toolbox, Gerd Gigerenzer and Reinhard Selten (eds.). Cambridge, Massachusetts: MIT Press.

Fessler, D.M. (2007): From appeasement to conformity: evolutionary and cultural perspectives on shame, competition, and cooperation. In The Self-Conscious Emotions: Theory and Research, J.L. Tracy, R.W. Robins, and J.P. Tangney (eds.), pp. 174-193. New York: Guilford.

Fessler, D.M. (2010). Madmen: An evolutionary perspective on anger and men's violent responses to transgression. In Handbook of Anger: Constituent and Concomitant Biological, Psychological, and Social Processes, M. Potegal, G. Stemmler and C. Spielberger (eds.), pp. 361-381. New York: Springer.

Fessler, D.M. \& Haley, K.J. (2003). The strategy of affect: Emotions in human cooperation. In The Genetic and Cultural Evolution of Cooperation, P. Hammerstein (ed.), pp. 7-36. Cambridge: MIT Press.

Fessler, D.M. \& Navarrete, C.D. (2003). Domain-specific variation in disgust sensitivity across the menstrual cycle. Evolution and Human Behavior, 24, 406-417.

Fessler, D.M. \& Navarrete, C.D. (2004). Third-party attitudes toward sibling incest: Evidence for Westermarck's Hypotheses. Evolution and Human Behavior, 25(5):277-294.

Fessler, D.M., Pillsworth, E.G., \& Flamson, T.J. (2004). Angry men and disgusted women: An evolutionary approach to the influence of emotions on risk taking. Organizational Behavior and Human Decision Processes, 95, 107-123.

Folkman, S., \& Lazarus, R.S. (1988). The relationship between coping and emotion: Implications for theory and research. Social Science \& Medicine, 26(3):309-317.

Frank, R.L. (1988). Passions Within Reason: the Strategic Role of the Emotions. NY: Norton.

Frank, R., Gilovich, T., \& Regan, D.T. (1993). The evolution of one-shot cooperation: An experiment. Ethology and Sociobiology, 14, 247-256.

Fredrickson, B.L. (1998). What good are positive emotions? Review of General Psychology, 2, 300-319.

Frijda, N.H. (1986). The Emotions. Cambridge: Cambridge University Press.

Frijda, N.H. (2000). 'The Psychologist's Point of View.', In Handbook of Emotions, 2nd Edition, M. Lewis and J.M. Haviland-Jones (eds.), pp. 59-74. New York: Guilford.

Frijda, N.H., \& Mesquita, B. (1994). The social roles and functions of emotions. In Emotion and Culture, H.R. Markus, S. Kitayama (eds.), pp. 51-87, New York: American Psychological Association.

Gallup, G.G. (1998). Self-awareness and the evolution of social intelligence. Behavioural Processes, 42, 239-247.

Gefen, D., \& Pavlou, P.A. (2012). The Boundaries of trust and risk: The quadratic moderating role of institutional structures. Information Systems Research, 23(3), 940-959. 
Gefen, D., Rigdon, E. \& Straub, D.W. (2011). An Update and Extension to SEM Guidelines for Administrative and Social Science Research. MIS Quarterly 35(2), III-XIV.

Gilbert, P. \& Trower, P. (1990). The evolution and manifestation of social anxiety. In Shyness and Embarrassment: Perspectives From Social Psychology, WR Crozier (ed.), pp. 144179. Cambridge: Cambridge University Press.

Gilbert, P. \& Andrews, B. (1998). Shame: Interpersonal Behavior, Psychopathology, and Culture. Series in Affective Science. New York: Oxford University Press.

Giner-Sorolla, R., Castano, E., Espinosa, P. and Brown, R. (2008). Shame expressions reduce the recipient's insult from outgroup reparations. Journal of Experimental Social Psychology, 44, 519-526.

Goffman, E. (1967). Interaction Ritual: Essays on Face-to-Face Behavior. Garden City, NY: Anchor.

Gómez-Miñambres, J. \& Schniter, E. (2013). Menu-dependent emotions and selfcontrol.Economic Science Institute working paper. Retrieved April 9, 2013, from http://ssrn.com/abstract=2152036

Gouldner, A.W. (1960). The norm of reciprocity: A preliminary statement. American Sociological Review, 25, 161-178.

Gray, J.A. (1971). The Psychology of Fear and Stress. New York: McGraw-Hill

Griffiths, P.E. (1990). Modularity, and the psychoevolutionary theory of emotion. Biology and Philosophy, 5(2), 175-196.

Griffiths, P.E. (1997). What emotions really are: The problem of psychological categories. University of Chicago Press.

Grinde, B. (2002). Happiness in the perspective of evolutionary psychology. Journal of Happiness Studies, 3, 331-354.

Guilford, J.P. \& Zimmerman, W.S. (1956). Fourteen dimensions of temperament. Psychological Monograph, 70(417), 10.

Güntekin, B., \& Basar, E. (2007). Emotional face expressions are differentiated with brain oscillations. International Journal of Psychophysiology, 64, 91-100.

Gurven, M. (2004). To give and to give not: The behavioral ecology of human food transfers. Behavioral and Brain Sciences, 27(4), 543-583.

Gut, E. (1989). Productive and Unproductive Depression: Success or Failure of a Vital Process. New York: Basic Books

Hagen, E. (2003). The Bargaining Model of Depression. In Genetic and Cultural Evolution of Cooperation, P. Hammerstein (ed.) pp. 95-123. Cambridge: MIT Press.

Hare, T.A., C.F. Camerer, \& Rangel, A. (2009). .Self-Control in Decision Making Involves Modulation of the vmPFC Valuation System. Science, 324, 646-648.

Haidt, J. (2001). The emotional dog and its rational tail: a social intuitionist approach to moral judgment. Psychological review, 108(4), 814.

Haidt, J. (2003). The moral emotions. In Handbook of Affective Sciences, R. J. Davidson, K. R. Scherer, and H. H. Goldsmith (eds.), pp. 852-870. Oxford: Oxford University Press.

Hamilton, W.D. (1964). The genetical evolution of social behaviour. Journal of Theoretical Biology, 7, 17-52.

Haselton, M.G. \& Ketelaar, T. (2006). Irrational emotions or emotional wisdom? The evolutionary psychology of emotions and behavior. In Hearts and minds: Affective 
influences on social cognition and behavior, J. P. Forgas (ed.), pp. 21-40. New York: Psychology Press.

Hawkes, K., O’Connell, J., Jones, N., Oftedal, O., \& Blumenschine, R. (1991). Hunting income patterns among the Hadza: Big game, common goods, foraging goals and the evolution of the human diet. Philosophical Transactions: Biological Sciences, 1270(Nov), 243-251.

Heckhausen, J. \& Schulz, R. (1995). A Life-span theory of control. Psychological Review, 102(2): 284-30.

Hessling, R., Schmidt, T., \& Traxel, N. (2004). Floor effect. In M. Lewis-Beck, A. Bryman, and T. Liao (eds.), Encyclopedia of Social Science Research Methods. (pp. 391-392).

Thousand Oaks, CA: SAGE Publications, Inc.

Higgins, E.T. (1997). Beyond pleasure and pain. American Psychologist, 52, 1280-1300.

Hill, K., Walker, R.S., Bozicevic, M., Eder, J., Headland, T., Hewlett, B., Hurtado, A.M., Marlowe, F., Wiessner, P., \& Wood, B. (2011). Co-residence patterns in hunter-gatherer societies show unique human social structure. Science, 331, 1286-1289.

Hirschleifer, J. (1987). On the emotions as guarantors of threats and promises. In The Latest On the Best: Essays on Evolution and Optimality, J. Dupre, (ed.), pp.307-326. Boston: MIT Press.

Hogarth, R.M., Portell, M., Cuxart, A., \& Kolev, G.I. (2011). Emotion and reason in everyday risk perception. Journal of Behavioral Decision Making, 24(2), 202-222.

Houser, D., Xiao, E., McCabe, K., \& Smith, V. (2008). When punishment fails: Research on sanctions, intentions and non-cooperation. Games and Economic Behavior, 62(2), 509532.

Hovland, C.I., Janis, I.L., \& Kelley, H. (1953). Communication and Persuasion. New Haven, CT: Yale University Press.

Hume, D. (1740/1978) A treatise of human nature. Reprinted in David Hume: A treatise of human nature. $2^{\text {nd }}$ edition. L.A. Selby-Bigge and P.H. Nidditch (eds.). New York: Oxford University Press.

Humphrey, N. (1976). The social function of intellect. Reprinted in (1988) Machiavellian Intelligence, R. Byrne and A. Whiten (eds.), pp. 13-26. Oxford: Oxford University Press.

Isaac, G. (1978). The food-sharing behavior of protohuman hominids. Scientific American, 238(4), 90-108.

Izard, C.E. (1977). Human Emotions. New York: Plenum.

Izard, C.E. (1991). The Psychology of Emotions. New York: Plenum.

James, W. (1884). What is an Emotion? Mind, 9, 188-205

James, W. (1890). The Principles of Psychology, (Vol. 2. Chapter 25: The Emotions). New York: Henry Holt \& Co.

Johnson, D., Stopka, P., \& Knights, S., (2003). The puzzle of human cooperation. Nature, 421, 911-912.

Johnson, S. (1755). A Dictionary of the English Language. (1st edition) London: G. Olms. In A Digital Edition of the 1755 Classic by Samuel Johnson. Retrieved April 17th 2013 from http://johnsonsdictionaryonline.com

Kahneman, D., Wakker, P.P., \& Sarin, R.(1997) Back to Bentham? Explorations of experienced utility. Quarterly Journal of Economics, 112(20, 375-405. 
Kaplan, H., Hill, K., Cadelina, R., Hayden, B., Hyndman, D., Preston, R., Smith, E., Stuart, D., \& Yesner, D. (1985). Food sharing among Ache foragers: Tests of explanatory hypotheses. Current Anthropology, 26(2), 223-246.

Kaplan, H., Gurven, M., \& Winking, J. (2009). An Evolutionary Theory of Human Lifespan: Embodied Capital and the Human Adaptive Complex. In Handbook of Theories of Aging, V. Bengtson, M. Silverstein, N. Putney, and D. Gans (eds.) pp. 39-66. New York: Springer.

Kaplan, H., Schniter, E., Smith, V., \& Wilson, B. (2012). Risk and the evolution of human exchange. Proceedings of the Royal Society: Biological Sciences. Published online before print April 18, 2012.

Kassin, S.M., \& Fong, C.T. (1999). “I'm innocent!”: Effects of training on judgments of truth and deception in the interrogation room. Law and Human Behavior, 23, 499-516.

Kaufman, G. (1989). The Psychology of Shame: Theory and Treatment of Shame-based Syndromes. New York: Springer.

Keller, K.I, \& Aaker, D.A. (1998). Corporate-level marketing: the impact of credibility on a company's brand extensions. Corporate Reputation Review, 1(4):356-378.

Kelly, R.L. (1983). Hunter-gatherer mobility strategies. Journal of Anthropological Research, 39(3):277-306.

Keltner, D. (1995). The signs of appeasement: Evidence for the distinct displays of embarrassment, amusement, and shame. Journal of Personality and Social Psychology, $68,441-454$.

Keltner, D. \& Buswell, B.N. (1996). Evidence for the distinctness of embarrassment, shame, and guilt: A study of recalled antecedents and facial expressions of emotion. Cognition and Emotion, 10, 155-171.

Keltner, D. \& Buswell, B.N. (1997). Embarrassment: Its distinct form and appeasement functions. Psychological Bulletin, 122(3), 250-270.

Keltner, D., Ellsworth, P.C., \& Edwards, K. (1993). Beyond simple pessimism: Effects of sadness and anger on social perception. Journal of Personality and Social Psychology, 64, 740-752.

Keltner, D., \& Kring, A.M. (1998). Emotion, social function, and psychopathology. Review of General Psychology, 2, 320-342.

Keltner, D., Young, R.C., \& Buswell, B.N. (1997). Appeasement in human emotion, social practice, and personality. Aggressive Behavior, 23, 359-374.

Ketelaar, T. (2006). The role of moral sentiments in economic decision making. In Social Psychology and Economics, D. DeCremer, M. Zeelenberg, and K. Murnighan (eds.), pp. 97-116. New York: Lawrence Erlbaum Associates.

Ketelaar, T. \& Au, W.T. (2003). The effects of guilty feelings on the behavior of uncooperative individuals in repeated social bargaining games: An Affect-as-information interpretation of the role of emotion in social interaction. Cognition \& Emotion, 17, 429453.

Ketelaar, T., \& Todd, P.M. (2001). Framing our thoughts: Ecological rationality as evolutionary psychology's answer to the frame problem. In Conceptual challenges in evolutionary psychology, pp. 179-211. Netherlands: Springer. 
King, P. (2010). Emotions in Medieval Thought. In The Oxford Handbook of Philosophy of Emotion, 167-187. Oxford: Oxford University Press.

Kohlberg, L. (1971). Stages of moral development. In Moral Education, C.M. Beck, B.S. Crittenden, and E.V. Sullivan (eds.). Toronto: University of Toronto Press.

Krasnow, M. M., Delton, A.W., Tooby, J., \& Cosmides, L. (2013). Meeting now suggests we will meet again: Implications for debates on the evolution of cooperation. Scientific Reports, 3(1747).

Krumhuber, E., Manstead, A.S., Cosker, D., Marshall, D., Rosin, P.L., \& Kappas, A. (2007). Facial dynamics as indicators of trustworthiness and cooperative behavior. Emotion, 7(4), 730-735.

Kurzban, R. (2012). Why everyone (else) is a hypocrite: Evolution and the modular mind. Princeton University Press.

Lang, P.J. (1980). Behavioral treatment and bio-behavioral assessment: computer applications. In Technology in Mental Health Care Delivery Systems, J.B. Sidowski, J.H. Johnson, \& T.A. Williams (Eds.), pp. 119-137. Norwood, NJ: Ablex.

Lang, P.J., Greenwald, M.K., Bradley, M.M, \& Hamm, A.O. (1993). Looking at pictures: Affective, facial, visceral, and behavioral reactions. Psychophysiology, 30, 261-273.

Lang, P.J., Bradley, M.M., \& Cuthbert, B.N. (1997). Motivated attention: Affect, activation, and action. In Attention and Orienting: Sensory and Motivational Processes, P. J. Lang, R. F. Simons, and M. T. Balaban (eds.), pp. 97-135. Mahwah, NJ: Lawrence Erlbaum Associates.

Lang, P.J., Bradley, M.M., \& Cuthbert, B.N. (1999). International Affective Picture System (IAPS): Instruction Manual and Affective Ratings. Gainesville: University of Florida, Center for Research in Psychophysiology.

Larsen, J.T., McGraw, A.P., \& Cacciopo, J.T. (2001). Can people feel happy and sad at the same time? Journal of Personality and Social Psychology, 81,684-696.

Larsen, J.T., McGraw, A.P., Mellers, B.A., \& Cacioppo, J.T. (2004). The agony of victory and thrill of defeat. Psychological Science, 15(5), 325-330.

Lawrence, A.D., \& Calder, A.J. (2004). Homologizing human emotions. In Emotion, Evolution, \& Rationality, Dylan Evans and Pierre Cruse (eds.), p.15-47.

Lazarus, R.S. (1991). Emotion and Adaptation. New York: Oxford University Press.

Lazarus, R.S., \& Lazarus, B.N. (1994). Passion and Reason: Making Sense of Our Emotions. New York: Oxford University Press.

Lazarus, R.S., Kanner, A.D., \& Folkman, S. (1980). Emotions; A Cognitive phenomenological analysis. In Emotion: Theory, Research, and Experience. Vol. 1 Theories of Emotion, R. Plutchik and H. Kellerman (eds.), pp.189-217. New York: Plenum Press

Leith, K.P., \& Baumeister, R.F. (1998). Empathy, shame, guilt, and narratives of interpersonal conflicts: Guilt-prone people are better at perspective taking. Journal of Personality, 66, 1-37.

Lelieveld, G.J., Van Dijk, E., Van Beest, I., Steinel, W., \& Van Kleef, G.A. (2011). Disappointed in you, angry about your offer: Distinct negative emotions induce concessions via different mechanisms. Journal of Experimental Social Psychology, 47(3), 635-641. 
Lerner, J.S. \& Keltner, D. (2000). Beyond valence: Toward a model of emotion-specific influences on judgment and choice. Cognition and Emotion, 14(4), 473-493.

Lerner, J.S. \& Keltner, D. (2001). Fear, anger, and risk. Journal of Personality and Social Psychology, 81, 146-159.

Lerner, J.S., \& Tiedens, L.Z. (2006). Portrait of the angry decision maker: How appraisal tendencies shape anger's influence on cognition. Journal of Behavioral Decision Making, 19(2), 115-137.

Levenson, R.W. (1994). Human emotion: A functional view. In The Nature of Emotion: Fundamental Questions, P. Ekman \& R .J. Davidson (eds.), pp. 123-126. New York: Oxford University Press.

Levenson, R.W. (1999). The Intrapersonal functions of emotion. Cognition and Emotion, 13(5), 481-504.

Lewis A.J. (1934). Melancholia: A clinical survey of depressive states. Journal of Mental Science, 80, 1-43.

Lewis, H.B. (1971). Shame and Guilt in Neurosis. New York: International Universities Press.

Lewis, H.B. (1990). Thinking and feeling - the elephant's tail. In Thinking and Problemsolving in the Developmental Process: International Perspectives (the WORK) C.A. Maher, M. Schwebel, and N.S. Fagley (eds.), pp.89-110). Hillsdale, NJ: Erlbaum.

Lewis, M. (2008). Self-conscious emotions: Embarrassment, pride, shame, and guilt. In Handbook of Emotions ( $3^{\text {rd }}$ edition) M. Lewis \& J. M. Haviland-Jones (eds.), pp. 742756. New York: Guilford Press.

Li, J., Xiao, E., Houser, D., \& Montague, P. R. (2009). Neural responses to sanction threats in two-party economic exchange. Proceedings of the National Academy of Sciences, 106(39), 16835-16840.

Lieberman, D., Tooby, J. \& Cosmides, L. (2003). Does morality have a biological basis? An empirical test of the factors governing moral sentiments regarding incest. Proceedings of the Royal Society of London: B Biological Sciences, 270, 819-826.

Livnat, A. \& Pippenger, N. (2006). An optimal brain can be composed of conflicting agents. Proceedings of the National Academy of Sciences, 103(9), 3198-3202.

Luckenbill, D. (1977). Criminal homicide as a situated transaction. Social Problems, 25, 176186.

Lutz, C. (1982). The domain of emotion words on Ifaluk. American Ethnologist, 9, 113-128.

Maathius O., Rodenburg J., \& Sikkel D. (2004). Credibility, Emotion or Reason? Corporate Reputation Review, 6(4), 333-345

Markus, H.R., \& Kitayama, S. (1991). Culture and the self: Implications for cognition, emotion, and motivation. Psychological Review, 98(2), 224.

McCullough, M.E., Kilpatrick, S.D., Emmons, R.A., \& Larson, D.B. (2001). Is gratitude a moral affect? Psychological Bulletin, 127, 249-266.

McCloskey, D.N. (2006). The Bourgeois Virtues: Ethics for an Age of Commerce. Chicago: University of Chicago Press.

McClure, S.M., Laibson, D., Loewenstein, G., \& Cohen, J.D. (2004) Separate neural systems value immediate and delayed monetary rewards. Science, 306, 503-507. 
McCullough, M.E., Kilpatrick, S.D., Emmons, R.A., \& Larson, D.B. (2001). Is gratitude a moral affect? Psychological Bulletin, 127, 249-266.

Mehu, M., Grammer, K. \& Dunbar, R. (2007). Smiles when sharing. Evolution and Human Behavior, 28, 415-422.

Metts, S. \& Bowers, J. (1994). Emotion in interpersonal communication. In Handbook of Interpersonal Communication, Mark Knapp, Gerald Miller (eds.) Thousand Oaks, CA: Sage.

Miller, R.S. (1992). The nature and severity of self-reported embarrassing circumstances. Personality and Social Psychology Bulletin, 18,190-198.

Miller, R.S., \& Tangney, J.P. (1994). Differentiating embarrassment from shame. Journal of Social and Clinical Psychology, 13,273-287.

Miller, R.S., \& Leary, M.R. (1992). Social sources and interactive functions of embarrassment. In Emotion and Social Behavior, M. Clark (ed.), pp. 322-339. New York: Russell Sage Foundation.

Moretti, L. \& di Pellegrino, G. (2010). Disgust selectively modulates reciprocal fairness in economic interactions. Emotion, 10(2), 169-180.

Morris, J.D. (1995) Observations: SAM: The Self-Assessment Manikin - An efficient crosscultural measurement of emotional response. Journal of Advertising Research, 35(6), 6368.

Murray, S.L., Bellavia, G., Rose, P., \& Griffin, D. (2003). Once hurt, twice hurtful: How perceived regard regulates daily marital interaction. Journal of Personality and Social Psychology, 84, 126-147.

Nesse, R.M. (1990). Evolutionary explanations of emotions. Human Nature, 1(3), 261-289.

Nesse, R.M. (1991). What good is feeling bad? The evolutionary benefits of psychic pain. The Sciences, November/December: 30-37

Nesse, R.M. (1999). Proximate and evolutionary studies of stress and depression: Synergy at the Interface. Neuroscience and Biobehavioral Reviews, 23(7), 895-903.

Nesse, R.M. (2000). Is Depression an Adaptation? Archives of General Psychiatry, 57, 14-20.

Nesse, R.M., \& Williams, G.C. (1999). Why We Get Sick: The New Science of Darwinian Medicine. New York: Random House.

Oda, R., Naganawa, T., Yamauchi, S., Yamagata, N., \& Matsumoto-Oda, A. (2009). Altruists are trusted based on non-verbal cues. Biology Letters, 5(6), 752-754.

Ohtsubo, Y., \& Watanabe, E. (2009). Do sincere apologies need to be costly? Test of a costly signaling model of apology. Evolution and Human Behavior, 30(2), 114-123.

Ortony, A., \& Turner, T. J. (1990). What's basic about basic emotions? Psychological Review, 97, 315-331.

Ortony, A., Clore, G.L. \& Collins, A. (1988) The Cognitive Structure of Emotions. Cambridge, NY: Cambridge University Press.

Osgood, C.E., May, W.H., \& Miron, M.S. (1975). Cross-cultural Universals of Affective Meaning. Urbana: University of Illinois Press.

O'Sullivan, M., \& Ekman, P. (2004). The wizards of deception detection. In Deception Detection in Forensic Contexts, P. A. Granhag and L. A. Stromwall (eds.), pp. 269-286. Cambridge, UK: Cambridge Press. 
Panksepp, J. (1996). Affective neuroscience: A paradigm to study the animate circuits for human emotions. In Emotion: Interdisciplinary Perspectives, R.D. Kavanaugh, B. Zimmerberg, S. Fein (eds.), pp. 29-60. Mahwah, NJ: Lawrence Erlbaum.

Panksepp, J. (1998). Affective neuroscience: The foundations of human and animal emotions. New York: Oxford University Press.

Parks, C.D., \& Hulbert, L.G. (1995). High and low trusters' responses to fear in a payoff matrix. Journal of Conflict Resolution, 39(4), 718-730.

Parrott, W.G. (1995). But emotions are sometimes irrational. Psychological Inquiry, 6(3), 230-232.

Parrot, W.G. \& Smith, R.H. (1993). Distinguishing the experiences of envy and jealousy. Journal of Personality and Social Psychology, 64, 906-920

Pinker, S. (2011). The better angels of our nature: Why violence has declined. New York: Penguin Books.

Plutchik, R. (1980). Emotion: A Psychoevolutionary Synthesis. New York: Harper \& Row.

"pride" (2013). In wiktionary.org. Retrieved April 9, 2013, from http://en.wiktionary.org/wiki/pride

Porter, S., \& ten Brinke, L. (2008). Identifying concealed and falsified emotions in universal facial expressions. Psychological Science, 19(5), 508-514.

Proverbio, A.M., Zani, A., \& Adorni, R. (2008). Neural markers of a greater female responsiveness to social stimuli. BMC Neuroscience, 9, 56.

Rand, A. (1964). The Virtue of Selfishness. New York: New American Library.

Rayo, L. \& Becker, G.S. (2007). Habits, peers, and happiness: an evolutionary perspective. American Economic Review, 97(2), 487-491.

Reid, A.A. \& Gonzalez-Vallejo, C. (2009). Emotion as a tradeable quantity. Journal of Behavioral Decision Making, 22, 62-90.

Rietz, T., Schniter, E., Sheremeta, R.M., and Shields, T.W. (2013). Trust, Reciprocity, \& Rules. Economic Science Institute working paper. Retrieved April 9, 2013, from http://ssrn.com/abstract=1923831

Rousseau, D.M., Sitkin, S.B., Burt, R.S., \& Camerer, C. (1998). Not so different after all: A cross-discipline view of trust. Academy of Management Review, 23, 393-404.

Rozin, P., Haidt, J., \& McCauley, C.R. (1993). Disgust. In Handbook of Emotions, M. Lewis \& J. Haviland (eds.), pp. 575-594. New York: Guilford Press.

Rozin, P., Lowery, L., \& Ebert, R. (1994). Varieties of disgust faces and the structure of disgust. Journal of Personality and Social Psychology, 66, 870-881.

Russell, J.A. (1983). Pancultural aspects of the human conceptual organization of emotions. Journal of Personality and Social Psychology, 45, 1281-1288.

Sahlins, M.D. (1972). Stone Age Economics. New York, NY: Aldine Publishing Co.

Sandars, N. (1972). The Epic of Gilgamesh. New York: Penguin Books.

Sauter, D.A. \& Scott, S.K. (2007). More than one kind of happiness: can't we recognize vocal expressions of different positive states? Motivation and Emotion, 31, 192-199.

Schachter, S., \& Singer, J. (1962). Cognitive, Social, and Physiological Determinants of Emotional State. Psychological Review, 69, 379-399.

Scheff, T.J. (1988). Shame and conformity: The deference emotion system. American Sociological Review, 53, 395-406. 
Scherer, K.R. (1984). On the nature and function of emotion: A component process approach. in K.R. Scherer and P. Ekman (eds.) Approached to Emotion. Hillsdale, NJ: Lawrence Erlbaum.

Schlösser, T., Dunning, D., \& Fetchenhauer, D. (2013). What a feeling: the role of immediate and anticipated emotions in risky decisions. Journal of Behavioral Decision Making, 26(1), 13-30.

Schneier, B. (2008). The psychology of security. In The Proceedings of Africacrypt 2008; Lecture Notes in Computer Science 5023, (pp. 50-79), S. Vaudenay (ed.). Berlin: Springer-Verlag.

Schniter, E., Sheremeta, R.M., and Shields, T.W. (2013). Conflicted Minds: Recalibrational Emotions Following Trust Based Interaction. Economic Science Institute working paper. Retrieved April 9, 2013, from http://ssrn.com/abstract=1937822

Schug, J, Matsumoto, D, Horita, Y, Yamagishi, T, \& Bonnet, K (2010). Emotional expressivity as a signal of cooperation. Evolution and Human Behavior, 31, 87-94

Screenivas, S., Boehm, S.G., Linden, D.E. (2012). Emotional Faces and the default mode network. Neuroscience Letters, 506(2), 229-234.

Sell, A. (2006). Regulating welfare tradeoff ratios: three tests of an evolutionary computational model of human anger. Doctoral dissertation, Department of Psychology, University of California, Santa Barbara.

Sell, A., Tooby, J., \& Cosmides, L. (2009). Formidability and the logic of human anger. Proceedings of the National Academy of Science, 106(35), 15073-78.

Semin, G.R., Manstead, A.S. (1982). The social implications of embarrassment displays and restitution behavior. European Journal of Social Psychology, 12, 367-377.

Scharlemann, J.P., Eckel, C.C., Kacelnik, A., \& Wilson, R.K. (2001). The value of a smile: Game theory with a human face. Journal of Economic Psychology, 22, 617-640.

Shallcross, S.L., \& Simpson, J.A. (2012). Trust and responsiveness in strain-test situations: A dyadic perspective. Journal of Personality and Social Psychology, 102 (5), 1031.

Shaver, P., Schwartz, J., Kirson, D., \& O'Connor, C. (1987). Emotion knowledge: further exploration of a prototype approach. Journal of Personality and Social Psychology, 52(6), 1061-1086.

Shields, S.A., Mallory, M.E., \& Simon, A. (1990). The experience and symptoms of blushing as a function of age and reported frequency of blushing. Journal of Nonverbal Behavior, 14, 171-187.

Silvia, P. (2009). Looking past pleasure: Anger, confusion, disgust, pride, surprise, and other unusual aesthetic emotions. Psychology of Aesthetics, Creativity, and the Arts, 3(1), 4851.

Simmel, G. (1950). The sociology of Georg Simmel. Glencoe, IL: Free Press.

Simon, H.A. (1985). Human nature in politics: The dialogue of psychology with political science. The American Political Science Review, 79(2), 293-304.

Simon, H.A. (1987). Bounded rationality. In: The New Palgrave. A Dictionary of Economics. J. Eatwell et al., (eds.), pp.266-268. London: Macmillan.

Slovic, P., Finucane, M., Peters, E., \& MacGregor, D.G. (2002). Rational actors or rational fools: Implications of the affect heuristic for behavioral economics. Journal of Socioeconomics, 31(4), 329-342. 
Smith, A. (1759). The Theory of Moral Sentiments. Year 2000 edition. New York: Prometheus Books.

Smith, C.A. \& Lazarus, R.S. (1990). Emotion and adaptation. In Handbook of Personality: Theory and Research, L.A. Pervin (ed.), pp.609-637. New York: Guilford.

Smith, V.L., \& Wilson, B.J. (2013). Sentiments, Conduct, and Trust in the Laboratory. Economic Science Institute working paper. Accessed April 9 ${ }^{\text {th }}, 2013$ from: http://www.masonlec.org/site/rte_uploads/files/Smith\%202.pdf

Sternthal, B. \& Craig, C.S. (1982). Consumer Behaviour: An Informatic Processing Perspective. Englewood Cliffs, NJ: Prentice Hall.

Stouten, J., \& De Cremer, D. (2010). "Seeing is believing": The effects of facial expressions of emotion and verbal communication in social dilemmas. Journal of Behavioral Decision Making, 23(3), 271-287.

Sugiyama, L.S. (2004). Illness, injury, and disability among Shiwiar forager-horticulturalists: Implications of health-risk buffering for the evolution of human life history. American Journal of Physical Anthropology, 123(4), 371-389.

Sugiyama, L.S., \& Sugiyama, M.S. (2003). Social roles, prestige, and health risk. Human Nature, 14(2), 165-190.

Suk, Hyeon-Jeong (2006). Color and Emotion - A Study on the Affective Judgment across Media and in Relation to Visual Stimuli. University of Mannheim: Dissertation.

Sznycer, D., Takemura, K., Delton, A.W., Sato, K., Robertson, T., Cosmides, L., \& Tooby, J. (2012). Cross-cultural differences and similarities in proneness to shame: An adaptationist and ecological approach. Evolutionary psychology: an international journal of evolutionary approaches to psychology and behavior, 10(2), 352.

Tangney, J.P. (1991). Moral affect: The good, the bad, and the ugly. Journal of Personality and Social Psychology, 61(4), 598-607.

Tangney, J.P. (1992): Situational determinants of shame and guilt in young adulthood. Personality and Social Psychology Bulletin, 18, 199-206.

Tangney, J.P., Miller, R.S., Flicker, L., \& Barlow, D.H. (1996). Are shame, guilt, and embarrassment distinct emotions? Journal of Personality and Social Psychology, 70, $1256-1269$.

Taylor, S.E. (1989). Positive Illusions: Creative self-deception and the healthy mind. New York: Basic Books

Taylor, C.C.W. (2005). Democritus. In The Cambridge History of Greek and Roman Political Thought, C. Rowe \& M. Schofield (eds.). New York: Cambridge University Press.

Tellegen, A., Watson, D., \& Clark, L.A. (1999). On the dimensional and hierarchical structure of affect. Psychological Science, 10, 297-303.

Thornhill, R. \& Palmer, C.T. (2000). A Natural History of Rape: Biological Bases of Sexual Coercion. Cambridge MA: MIT Press

Thrash, T.M., \& Elliot, A.J. (2004). Inspiration: core characteristics, component processes, antecedents, and function. Journal of Personality and Social Psychology, 87(6):957-973.

Timmers, M., Fischer, A.H., \& Manstead, A.S. (1998). Gender differences in motives for regulating emotions. Personality and Social Psychology Bulletin, 24, 974-985.

Toch, H. (1969). Violent men. Chicago: Aldine 
Todd, P.M. (2001). Fast and frugal heuristics for environmentally bounded minds. In Bounded Rationality: the Adaptive Toolbox, G. Gigerenzer and R. Selten (eds.). Cambridge MA: MIT Press.

Tomkins, S.S. (1962). Affect, imagery, consciousness: Vol. 1 The positive affects. New York: Springer

Tooby, J. \& Cosmides, L. (1990). The past explains the present: Emotional adaptations and the structure of ancestral environments. Ethology and Sociobiology, 11, 375-424.

Tooby, J., \& Cosmides, L. (1992). The Psychological foundations of culture, In The Adapted Mind: Evolutionary Psychology and the Generation of Culture, J.H. Barkow, L. Cosmides, and J. Tooby (eds.), pp. 19-36. Oxford: Oxford University Press.

Tooby, J. \& Cosmides, L. (2008). The evolutionary psychology of the emotions and their relationship to internal regulatory variables. In Handbook of Emotions, $3^{\text {rd }}$ edition, M. Lewis, J.M. Haviland-Jones, and L.F. Barrett (eds.), pp. 114-137. New York: Guilford.

Tooby, J., Cosmides, L., Sell, A., Lieberman, D., \& Sznycer, D. (2008). Internal regulatory variables and the design of human motivation: a computational and evolutionary approach. In Handbook of Approach and Avoidance Motivation, pp. 251-271. Mahwah, NJ: Lawrence Erlbaum Associates.

Trivers, R.L. (1971). The Evolution of Reciprocal Altruism. The Quarterly Review of Biology, 46(4):35-39.

Tybur, J.M., Lieberman, D., \& Griskevicius, V. (2009). Microbes, mating, and morality: individual differences in three functional domains of disgust. Journal of Personality and Social Psychology, 97(1), 103-122.

Van den Berg, B., Dewitte, S., \& Warlop, L. (2008). Bikinis instigate generalized impatience in intertemporal choice. Journal of Consumer Research 35(1):85-97.

Van Kleef, G.A., de Dreu, C.W., \& Manstead, A. S. (2004). The interpersonal effects of emotion in negotiations: A motivated information processing approach. Journal of Personality and Social Psychology, 87, 510-528.

Van Kleef, G.A., De Dreu, C.K., \& Manstead, A. S. (2006). Supplication and appeasement in conflict and negotiation: The interpersonal effects of disappointment, worry, guilt and regret. Journal of Personality and Social Psychology, 91, 124-142.

Van Dijk, W.W., \& Van Harreveld, F. (2008). Disappointment and regret. In Research Companion to Emotions in Organizations, N. M. Ashkanasy and C. L. Cooper (eds.), pp. 90-102. London: Elgar

Van Kleef, G.A., \& Van Lange, P.A. (2008). What other's disappointment may do to selfish people: Emotion and social value orientation in a negotiation context. Personality and Social Psychology Bulletin, 34, 1084-1095.

Van Dijk, W.W., Zeelenberg, M., \& Van der Pligt, J. (1999). Not having what you want versus having what you do not want: The impact of type of negative outcome on the experience of disappointment and related emotions. Cognition and Emotion, 13, 129-148.

von Neumann, J \& Morgenstern, O. (1944). The Theory of Games and Economic Behavior. Princeton, N.J.: Princeton University Press.

Wallington, S.A. (1973). Consequences of transgression: self-punishment and depression. Journal of Personality and Social Psychology, 28, 1-7. 
Watson, D., \& Clark, L.A. (1999). The PANAS-X: Manual for the positive and negative affect schedule-expanded form. University of Iowa, Department of Psychology Publications.

Watson, D., Wiese, D., Vaidya, J., \& Tellegen, A. (1999). The two general activation systems of affect: structural findings, evolutionary considerations, and psychobiological evidence. Journal of Personality and Social Psychology, 76, 820-838.

Webster, G.D. \& Kirkpatrick, L.A. (2006). Behavioral and self-reported aggression as a function of domain-specific self-esteem. Aggressive Behavior, 32(1), 17-27.

Westermarck, E. (1926). A Short History of Marriage. New York: Macmillan \& Co.

Wicker, F. W., Payne, G. C., \& Morgan, R. D. (1983). Participant descriptions of guilt and shame. Motivation and Emotion, 7(1), 25-39.

Wierzbicka, A. (1986). Human emotions: universal or culture-specific? American Anthropologist, 88(3), 584-594.

Wierzbicka, A. (1992). Defining emotion concepts. Cognitive Science, 16, 539-581.

Willis, J., Todorov, A. (2006). First Impressions: Making up Your Mind After a 100-ms Exposure to a Face. Psychological Science 17, 592-598.

Wubben, M.J., De Cremer, D., \& Van Dijk, E. (2009). How emotion communication guides reciprocity: Establishing cooperation through disappointment and anger. Journal of Experimental Social Psychology, 45, 987-990.

Yakovleva, M., Reilly, R.R., \& Werko, R. (2010). Why do we trust? Moving beyond individual to dyadic perceptions. Journal of Applied Psychology, 95, 79-91.

Yamagishi, T. (2011). Trust: The Evolutionary Game of Mind and Society. New York: Springer.

Zeelenberg, M. (1999). Anticipated regret, expected feedback and behavioral decisionmaking. Journal of Behavioral Decision Making, 12, 93-106.

Zeelenberg, M., \& Beattie, J. (1997). Consequences of regret aversion 2: Additional evidence for effects of feedback on decision making. Organizational Behavior and Human Decision Processes, 72(1), 63-78.

Zeelenberg, M., Nelissen, R.M., Breugelmans, S.M., \& Pieters, R. (2008). On emotion specificity in decision making: Why feeling is for doing. Judgment and Decision Making $3(1), 18-27$. 
2013

\section{Economic Science Institute Working Papers}

13-15 Corgnet, B., Hernán-Gonzalez, R., and Rassenti, S. Firing Threats and Tenure: Incentive effects and impression management.

13-14 Erik O. Kimbrough, E., and Rubin, J. Sustaining Group Reputation.

13-13 Moore, K., Sun, P., de Vries, C., and Zhou, C. Shape Homogeneity and Scale Heterogeneity of Downside Tail Risk.

13-12 Chowdhury, S., Lee, D., and Sheremeta, R. Top Guns May Not Fire: Best-Shot Group Contests with Group-Specific Public Good Prizes.

13-11 Kimbrough, E., Rubin, J., Sheremeta, R., Shields, T. Commitment Problems in Conflict $\underline{\text { Resolution. }}$

13-10 Klose, B. and Kovenock, D. The All-Pay Auction with Complete Information and Identity-Dependent Externalities.

13-09 Branas-Garza, P., Kovarik, J., and Neyse, L. Second-to-Fourth Digit Ratio has a NonMonotonic Impact on Altruism.

13-08 McCarter, M., Samak, A., and Sheremeta, R. Divided Loyalties or Conditional Cooperation? An experimental study of contributions to multiple public goods.

13-07 Gabaix, X., Laibson, D., Li, D., Li, H., Resnick, S., and de Vries, C. The Impact of Competition on Prices with Numerous Firms.

13-06 Sheremeta, R. Overbidding and Heterogeneous Behavior in Contest Experiments.

13-05 Deck, C. and Porter, D. Prediction Markets in the Laboratory.

13-04 Corgnet, B., Hernán-Gonzalez, R., Kujal, P., and Porter, D. The Effect of Earned vs. House Money on Price Bubble Formation in Experimental Asset Markets.

13-03 Sheremeta, R. and Zhang, J. Three-Player Trust Game with Insider Communication.

13-02 McCarter, M. and Sheremeta, R. You Can't Put Old Wine in New Bottles: The Effect of Newcomers on Coordination in Groups.

13-01 Corgnet, B., Hernan-Gonzalez, R., and Rassenti, S. Peer Pressure and Moral Hazard in Teams: Experimental Evidence. 
12-31 Thomas, C. An Alternating-Offers Model of Multilateral Negotiations.

12-30 Mago, S., Sheremeta, R. and Yates, A. Best-of-Three Contest Experiments: Strategic versus psychological momentum.

12-29 Bigoni, M., Camera, G. and Casari, M. Strategies of Cooperation and Punishment among Students and Clerical Workers.

12-28 Camera, G. and Kim, J. Buyer's Equilibrium with Capacity Constraints and Restricted Mobility: A recursive approach.

12-27 Camera, G., Casari, M., and Bigoni, M. Binding Promises and Cooperation Among Strangers.

12-26 Schniter, E., Shields, T. and Dickhaut, J. Ageism \& Cooperation.

12-25 Gjerstad, S. and Smith, V. Balance Sheet Crises: Causes, Consequences and Responses.

12-24 Gómez-Miñambres, J., Corgnet, B. and Hernán-Gonzalez, R. Goal Setting and Monetary Incentives: When Large Stakes Are Not Enough.

12-23 Clots-Figueras, I., Hernán González, R., and Kujal, P. Asymmetry and Deception in the Investment Game.

12-22 Dechenaux, E., Kovenock, D. and Sheremeta, R. A Survey of Experimental Research on Contests, All-Pay Auctions and Tournaments.

12-21 Rubin, J. and Sheremeta, R. Principal-Agent Settings with Random Shocks.

12-20 Gómez-Miñambres, J. and Schniter, E. Menu-Dependent Emotions and Self-Control.

12-19 Schniter, E., Sheremeta, R., and Sznycer, D. Building and Rebuilding Trust with Promises and Apologies.

12-18 Shields, T. and Xin, B. Higher-order Beliefs in Simple Trading Models.

12-17 Pfeiffer, G. and Shields, T. Performance-Based Compensation and Firm Value: Experimental evidence.

12-16 Kimbrough, E. and Sheremeta, R. Why Can't We Be Friends? Entitlements, bargaining, and conflict.

12-15 Mago, S., Savikhin, A., and Sheremeta, R. Facing Your Opponents: Social identification and information feedback in contests.

12-14 McCarter, M., Kopelman, S., Turk, T. and Ybarra, C. Too Many Cooks Spoil the Broth: How the tragedy of the anticommons emerges in organizations. 
12-13 Chowdhury, S., Sheremeta, R. and Turocy, T. Overdissipation and Convergence in Rent-seeking Experiments: Cost structure and prize allocation rules.

12-12 Bodsky, R., Donato, D., James, K. and Porter, D. Experimental Evidence on the Properties of the California's Cap and Trade Price Containment Reserve.

12-11 Branas-Garza, P., Espin, A. and Exadaktylos, F. Students, Volunteers and Subjects: Experiments on social preferences.

12-10 Klose, B. and Kovenock, D. Extremism Drives Out Moderation.

12-09 Buchanan, J. and Wilson, B. An Experiment on Protecting Intellectual Property.

12-08 Buchanan, J., Gjerstad, S. and Porter, D. Information Effects in Multi-Unit Dutch Auctions.

12-07 Price, C. and Sheremeta, R. Endowment Origin, Demographic Effects and Individual Preferences in Contests.

12-06 Magoa, S. and Sheremeta, R. Multi-Battle Contests: An experimental study.

12-05 Sheremeta, R. and Shields, T. Do Liars Believe? Beliefs and Other-Regarding Preferences in Sender-Receiver Games.

12-04 Sheremeta, R., Masters, W. and Cason. T. Winner-Take-All and Proportional-Prize Contests: Theory and experimental results.

12-03 Buchanan, J., Gjerstad, S. and Smith, V. There's No Place Like Home.

12-02 Corgnet, B. and Rodriguez-Lara, I. Are you a Good Employee or Simply a Good Guy? Influence Costs and Contract Design.

12-01 Kimbrough, E. and Sheremeta, R. Side-Payments and the Costs of Conflict. 2011

11-20 Cason, T., Savikhin, A. and Sheremeta, R. Behavioral Spillovers in Coordination Games.

11-19 Munro, D. and Rassenti, S. Combinatorial Clock Auctions: Price direction and performance.

11-18 Schniter, E., Sheremeta, R., and Sznycer, D. Restoring Damaged Trust with Promises, Atonement and Apology.

11-17 Brañas-Garza, P., and Proestakis, A. Self-discrimination: A field experiment on obesity.

11-16 Brañas-Garza, P., Bucheli, M., Paz Espinosa, M., and García-Muñoz, T. Moral Cleansing and Moral Licenses: Experimental evidence.

11-15 Caginalp, G., Porter, D., and Hao, L. Asset Market Reactions to News: An experimental study. 
11-14 Benito, J., Branas-Garz, P., Penelope Hernandez, P., and Sanchis Llopis, J. Strategic Behavior in Schelling Dynamics: A new result and experimental evidence.

11-13 Chui, M., Porter, D., Rassenti, S. and Smith, V. The Effect of Bidding Information in Ascending Auctions.

11-12 Schniter, E., Sheremeta, R. and Shields, T. Conflicted Minds: Recalibrational emotions following trust-based interaction.

11-11 Pedro Rey-Biel, P., Sheremeta, R. and Uler, N. (Bad) Luck or (Lack of) Effort?: Comparing social sharing norms between US and Europe.

11-10 Deck, C., Porter, D., and Smith, V. Double Bubbles in Assets Markets with Multiple Generations.

11-09 Kimbrough, E., Sheremeta, R., and Shields, T. Resolving Conflicts by a Random Device.

11-08 Brañas-Garza, P., García-Muñoz, T., and Hernan, R. Cognitive effort in the Beauty Contest Game.

11-07 Grether, D., Porter, D., and Shum, M. Intimidation or Impatience? Jump Bidding in On-line Ascending Automobile Auctions.

11-06 Rietz, T., Schniter, E., Sheremeta, R., and Shields, T. Trust, Reciprocity and Rules.

11-05 Corgnet, B., Hernan-Gonzalez, R., and Rassenti, S. Real Effort, Real Leisure and Real-time Supervision: Incentives and peer pressure in virtual organizations.

11-04 Corgnet, B. and Hernán-González R. Don’t Ask Me If You Will Not Listen: The dilemma of participative decision making.

11-03 Rietz, T., Sheremeta, R., Shields, T., and Smith, V. Transparency, Efficiency and the Distribution of Economic Welfare in Pass-Through Investment Trust Games.

11-02 Corgnet, B., Kujal, P. and Porter, D. The Effect of Reliability, Content and Timing of Public Announcements on Asset Trading Behavior.

11-01 Corgnet, B., Kujal, P. and Porter, D. Reaction to Public Information in Markets: How much does ambiguity matter?

\section{0}

10-23 Sheremeta, R. Perfect-Substitutes, Best-Shot, and Weakest-Link Contests between Groups.

10-22 Mago, S., Sheremeta, R., and Yates, A. Best-of-Three Contests: Experimental evidence.

10-21 Kimbrough, E. and Sheremeta, R. Make Him an Offer He Can't Refuse: Avoiding conflicts through side payments. 
10-20 Savikhim, A. and Sheremeta, R. Visibility of Contributions and Cost of Inflation: An experiment on public goods.

10-19 Sheremeta, R. and Shields, T. Do Investors Trust or Simply Gamble?

10-18 Deck, C. and Sheremeta, R. Fight or Flight? Defending Against Sequential Attacks in the Game of Siege.

10-17 Deck, C., Lin, S. and Porter, D. Affecting Policy by Manipulating Prediction Markets: Experimental evidence.

10-16 Deck, C. and Kimbrough, E. Can Markets Save Lives? An Experimental Investigation of a Market for Organ Donations.

10-15 Deck, C., Lee, J. and Reyes, J. Personality and the Consistency of Risk Taking Behavior: Experimental evidence.

10-14 Deck, C. and Nikiforakis, N. Perfect and Imperfect Real-Time Monitoring in a Minimum-Effort Game.

10-13 Deck, C. and Gu, J. Price Increasing Competition? Experimental Evidence.

10-12 Kovenock, D., Roberson, B., and Sheremeta, R. The Attack and Defense of Weakest-Link Networks.

10-11 Wilson, B., Jaworski, T., Schurter, K. and Smyth, A. An Experimental Economic History of Whalers' Rules of Capture.

10-10 DeScioli, P. and Wilson, B. Mine and Thine: The territorial foundations of human property.

10-09 Cason, T., Masters, W. and Sheremeta, R. Entry into Winner-Take-All and Proportional-Prize Contests: An experimental study.

10-08 Savikhin, A. and Sheremeta, R. Simultaneous Decision-Making in Competitive and Cooperative Environments.

10-07 Chowdhury, S. and Sheremeta, R. A generalized Tullock contest.

10-06 Chowdhury, S. and Sheremeta, R. The Equivalence of Contests.

10-05 Shields, T. Do Analysts Tell the Truth? Do Shareholders Listen? An Experimental Study of Analysts' Forecasts and Shareholder Reaction.

10-04 Lin, S. and Rassenti, S. Are Under- and Over-reaction the Same Matter? A Price Inertia based Account.

10-03 Lin, S. Gradual Information Diffusion and Asset Price Momentum.

10-02 Gjerstad, S. and Smith, V. Household Expenditure Cycles and Economic Cycles, 1920 - 2010. 
10-01 Dickhaut, J., Lin, S., Porter, D. and Smith, V. Durability, Re-trading and Market Performance.

\section{9}

09-11 Hazlett, T., Porter, D., and Smith, V. Radio Spectrum and the Disruptive Clarity OF Ronald Coase.

09-10 Sheremeta, R. Expenditures and Information Disclosure in Two-Stage Political Contests.

09-09 Sheremeta, R. and Zhang, J. Can Groups Solve the Problem of Over-Bidding in Contests?

09-08 Sheremeta, R. and Zhang, J. Multi-Level Trust Game with "Insider" Communication.

09-07 Price, C. and Sheremeta, R. Endowment Effects in Contests.

09-06 Cason, T., Savikhin, A. and Sheremeta, R. Cooperation Spillovers in Coordination Games.

09-05 Sheremeta, R. Contest Design: An experimental investigation.

09-04 Sheremeta, R. Experimental Comparison of Multi-Stage and One-Stage Contests.

09-03 Smith, A., Skarbek, D., and Wilson, B. Anarchy, Groups, and Conflict: An experiment on the emergence of protective associations.

09-02 Jaworski, T. and Wilson, B. Go West Young Man: Self-selection and endogenous property rights.

09-01 Gjerstad, S. Housing Market Price Tier Movements in an Expansion and Collapse.

\section{8}

08-09 Dickhaut, J., Houser, D., Aimone, J., Tila, D. and Johnson, C. High Stakes Behavior with Low Payoffs: Inducing preferences with Holt-Laury gambles.

08-08 Stecher, J., Shields, T. and Dickhaut, J. Generating Ambiguity in the Laboratory.

08-07 Stecher, J., Lunawat, R., Pronin, K. and Dickhaut, J. Decision Making and Trade without Probabilities.

08-06 Dickhaut, J., Lungu, O., Smith, V., Xin, B. and Rustichini, A. A Neuronal Mechanism of Choice.

08-05 Anctil, R., Dickhaut, J., Johnson, K., and Kanodia, C. Does Information Transparency Decrease Coordination Failure?

08-04 Tila, D. and Porter, D. Group Prediction in Information Markets With and Without Trading Information and Price Manipulation Incentives.

08-03 Thomas, C. and Wilson, B. Horizontal Product Differentiation in Auctions and Multilateral Negotiations. 
08-02 Oprea, R., Wilson, B. and Zillante, A. War of Attrition: Evidence from a laboratory experiment on market exit.

08-01 Oprea, R., Porter, D., Hibbert, C., Hanson, R. and Tila, D. Can Manipulators Mislead Prediction Market Observers? 